\title{
Autophagy signal transduction by ATG proteins: from hierarchies to networks
}

\author{
Sebastian Wesselborg ${ }^{1} \cdot$ Björn Stork $^{1}$
}

Received: 3 April 2015/Revised: 13 August 2015/Accepted: 31 August 2015/Published online: 21 September 2015

(C) The Author(s) 2015. This article is published with open access at Springerlink.com

\begin{abstract}
Autophagy represents an intracellular degradation process which is involved in both cellular homeostasis and disease settings. In the last two decades, the molecular machinery governing this process has been characterized in detail. To date, several key factors regulating this intracellular degradation process have been identified. The so-called autophagy-related (ATG) genes and proteins are central to this process. However, several additional molecules contribute to the outcome of an autophagic response. Several review articles describing the molecular process of autophagy have been published in the recent past. In this review article we would like to add the most recent findings to this knowledge, and to give an overview of the network character of the autophagy signaling machinery.
\end{abstract}

\section{Keywords Autophagy $\cdot$ ATG $\cdot$ ULK $\cdot$ PtdIns3K · LC3}

\section{Introduction}

The term autophagy originates from the Greek expressions

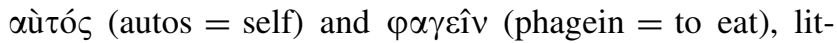
erally meaning the self-eating of a cell. Next to the

Electronic supplementary material The online version of this article (doi:10.1007/s00018-015-2034-8) contains supplementary material, which is available to authorized users.

Björn Stork

bjoern.stork@uni-duesseldorf.de

1 Institute of Molecular Medicine I, Heinrich-HeineUniversity, Universitätsstr. 1, Building 23.12, 40225 Düsseldorf, Germany ubiquitin-proteasome system (UPS), autophagy is a major pathway for the degradation of intracellular cargo. Autophagy occurs at basal levels in any cell to carry out the proper degradation of long-lived proteins, protein aggregates or damaged organelles, ultimately ensuring cellular homeostasis. However, different stress conditions can cause the active induction of the autophagic machinery. These stress conditions include nutrient deprivation, growth factor withdrawal, hypoxia, or pathogen infection. Of note, the basic autophagic machinery is conserved among different eukaryotes, including yeast, animals, and plants.

\section{Types of autophagy and morphology}

In 1962, Ashford and Porter observed cytoplasmic components, i.e., mitochondria or remnants thereof, in lysosomes of hepatic cells which had been perfused with glucagon [1]. In the same year, Novikoff and Essner observed similar mitochondria-containing vacuoles in hepatic cells from mice intravenously treated with the detergent Triton WR-1339 [2]. They termed these structures cytolysomes. In 1963, Christian de Duve suggested the name "autophagic vacuoles" for these cytolysomes and "autophagy" for the process of cellular self-eating [3].

Today, autophagy has become one of the most intensely investigated fields of cell biological research. This might partly be attributed to the fact that the process of autophagy or its dysregulation contribute to the onset of diverse human diseases or clinically relevant processes, including cancer, neurodegeneration, immune responses, or aging [47]. There exist three types of autophagy, i.e., macroautophagy, microautophagy, and chaperone-mediated autophagy [8]. Within chaperone-mediated autophagy, 
target proteins are directly recognized by cytosolic chaperones and transported across the lysosomal membrane [8]. Microautophagy describes a process by which the lysosomal membrane directly engulfs small portions of the cytoplasm [8]. During the process of macroautophagy (herein referred to as autophagy), cytoplasmic cargo is enveloped within a double-membraned vesicle, called autophagosome. Autophagosomes are transported to and fuse with lysosomes, leading to the generation of autolysosomes. Within autolysosomes, the sequestered cargo and the inner membrane of the autophagosome are degraded, and the resulting molecular building blocks such as amino acids or fatty acids are transported back to the cytosol through lysosomal permeases and are available for anabolic processes $[9,10]$. Autophagy might be non-selective, leading to the bulk degradation of cytoplasm. However, in recent years different selective forms of autophagy have been identified and characterized, leading to the specific degradation of organelles or pathogens. These selective pathways include the autophagic degradation of mitochondria (mitophagy), peroxisomes (pexophagy), endoplasmic reticulum (reticulophagy or ERphagy), ribosomes (ribophagy), protein aggregates (aggrephagy), lipid droplets (lipophagy), spermatozooninherited organelles following fertilization (allophagy), secretory granules within pancreatic cells (zymophagy), or intracellular pathogens (xenophagy) [11-14].

The formation of autophagosomes is a central hallmark of autophagy, and includes different discrete steps, i.e., nucleation, elongation and closure of the double-membraned vesicle. The cellular source of the autophagosomal membrane has been controversially discussed in the recent past. In yeast, a specific platform for the biogenesis of autophagosomes has been identified, the pre-autophagosomal structure (PAS) [15]. The PAS is a single punctate structure adjacent to the yeast vacuole, where most of the Atg proteins (see below) are present [8]. From the PAS the phagophore (also referred to as isolation membrane, IM) is generated, which envelopes cytoplasmic cargo to ultimately form the complete autophagosome [8]. In 2008, Axe et al. reported that the phosphatidylinositol 3-phosphate (PtdIns3P)-binding protein double FYVE domaincontaining protein 1 (DFCP1) translocates to a punctate compartment upon nutrient starvation in mammalian cells [16]. The observed compartment is in dynamic equilibrium with the ER and provides a platform for the generation of the phagophore and the release of fully formed autophagosomes [16]. Since these structures were seen in association with the underlying ER forming an $\Omega$-like shape, the authors termed them "omegasomes" [16]. Interestingly, so far no DFCP1 homolog has been reported for yeast [16]. Two further groups confirmed the physical connection between the ER and the phagophore by 3D electron microscopy $[17,18]$. Collectively, these results strongly suggest that the phagophore originates from specialized subdomains of the ER. However, different other sources for autophagosomal membrane lipids have been suggested, including mitochondria, the Golgi complex, recycling endosomes, the nuclear envelope and the plasma membrane (reviewed in $[8,19,20])$. For example, it has been reported that mitochondria supply membranes for autophagosomes during starvation [21]. Apparently, autophagosome formation is dependent on ER/mitochondria connections. It has been proposed that these connections are necessary to transfer phosphatidylserine (PS) to the mitochondria, where PS is converted to phosphatidylethanolamine (PE). PE in turn is the target of Atg8/ LC3-conjugation (described in "Two ubiquitin-like conjugation systems in autophagy: Atg12/ATG12-Atg5/ATG5 and Atg8/LC3-PE"). It has also been reported that autophagosomes themselves form at ER-mitochondria contact sites [22]. Recent data indicate that several specific organelles contribute to autophagosome formation, e.g., ER exit sites (ERES), coat protein II (COPII)-coated vesicles leaving the ERES, or the ER-Golgi intermediate compartment (ERGIC) [23-25]. Biazik et al. reported that forming phagophores can have multiple simultaneous membrane contact sites with surrounding organelles [26]. Presumably, different sources contribute to the completion of autophagosomes, presumably also depending on the autophagy-inducing stimulus and on the cargo to be degraded.

\section{Molecular regulation of autophagy}

In the late 1990s, another era of autophagy research has evolved, leading to the molecular characterization of this process [27]. In 1993, Tsukada and Ohsumi reported the isolation and characterization of $15 \mathrm{~S}$. cerevisiae mutants that displayed defective autophagy and named them apg115 (autophagy) [28]. Similar screens were performed by other research groups, and the identified mutants defective in either autophagy, pexophagy, or the cytoplasm-to-vacuole pathway were called aut, cvt, pdd, gsa, pag, or paz, respectively [29-35]. In 2003, a unified nomenclature for the so-called autophagy-related genes/proteins, Atgs, was proposed [30]. Recently, yeast Atg39 and Atg40 have been identified as receptors which are apparently involved in the selective removal of the cytoplasmic and perinuclear ER and the nucleus [36]. Most of the yeast Atgs have homo$\log$ in the mammalian system (abbreviated as ATGs). However, sometimes homology is only based on function but not on sequence. Additionally, there exists one mammalian ATG, ATG101, which does not have an obvious counterpart in yeast [37, 38]. Frequently, in mammals 
different isoforms of a certain yeast Atg exist. Furthermore, different non-ATG proteins are involved in the regulation and process of autophagy, e.g., the mammalian/mechanistic target of rapamycin (mTOR), AMPK, AKT, AMBRA1, BCL2, DFCP1, or vacuolar protein sorting protein 34 (VPS34), which is the catalytic subunit of the class III phosphatidylinositol 3-kinase (PtdIns3K). Finally, different functions of ATGs in non-autophagic processes have been reported and are likely to emerge in the future (reviewed in [39]).

Functionally, mammalian ATGs can be subdivided in six functional clusters (Fig. 1): (1) the ULK1-ATG13FIP200-ATG101 protein kinase complex; (2) the PtdIns3K class III complex containing the core proteins VPS34, VPS15 and Beclin 1; (3) the PtdIns3P-binding WIPI/ ATG18-ATG2 complex; (4) the multi-spanning transmembrane protein ATG9A; (5) the ubiquitin-like ATG5/ ATG12 system and (6) the ubiquitin-like ATG8/LC3 conjugation system (reviewed in [8]). These six modules regulate different steps during autophagosome biogenesis, i.e., vesicle nucleation, elongation of the autophagosomal membrane, and autophagosome completion. In the following, the autophagy-related functions of these six modules and their crosstalk will be described in detail, with the main focus laid onto the autophagy-initiating ULK1 kinase complex.

\section{The Atg1/ULK1 complex}

\section{The yeast Atg1-Atg13-Atg17 complex}

In 1997, Matsuura et al. showed that the apgl/atgl gene discovered in their first screen for autophagy-defective yeast strains encodes a protein kinase (Apg1p/Atg1), and they reported an overall homology to C. elegans UNC-51 protein [40]. Furthermore, they showed that Atg1 overexpression suppressed the autophagy-defective phenotype in the Aapg13/atg13 strain, indicating a linkage between Atg1
Fig. 1 Functional clusters of autophagy signaling. 1 The ULK1-ATG13-FIP200-ATG101 protein kinase complex, 2 the PtdIns3K class III complex containing the core proteins VPS34, VPS15 and Beclin 1, 3 the multi-spanning transmembrane protein ATG9A, 4 the PtdIns3Pbinding WIPI/ATG18-ATG2 complex, 5 the ubiquitin-like ATG5/ATG12 system and $\mathbf{6}$ the ubiquitin-like ATG8/LC3 conjugation system. For the ULK1 complex, mTOR-dependent inhibitory phosphorylations are depicted as red arrows, and ULK1-dependent activatory phosphorylations are depicted as black arrows. For the PtdIns3K class III complex, the mutually exclusive interactions of ATG14 or UVRAG with Beclin 1 are-for simplicity-shown within one complex

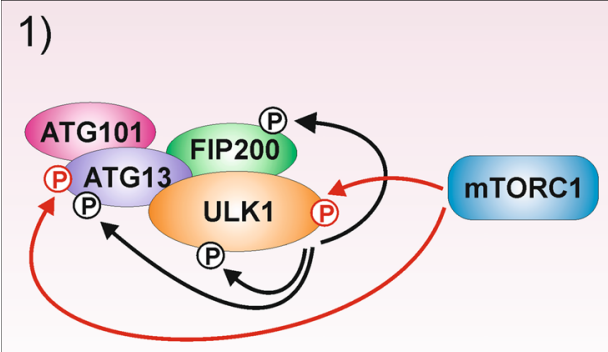

\section{ULK1-ATG13-FIP200-ATG101 complex}

3)

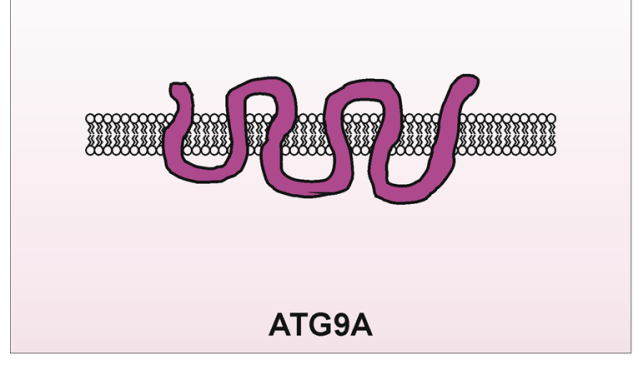

5)

AT-ATG5 conjugation system

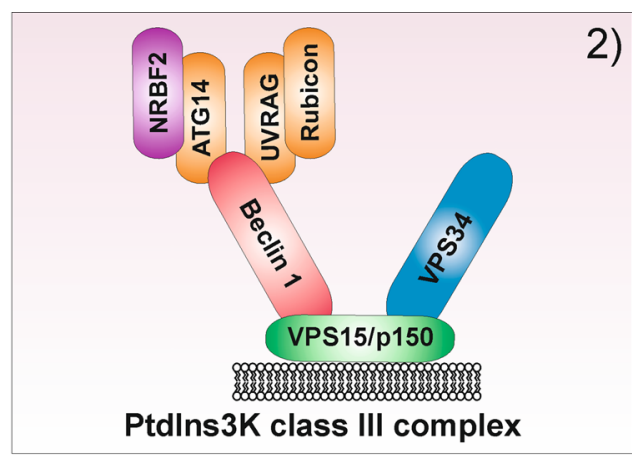

4)

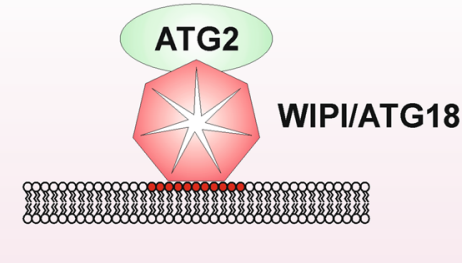

WIPI/ATG18-ATG2 complex

6)

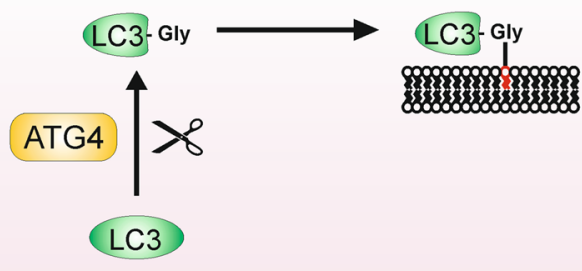

LC3/ATG8-PE conjugation system 
and Atg13 [41]. In the following years, the exact molecular details of the Atg1-dependent initiation of autophagy were deciphered. Yeast Atg1 associates with pathway-specific sets of Atg proteins, regulating either canonical autophagy or the yeast-specific cytoplasm-to-vacuole targeting ( $\mathrm{Cvt})$ pathway, respectively (reviewed in [42-45]). During canonical autophagy, Atg1 associates with Atg13, Atg17, Atg29 and Atg31. In contrast, during the Cvt pathway, Atg1 interacts with Atg11, Atg13, Atg20, Atg24 and Vac8 [44]. Accordingly, Atg17, Atg29 and Atg31 are selectively important for autophagy [46-48]. These three Atgs form a complex which is constitutively assembled and represents a scaffold for the recruitment of further Atgs to the PAS [4951]. Upon starvation, Atg1 binds to Atg17, and this association is primarily mediated by $\operatorname{Atg} 13$ [52, 53]. Both the Atg1-Atg13 kinase complex and the autophagy-specific Atg17-Atg29-Atg31 complex cooperatively regulate the subsequent recruitment of downstream Atgs to the PAS, and for this function their physical interaction is mandatory [50, 54].

In 1998, it was reported that autophagy is negatively regulated by the protein kinase target of rapamycin (TOR), and that rapamycin accordingly induces the autophagic flux [55]. Two years later, Kamada et al. published a pioneering work demonstrating that this TOR-dependent control of autophagy is mediated by the Atg1 kinase complex [47]. The authors observed that both starvation and rapamycin enhanced the kinase activity of Atg1. Furthermore, Atg13 is hyperphosphorylated by TOR, resulting in a reduced affinity to Atg1. Accordingly, rapamycin treatment favors the dephosphorylation of Atg13 and its association with Atg1, resulting in increased Atg1 activity. Finally, the authors reported that rapamycin-induced Atg1 activity was decreased in the $\Delta \operatorname{atg} 17$ strain, indicating that both Atg13 and Atg17 are important for Atg1 activation [47]. Subsequently the same group discovered that TOR phosphorylates Atg13 at S437, S438, S646, and S649. The authors mutated these four sites and four additional putative TOR sites (S348, S496, S535, S541) to alanines, and demonstrated that expression of the nonphosphorylatable Atg13-8SA mutant induced autophagy independently of TOR activity or nutrient status, apparently mimicking rapamycin treatment [56].

Notably, it has also been reported that Atg1 and Atg13 constitutively interact in vivo, irrespective of nutrient availability [57]. This situation would resemble the ULK1 complex constitution in higher eukaryotes (see below). Although the authors confirmed that binding of Atg13 to Atg1 indeed promotes its kinase activity and is important for efficient autophagy in vivo, the described observation would suggest that Atg1 activation in yeast is not exclusively controlled by regulated Atg13 binding, but rather involves additional levels of control. This could include conformational alterations or recruitment of additional factors regulated by the Atg13 phospho-status. Additionally, Atg1 phosphorylation itself is important for activation, as confirmed by two independent studies [58, 59]. However, next to TOR-regulation and Atg1 autophosphorylation additional kinases have been implicated in the regulation of the yeast Atg1-Atg13 complex, including PKA, Ksp1, Sch9 (yeast ortholog of mammalian AKT or p70S6K), or Snflp [yeast ortholog of the mammalian AMP-activated protein kinase (AMPK)] [60-64]. Additionally, the phospho-status of the Atg1-Atg13 complex is likely to be regulated by phosphatases [65]. With regard to the downstream Atg1 substrates which regulate the initiation of autophagy in yeast, the current knowledge is less complete. Although different in vitro substrates have been identified for Atg1 by a global phosphorylation analysis, including Atg8 and Atg18, their in vivo relevance awaits further confirmation [66]. Previously it has been reported that Atg9 cycling depends on Atg1-Atg13 (described in "Atg9/ATG9A"), but apparently the kinase activity of Atg1 is not important [67]. Nevertheless, recently it has been reported that Atg1 can directly phosphorylate Atg9 and that this phosphosphorylation is required for the efficient recruitment of Atg8 and Atg18 to the site of autophagosome formation and subsequent expansion of the IM [68]. Identified Atg1 substrates are summarized in Table 1.

In the last few years, the understanding of the signal transduction by the yeast Atg1 complex has significantly been complemented by several works investigating its structure. Ragusa et al. reported the crystal structure of a 2:2:2 complex of Atg17, Atg29 and Atg31 [69]. Atg17 is crescent-shaped with a $10 \mathrm{~nm}$ radius of curvature. During PAS organization and autophagy, the Atg17-Atg29-Atg31 complex dimerizes, and each dimer contains two complete crescents. The C-terminal "early autophagy targeting/ tethering" (EAT) domain of Atg1 senses membrane curvature, dimerizes, and tethers lipid vesicles [69]. This double-crescent/S-shape architecture was also reported by Chew et al. [70]. The crystal structure of the N-terminal domain of yeast Atg13 has also been published [71]. Atg13 contains a HORMA (Hop1p, Rev7p, Mad2) domain at its N terminus. The HORMA domain is dispensable for the interaction with Atg1 or Atg13 recruitment to the PAS, but is apparently required for autophagy and the recruitment of the PtdIns3K subunit Atg14 (see "The PtdIns3K class III complex") [71]. Furthermore, it has been reported that the Atg13 HORMA domain recruits Atg9 vesicles during autophagosome formation [72]. Fujioka et al. reported the $\mathrm{X}$-ray crystallographic analysis of the interaction of yeast Atg13 with Atg1 and Atg17 [73]. Atg13 binds tandem microtubule interacting and transport (tMIT) domains in Atg1 via a 2-part MIT interacting motif (residues 


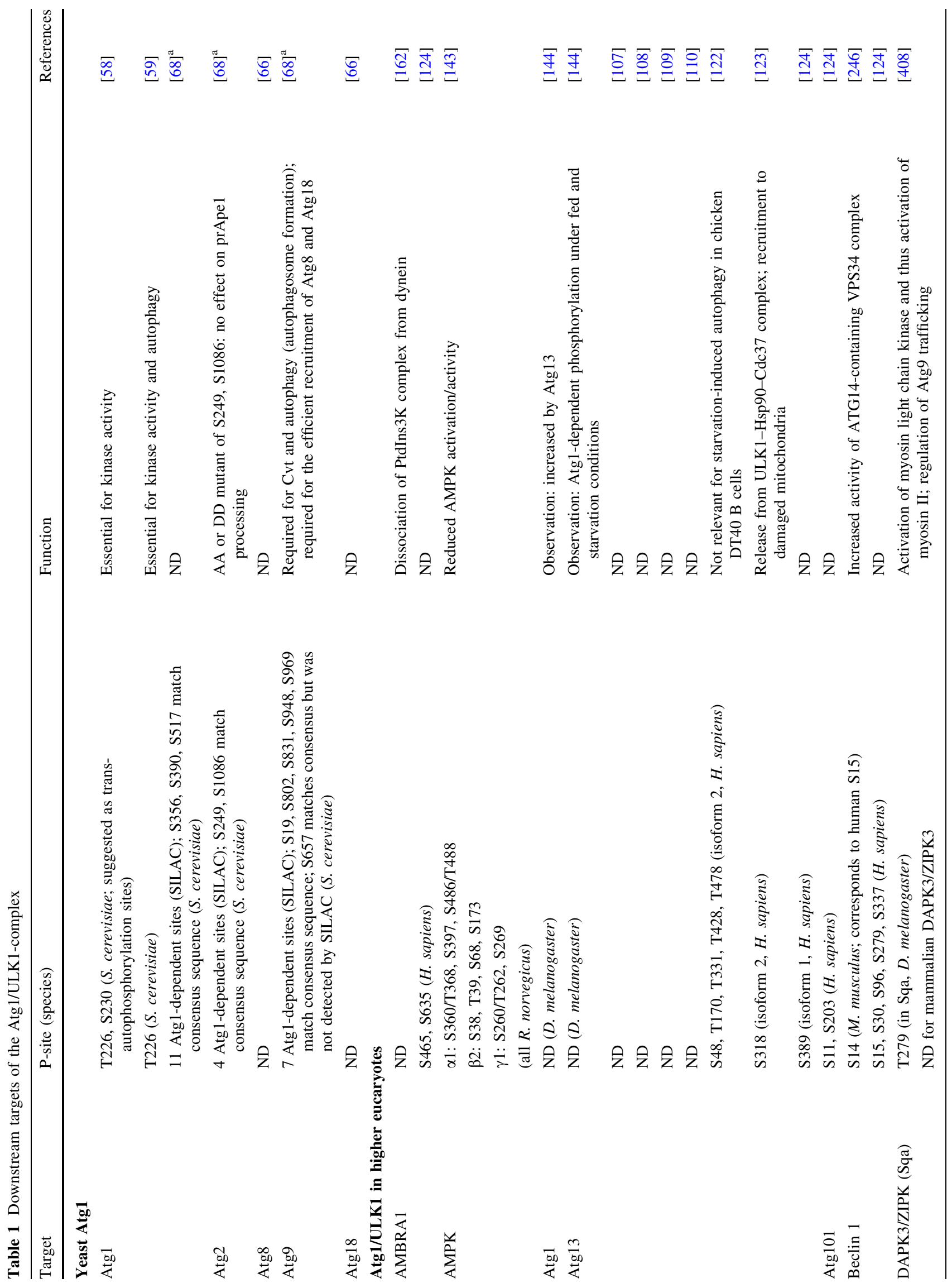




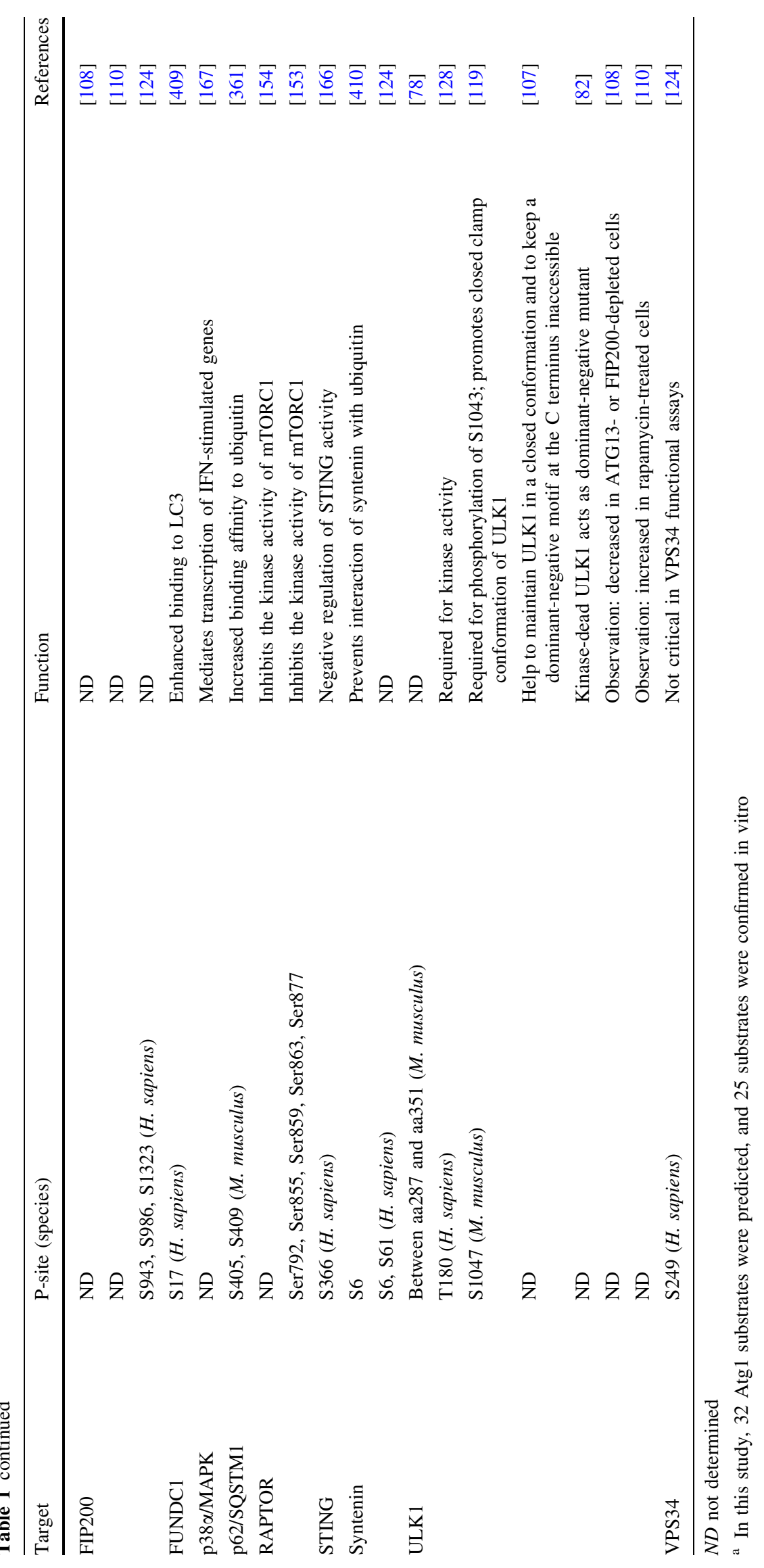


460-521). Additionally, the Atg17-binding region was mapped to amino acids 424-436 of Atg13. The authors propose that starvation-induced dephosphorylation of specific serine residues in Atg13 enhances the interaction with both Atg1 and Atg17, directly explaining the TORdependent regulation of these interactions described above. The Atg1-Atg13 interaction was essentially confirmed by Stjepanovic et al. [74]. They report that Atg1-Atg13 complex binds as a unit to the Atg17-Atg31-Atg29 scaffold with $\sim 10-\mu \mathrm{M}$ affinity via Atg13. The resulting complex consists primarily of a dimer of pentamers in solution [74]. Recently, it has been shown that the PAS contains $\sim 28$ copies of Atg17 and-upon autophagy induction-similar numbers of Atg1 and Atg13 molecules [75]. Furthermore, they observe tetramers of Atg1 pentamers that assemble via Atg17-Atg31-Atg29, ultimately proposing a model for the higher organization of the Atg1 complex at the PAS [75]. Further aspects about the structural analyses of the Atg1 complex have been summarized in a recent review article by Noda and Fujioka [76].

\section{The ULK1-ATG13-FIP200-ATG101 complex in higher eukaryotes}

Atg1 has orthologs in the nematode C. elegans and the fruit fly D. melanogaster, i.e., UNC-51 and ATG1, respectively. In mammals, so far five orthologs have been identified, i.e., ULK1, ULK2, ULK3, ULK4, and STK36 (also termed Fused homolog) (reviewed in [42-45, 77]). In 1998, murine ULK1 was cloned and its similarity to yeast Atg1 and C. elegans UNC-51 was reported [78]. ULK1 consists of an $\mathrm{N}$-terminal serine/threonine protein kinase domain, followed by a proline/serine (P/S)-rich domain and a conserved C-terminal domain (CTD). Shortly afterwards the same group reported the identification of human ULK1 and murine ULK2, respectively [79, 80]. In 2007, ULK1 was identified as an autophagy-modulating kinase by an siRNA screen of the kinome [81]. Knockdown of ULK1 in HEK293 cells blocked the autophagic response upon amino acid starvation or rapamycin treatment, respectively. ULK1 and ULK2 colocalize with ATG16L1 (see "Two ubiquitinlike conjugation systems in autophagy: Atg12/ATG12Atg5/ATG5 and Atg8/LC3-PE") and are accordingly targeted to the phagophore [82]. Notably, knockdown of ULK2 did not reveal any effect on autophagy induction in HEK293 cells, indicating that at least in this cellular system ULK1 and ULK2 cannot compensate each other [81]. However, compensatory roles of these two kinases can be deduced from the corresponding knockout mouse models. ULK1-deficient mice are viable and survive neonatal starvation periods [83]. Nonetheless, these mice reveal a delayed clearance of mitochondria from reticulocytes, indicating some differential roles of ULK1 and ULK2 for selective autophagy in general and for mitophagy in particular. Similarly, $U l k 2^{-l-}$ mice are viable and do not show an overt autophagy phenotype [84]. In contrast, ULK1/2double-deficient mice die shortly after birth, similar to mice deficient for ATG3, ATG5 or ATG7 [84]. Furthermore, autophagy induced by amino acid starvation is blocked in MEFs of these double-deficient mice [84]. The homology between ULK1 and ULK2 comprises the full length of the kinases, i.e., kinase domain, PS-rich domain, and CTD. In contrast, homology towards the other ULK family members is restricted to the kinase domain (reviewed in [42-45, 77]). However, ULK3 overexpression induced autophagy and premature senescence in a human fetal lung fibroblast cell line [85].

In 2007, Meijer et al. analyzed the degree of conservation for different Atgs/ATGs between different species [86]. They predicted that the protein KIAA0652 represents the human ortholog of yeast Atg13. Notably, they failed to identify Atg17 and Atg29 orthologs in higher eukaryotes [86]. Additionally, an Atg31 ortholog has not been reported in higher eukaryotes so far [8, 43]. However, in 2008 Hara et al. reported that the focal adhesion kinase family interacting protein of $200 \mathrm{kDa}$ (FIP200) is an ULK1-interacting protein (Fig. 1, panel 1) [82]. Originally, FIP200 has been identified as a proline-rich tyrosine kinase 2 (Pyk2)- and focal adhesion kinase (FAK)-interacting protein which inhibits Pyk2 and FAK by direct binding to the kinase domains [87, 88]. FIP200 is also referred to as retinoblastoma 1-inducible coiled-coil 1 (RB1CC1) [89]. FIP200 is ubiquitously expressed and is involved in multiple cellular processes (reviewed in [90]). According to these multiple roles performed by FIP200, several FIP200interacting proteins next to Pyk2 and FAK have been identified so far, including ATG16L1 (see "Two ubiquitinlike conjugation systems in autophagy: Atg12/ATG12Atg5/ATG5 and Atg8/LC3-PE”), TSC1, p53, PP1, ASK1, TRAF2, Arkadia E3-ligase, COP1 E3-ligase, hSNF5, PIASy, $\beta$-catenin, ActA, and stathmin [91-105]. FIP200 comprises a putative nuclear localization signal (NLS) within the N-terminal half of the protein, a large coiled-coil domain and a leucine zipper motif at the $\mathrm{C}$ terminus [90]. FIP200 has been reported to localize in the cytoplasm, the nucleus and at focal adhesions [90]. The interaction between ULK1 and FIP200 requires the CTD of ULK1, and-similar to ULK1/2-FIP200 localizes to the phagophore upon starvation [82]. Furthermore, in FIP200deficient MEFs autophagy induction is blocked, and the defect in autophagosome formation occurs downstream of mTOR [82]. Within the "Discussion" section of this first report demonstrating the importance of FIP200 for autophagy, the authors already speculate that FIP200 might represent the functional counterpart of yeast Atg17, due to several functional and architectural similarities [82, 106]. 
As described below, this assumption was subsequently confirmed by several reports.

Following the prediction by Meijer et al., several groups demonstrated that KIAA0652 indeed represents the human ATG13 ortholog (Fig. 1, panel 1) [107-110]. Furthermore, three of these reports deciphered the mechanistic details how mTOR regulates autophagy through the mammalian ULK1-ATG13-FIP200 complex. Human ATG13 is a 517 aa protein (isoform 1) and exhibits a $16 \%$ identity to its yeast ortholog [109]. Chan et al. showed that knockdown of ATG13 blocks starvation-induced LC3 lipidation and ATG9A redistribution. They found that ATG13 binds to the CTD of Ulk1/2 [107]. Additionally, it was demonstrated that ATG13 serves as substrate for ULK1/2 and that the association between ULK proteins and ATG13 is not affected by the nutritional status or ATG13 phosphorylation [107]. In three almost simultaneously published studies, the mechanistic details how the mammalian ULK1-ATG13-FIP200 complex regulates autophagy and how mTOR transduces signals to this complex were elucidated [108-110]. ATG13 interacts with both ULK1/2 and FIP200 [108-110]. It appears that the association between ULK1 and FIP200 significantly depends on ATG13, but one group also demonstrated that ULK1 can independently interact with ATG13 and FIP200 [108]. Kim's group reported that the last 75 aa of ATG13 are mandatory for ULK1/2 binding, and the last 134 aa for binding of both FIP200 and ULK1/2 [110]. We have recently fine-mapped the interaction sites between ATG13/ULK1 and ATG13/ FIP200, respectively. It appears that the last three amino acids of ATG13 control binding to ULK1 and that the peptide sequence encoded by exon 14 of the human ATG13 gene mediates binding to FIP200 ([111] and unpublished results). Size exclusion analyses by Mizushima's group revealed that ULK1, ATG13 and FIP200 can be detected within a 3-MDa complex [109]. FIP200 is exclusively found in this mega-complex, and this complex cannot be detected in FIP $200^{-/-}$cells, indicating that FIP200 significantly contributes to the elution volume of this complex. The Jiang group performed size exclusion experiments with recombinant proteins and observed the three components within a complex with a molecular weight $>1$ MDa [108]. All three components of the complex localize to the phagophore upon induction of autophagy, and the assembly of the complex is not sensitive to starvation. Furthermore, ATG13 and FIP200 are required for maximal ULK1 kinase activity, ULK1 stability, and ULK1 recruitment to the phagophore. In turn, both ATG13 and FIP200 are substrates for ULK proteins. All three groups observed that either starvation or rapamycin treatment results in a faster migration of ULK1 and ATG13 in SDS-PAGE, and all three groups clearly demonstrated that mTOR phosphorylates both ULK1 and ATG13 [108-
110]. Furthermore, Hosokawa et al. showed that the mTOR complex 1 (mTORC1) associates with the 3-MDa complex under nutrient-rich conditions and dissociates under starvation [109]. This interaction is mediated by the mTORC1 component RAPTOR and the PS-domain of ULK1. Of note, the mTORC1 binding site has alternatively been mapped to the kinase domain of ULK1 [112]. Accordingly, the ATG13-interacting CTD of ULK1 is not necessary for mTORC1 recruitment [109].

The fourth component of the ULK kinase complex has been identified and characterized independently by two groups. This component does not have any obvious ortholog in S. cerevisiae and was thus termed ATG101 [37, 38]. Of note, the closely related fission yeast $S$. pombe harbors an ATG101 ortholog (alternatively named Mug66) [37, 113-115]. ATG101 directly interacts with the ULK1 kinase complex through ATG13, and this association is independent of nutrient supply [37]. Mercer et al. mapped the ATG101-binding site in ATG13 to amino acids 112-220 [38]. In contrast to the results described above, the binding site of ATG13-ATG101 within ULK1 was mapped to the N-terminal half of the PS-rich domain, proximal to the kinase domain [38]. Notably, siRNA-mediated depletion of ATG101 suppresses GFP-LC3 puncta formation or GST-BHMT fragmentation, indicating that ATG101 is essential for autophagy [37, 38]. Although yeast and higher eukaryotes share some overlapping components of the Atg1/ULK1 complexes, e.g., Atg1/ULK1 itself and ATG13, there exist significant differences in complex constitution. As described above, yeast Atg11 and Atg17 serve as scaffolds during Cvt pathway or autophagy, respectively. It appears that FIP200 and ATG101 have overtaken some corresponding functions, since primary sequence orthologs of $\operatorname{Atg} 11$ and $\operatorname{Atg} 17$ do not exist in higher eukaryotes. Although FIP200 presumably represents a functional Atg17 ortholog [106], it should be noted that FIP200 is listed as Atg11 family member in the NCBI Pfam database and is structurally similar to $S$. pombe and C. elegans Atg11s [116]. Additionally, ATG101 has been reported to show similarity to yeast Atg17 [116].

To date, structural analyses of the ULK1 complex in higher eukaryotes remain less advanced compared to their yeast orthologs, but some interesting observations have recently been published. Suzuki et al. reported the structural analysis of the $S$. pombe Atg101-Atg13 complex [115]. The fission yeast $S$. pombe is a suitable model system for studying the mammalian ULK complex, since it conserves Atg1, Atg13, Atg17 and Atg101 orthologs, but not Atg29 and Atg31 [114, 115]. S. pombe Atg101 harbors a HORMA domain similar to that of Atg13. The HORMAdomain protein $\mathrm{Mad} 2$ has an open $(\mathrm{O})$ and a closed (C) conformation, and it appears that Atg101 has a locked O-Mad2-like confirmation and stabilizes the C-Mad2-like 
conformation of Atg13. This in turn leads to the recruitment of downstream factors to the autophagosome formation site. In a parallel work, Michel et al. reported the crystal structure of human ATG101 [117]. The authors confirm the existence of ATG101 in a O-Mad2-like conformation. They also describe the presence of three large insertions relative to Mad2 (extensions 1, 2 and 3), which are all located to one pole of the molecule. Interestingly, extension 1 is missing in S. pombe Atg101, and extension 3 is significantly shorter [117]. The exact function of these extensions has to be unraveled in the future. Finally, the crystal structure of the ULK1 kinase domain in complex with different inhibitors has been reported by Lazarus et al. [118]. Whether the interaction mode between ATG13 and ULK1 is conserved in higher eukaryotes awaits further clarification, since (1) yeast and mammalian Atg13/ATG13 are not very homologous and (2) we observed that this interaction is-not necessarily directly mediated but at least - controlled by the last three amino acids of ATG13 [111].

Taking all the experimental observations summarized above into consideration, the following model has been established [Figs. 1 (panel 1), 2]: under nutrient-rich conditions, mTORC1 associates with the ULK1-ATG13FIP200-ATG101 complex and phosphorylates ULK1 and ATG13. Under starvation conditions, mTORC1 dissociates from this mega-complex, and the inhibitory mTOR-dependent phospho-sites within ULK1 and ATG13 become dephosphorylated. Active ULK1 then autophosphorylates and phosphorylates ATG13 and FIP200, ultimately leading to the initiation of autophagosome formation. However, this proposed model leaves central remaining questions open, which will be partially addressed below or are currently being investigated: (1) how does mTOR-dependent phosphorylation of ULK1 and ATG13 keep the constitutively assembled complex in an inactive state; (2) which phosphatases dephosphorylate these inhibitory mTOR-sites and how does this contribute to the activation of the complex; (3) how is the phospho-status of ULK1 and ATG13 regulated in mTOR-independent pathways; (4) what is the role of the ULK-dependent phospho-sites in ATG13 and FIP200; (5) are additional interacting proteins and/or further post-translational modifications of this complex necessary for its autophagy-inducing function, and most importantly; (6) how does the ULK1-ATG13-FIP200-ATG101 complex initiate the downstream autophagy signaling machinery?

\section{Regulation of the ULK complex by post-translational modifications and downstream effectors}

According to the above described model, the phosphostatus of the ULK1-ATG13-FIP200-ATG101 complex is central for the regulation of autophagic processes. In general, global phosphorylation of ULK1 and ATG13 is decreased under starvation conditions and FIP200 phosphorylation is decreased under fed conditions $[44,45,108$ 110]. In other words, it appears that the phospo-status of ULK1 and ATG13 primarily depends on mTOR, whereas the phospho-status of FIP200 mainly depends on ULK1, respectively. Several groups identified phosphorylation sites within ULK1 by mass spectrometry (see supplemental Table 1), both under nutrient-rich and starvation conditions [119-121]. These phospho-acceptor sites are distributed over the full length protein, i.e., within the kinase domain, the PS-rich domain and the CTD. These proteomic screens revealed that some of the sites are constitutively phosphorylated whereas others show a dependency on the nutritional conditions. With regard to ULK1-dependent sites in ATG13, seven phospho-acceptor sites have been published [121-123]. The SILAC-based approach by Shang et al. revealed that total phosphorylation levels of ATG13 were low under nutrient-rich conditions and stayed largely unaltered upon starvation [121]. The authors could only identify phosphorylation of ATG13 S361 (isoform 1), and phosphorylation of this site did not significantly change during starvation [121]. This would indicate that rather the ULK1 phospho-status than the ATG13 phosphostatus governs autophagy initiation. Joo et al. showed that the Hsp90-Cdc37 chaperone complex regulates mitophagy by modulating ULK1 stability and function. They reported that ULK1-mediated phosphorylation of ATG13 at S318 (isoform 2; corresponds to $\mathrm{S} 355$ in isoform 1) is required for the release of ATG13 from an ULK1-Hsp90-Cdc37 complex and for the recruitment of ATG13 to damaged mitochondria, where it contributes to Parkin-mediated mitophagy (see "Two ubiquitin-like conjugation systems in autophagy: Atg12/ATG12-Atg5/ATG5 and Atg8/LC3PE") [123]. These results might account for the selective role of ULK1 for the mitochondrial clearance during reticulocyte development described above, and additionally the data suggest a phosphorylation-dependent regulation of the ULK1-ATG13 interaction during selective autophagy processes. We were able to identify five ULK1-dependent phospho-sites of ATG13 by an in vitro kinase assay (corresponding to S48, T170, T331, T428 and T478 in human isoform 2). However, mutation of these five sites did not alter starvation-induced autophagy in chicken DT40 B lymphocytes, although starvation-induced autophagy is completely blocked in $A T G 13^{-1-}$ DT40 cells [122]. Additionally, mTOR-dependent sites of mammalian ATG13 have not been reported so far [42, 45]. Recently, ULK1-dependent phospho-sites of FIP200 have been identified, but their functional relevance awaits further clarification [124].

On the basis of its central role for the regulation of the ULK1-ATG13-FIP200-ATG101 complex, mTOR has 


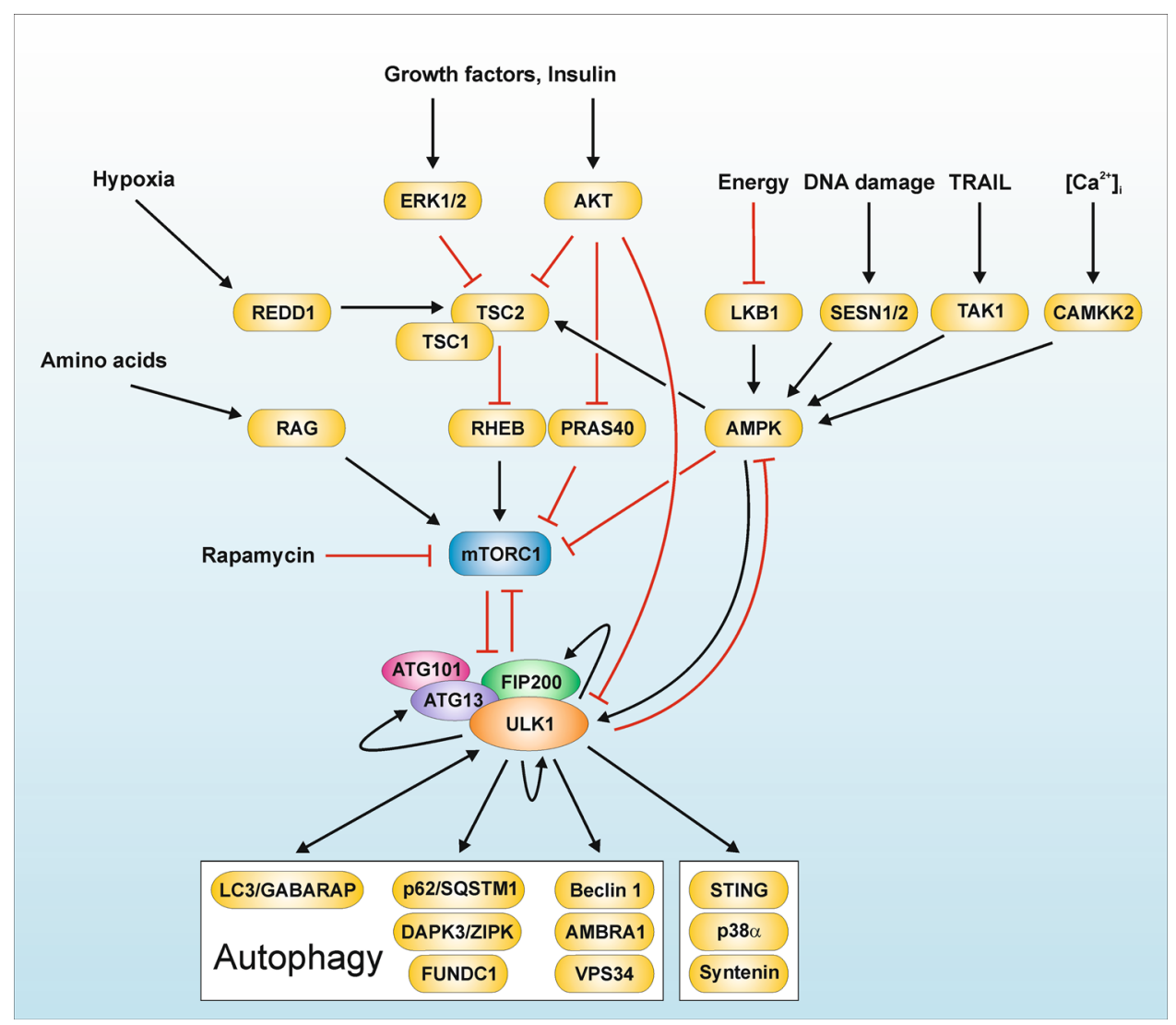

Fig. 2 Signaling machinery upstream and downstream of the ULK1 complex. In recent years, the mTORC1-dependent regulation of the ULK1-ATG13-FIP200-ATG101 complex has been deciphered. Under nutrient-rich conditions, mTORC1 associates with the ULK1-ATG13-FIP200-ATG101 complex and phosphorylates ULK1 and ATG13. Under starvation conditions or upon treatment with mTOR inhibitors, mTORC1 dissociates from this megacomplex, and the inhibitory mTOR-dependent phospho-sites within ULK1 and ATG13 become dephosphorylated. Active ULK1 then autophosphorylates and phosphorylates ATG13 and FIP200, ultimately leading to the initiation of autophagosome formation [44, 45, 108-110]. The depicted substrates of ULK1 are listed in Table 1. MTOR has been established as central "gatekeeper" of autophagy, since this kinase integrates (1) nutrient signals, e.g., generated by growth factors or amino acids; (2) energy signals, e.g., controlled by the cellular AMP/ATP ratio; and (3) stress signals such as hypoxia or DNA damage. The Ser/Thr kinase mTOR is the catalytic subunit of two distinct kinase complexes, i.e., mTORC1 and mTORC2. The two complexes contain unique associated proteins which serve as scaffolds and determine the substrate specificity of the complexes, i.e., regulatory-associated protein of mTOR (RAPTOR) and rapamycin-insensitive companion of mTOR (RICTOR), respectively [396398]. Next to these two proteins, the two complexes both harbor additional specific interacting proteins and share some components. Amino acids are sensed by the RAG family of small GTPases. Active

been dubbed the "gatekeeper" of autophagy (Fig. 2). The protein kinase mTOR integrates (1) nutrient signals, e.g., generated by growth factors or amino acids; (2) energy signals, e.g., controlled by the cellular AMP/ATP ratio; and (3) stress signals such as hypoxia or DNA damage
RAG heterodimers translocate mTORC1 to lysosomal surfaces, where they bind to the so-called Ragulator complex [399]. On the surface of lysosomes, mTORC1 is activated by another small GTPase termed RAS-homologue enriched in brain (RHEB). The presence of growth factors is transmitted to mTOR via AKT. AKT phosphorylates tuberous sclerosis 2 protein (TSC2; also termed tuberin), which together with TSC1 (also termed hamartin) forms the TSC1-TSC2 complex. AKT-dependent phosphorylation of TSC2 inhibits the GTPase activating protein (GAP) activity of the TSC1-TSC2 complex for RHEB, thus promoting mTORC1 activation by GTPloaded RHEB [400-402]. Alternatively, AKT phosphorylates PRAS40, which is subsequently bound by 14-3-3 proteins and cannot inhibit mTORC1 anymore [403-405]. Low energy levels as sensed by a high AMP/ATP ratio are transmitted to mTORC1 via AMPK. AMPK can-like AKT-phosphorylate TSC2. However, AMPKdependent TSC2 phosphorylation leads to increased GAP activity of the TSC1-TSC2 complex and thus to mTORC1 inhibition [406, 407]. Alternatively, AMPK can directly inhibit mTORC1 by RAPTOR phosphorylation [137]. Stress signals like hypoxia, DNA damage, TRAIL or $\mathrm{Ca}^{2+}$ signals also inhibit mTORC1 via AMPK and/or the TSC1-TSC2 complex (reviewed in [42, 126, 127]). Finally, AKT and AMPK can directly regulate ULK1, and ULK1 can-by negative feedback loops-regulate the upstream kinases mTORC1 and AMPK $[120,121,128,140,141,143,153,154]$

(reviewed in [125-127]). The growth factor and energy inputs are essentially controlled by the serine/threonine protein kinases AKT and AMP-activated protein kinase (AMPK), which both function as upstream regulators of mTOR. Both kinases have also been implicated in the 
direct regulation of the ULK1 kinase complex (Fig. 2). The serine/threonine kinase AKT (also termed protein kinase B, $\mathrm{PKB})$ translates signals received by receptor tyrosine kinases or receptor-associated tyrosine kinases into a diverse array of intracellular responses, including cell cycle control, metabolism, apoptosis, or autophagy. Bach et al. showed that ULK1 serves as direct substrate for AKT. The authors observed that insulin induces the AKT-dependent phosphorylation of ULK1 at S775 (human sequence) [128]. AMPK is the main sensor for cellular energy levels. AMPK consists of three subunits, i.e., the catalytic $\alpha$-subunit and the regulatory $\beta$ - and $\gamma$-subunits, respectively. Additionally, there exist several isoforms of the different subunits, i.e., $\alpha 1-2, \beta 1-2$, and $\gamma 1-3$ (reviewed in [129-131]). In order to exert its full catalytic activity, the $\alpha$-subunit has to be phosphorylated within its activation loop at T172. Besides T172 phosphorylation of the $\alpha$-subunit, the heterotrimeric AMPK complex is controlled by the regulatory $\beta$ - and $\gamma$-subunits. In 2001, Wang and colleagues reported that the yeast AMPK-ortholog Snf1p is a positive regulator of autophagy and probably functions via Atg1 and/or Atg13, respectively [63]. Subsequently, several reports analyzed the role of AMPK for mammalian autophagy. Although an initial study reported that the AMPK-activating substances adenosine, AICA riboside and N6mercaptopurine riboside inhibit autophagy [132], subsequently several works supported a positive regulatory role of AMPK for mammalian autophagy [133-136]. Generally, this positive effect of AMPK on autophagy has been attributed to its capability to inhibit mTOR (see Fig. 2). The inhibition of mTORC1 can be achieved by two different pathways, either by AMPK-mediated phosphorylation of the upstream regulator tuberous sclerosis complex 2 (TSC2) or by AMPK-mediated phosphorylation of the mTORC1-subunit RAPTOR (see Fig. 2) $[137,138]$. However, in recent years a direct regulation of the ULK1-ATG13-FIP200-ATG101 complex by AMPK has been established, which is accordingly mTOR-independent. How does this direct regulation work? We and others demonstrated that AMPK directly interacts with ULK1 ([112, 120, 121, 139-142]. We discovered that ULK1 phosphorylates all three subunits of AMPK. It appears that ULK1-dependent phosphorylation of AMPK negatively regulates both its activation and activity, possibly establishing a negative regulatory feedback loop contributing to the termination of an autophagic response [143]. Interestingly, several groups reported that AMPK in turn phosphorylates ULK1 [120, 121, 140, 141]. However, different groups mapped different phospho-acceptor sites in the ULK1 amino acid sequence. Together with the proteomic screens analyzing the global nutrient-dependent ULK1 phosphorylation described above, a rather complex picture of the "ULK1 phospho-barcode" evolves. The different identified phospho-sites are summarized in supplemental Table 1 and reviewed in Wong et al. and Alers et al. [42, 45]. However, three ULK1 phospho-sites appear to be of particular interest, since they were reported by three or more independent groups, i.e., S556, S638, and S758 of human ULK1 sequence [45]. The identification of different sites by different groups already emphasizes that the AMPK-dependent regulation of the ULK1 complex is far from being completely characterized. However, it has been stated that the function of AMPK in autophagy is rather a "fine-tuning" than an "on-off switch" [45].

Apparently, mTOR, AKT, AMPK and presumably additional kinases (see prediction in [120]) contribute to the regulation of the ULK1-ATG13-FIP200-ATG101 complex. It is conceivable that these phosphorylation processes depend on different factors, i.e., cell type or autophagic stimulus. Additionally, there appear to exist significant differences between metazoan lineages in the regulation of the ULK kinase complex. Chang and Neufeld reported the regulation of this complex in D. melanogaster in parallel to the works on the mammalian complex. Interestingly, they reported common and divergent aspects. Like for the mammalian system, ATG13 is essential for starvation-induced autophagy, the ATG1-ATG13 interaction is independent of the nutrient status, and ATG13 is required for the autophagy-promoting function of ATG1 [144]. In contrast to the mammalian system, ATG13 is hyperphosphorylated under starvation conditions, indicating that the ATG13 phospho-status might be more dependent on ATG1 than on TOR in D. melanogaster. Furthermore, the authors demonstrated that ATG13 overexpression blocks autophagy and that TOR associates with ATG1/ATG13 independently of nutrient supply.

Next to the diversity among different species, different cell types and different autophagy-inducing stimuli, the complexity of this regulatory system is even increased by two additional aspects: (1) the action of phosphatases and (2) ULK1-dependent feedback signaling targeting the upstream kinases. It can be assumed that phosphatases contribute to the dephosphorylation of the mTOR-sites in ULK1 and ATG13, respectively [45]. Notably, the direct interaction between ULK1 complex components and protein phosphatases has been documented. For example, UNC-51 interacts with the protein phosphatase 2A (PP2A) in C. elegans, and FIP200 harbors a docking motif for protein phosphatase 1 (PP1) [100, 145]. However, the dephosphorylation of specific sites by specific phosphatases has not been reported yet. Generally, the phosphatase inhibitor okadaic acid is viewed as inhibitor of autophagy [45, 146-149]. Furthermore, PP2A has already been implicated in the regulation of autophagic processes, both as positive and negative regulator [65, 146, 148, 150]. However, it should be noted that PP2A enzymes fulfill 
multiple cellular functions with several different interacting proteins, and the involvement of additional or more selective phosphatases in the regulation of autophagy is currently being intensely investigated.

Next to phosphatase-mediated dephosphorylation processes, it has been postulated that feedback signaling pathways originating from the ULK kinase complex contribute to the shaping of an autophagic response. Apparently, ULK1 can directly influence its upstream regulators mTOR and AMPK, respectively (Fig. 2). As described above, we were able to identify ULK1-dependent regulation of AMPK. With regard to mTOR, it has been well documented that Atg1/ULK1 activity affects this kinase and its downstream signaling. In 2007, two groups independently reported that ATG1 overexpression in $D$. melanogaster negatively regulates the activity of the (m)TOR downstream target S6K [151, 152]. Similarly, Jung et al. observed an increased S6K phosphorylation upon knockdown of ATG13 or ULK1 [110]. Congruent to these observations, Chang and Neufeld reported that ATG1-ATG13 complexes regulate TOR by modulating its intracellular distribution and trafficking [144]. However, these reports only indirectly show the effect of Atg1/ULK1 on mTOR activity. Two reports proved that activated ULK1 directly phosphorylates RAPTOR and thus inhibits mTORC1 signaling [153, 154]. Collectively, these reports indicate that there is a close connection between mTORdependent cell growth control and autophagy signaling. Again another level of complexity is added by the fact that the ULK1 kinase complex component FIP200 interacts with TSC1, which is an upstream regulator of mTOR [92, 95]. Interaction of FIP200 with the TSC1-TSC 2 complex results in the inhibition of this complex, ultimately leading to increased mTOR activity, S6K phosphorylation, and cell growth. Taken together, it appears that ULK1 and FIP200 have opposite effects on the regulation of mTOR activity, and future studies have to reveal the respective relative contributions.

In general, kinase-catalyzed phosphorylations and phosphatase-mediated dephosphorylations are the major molecular switches regulating the autophagy-initiating ULK1 complex. However, in the recent past alternative post-translational modifications have been implicated in this regulation, i.e., ubiquitination and acetylation. As described in "Two ubiquitin-like conjugation systems in autophagy: Atg12/ATG12-Atg5/ATG5 and Atg8/LC3PE", ubiquitination plays an essential role for cargo recognition during selective autophagy processes. Furthermore, this post-translational modification links the two major cellular degradation pathways, i.e., the ubiquitinproteasome system (UPS) and selective autophagy. Meanwhile it is well established that interference with one pathway influences the flux through the other [155].
Finally, there are several lines of evidence that the ULK1 complex is modified by ubiquitin chains as well. Our group observed that treatment with the deubiquitinase inhibitor WP1130 increases ULK1 ubiquitination, and subsequently leads to the transfer of ULK1 to cellular aggresomes and to the parallel loss of ULK1 activity [156]. Zhou et al. reported that nerve growth factor (NGF) can induce the interaction of ULK1 with the NGF receptor TrkA [157]. This apparently occurs through K63-polyubiquitination of ULK1 and binding of ULK1 to p62, which then recruits ULK1 to TrKA receptor complexes. The study by Joo et al. described above reporting ULK1-catalyzed phosphorylation of ATG13 at S318 indirectly confirms ULK1 ubiquitination. The authors demonstrate that the disruption of the association between the Hsp90-Cdc37 chaperone complex and ULK1 by the Hsp90 antagonist 17-allylamino-17-demethoxygeldanamycin (17AAG) leads to ULK1 destabilization, which can be inhibited with the proteasome inhibitor MG132 [123]. Jiao et al. identified the chaperone-like protein $\mathrm{p} 32$ as a key regulator of ULK1 stability [158]. P32 forms a complex with ULK1, and p32 depletion increased K48-linked but decreased K63-linked polyubiquitination of ULK1, leading to proteasome-mediated degradation of ULK1. Li et al. reported that the mitochondrial outer-membrane E3 ligase MUL1 ubiquitinates ULK1 and regulates selenite-induced mitophagy [159]. Finally, Nazio et al. reported that mTOR does not only regulate the ULK complex by phosphorylation, but also indirectly by regulating ULK1 ubiquitination [160]. In this study the authors show that under basal conditions mTOR phosphorylates activating molecule in Beclin 1-regulated autophagy 1 (AMBRA1; alternatively named autophagy/Beclin 1 regulator 1) and thus keeps it inactive. AMBRA1 is a Beclin 1-interacting protein (see "The PtdIns3K class III complex") [161]. Upon autophagy induction, AMBRA1 enhances ULK1 kinase activity and stability and promotes ULK1 self-association by enhancing K63 ubiquitination of ULK1 through the AMBRA1-associated E3-ligase tumor necrosis receptor-associated factor 6 (TRAF6) [160]. In turn, ULK1 phosphorylates AMBRA1 and thus promotes it detachment from the dynein complex [162]. Notably, Chang and Neufeld already observed that ATG1 and ATG13 levels were affected by TOR function in D. melanogaster, i.e., reduced levels in cells with high TOR activity and increased in cells with low TOR activity [144]. Generally, it appears that the components of the ULK1 complex are important for their mutual stabilization. ULK1 is destabilized in cells deficient for ATG13, FIP200 or ATG101 [37, 108-110]. Similarly, FIP200 is destabilized in cells deficient for ATG13 [109], and ATG13 is reduced in ATG101-depleted cells [37, 38].

Next to ubiquitination, acetylation has been reported to regulate autophagy. Gammoh et al. report that the histone 
deacetylase (HDAC) inhibitor suberoylanilide hydroxamic acid (SAHA) activates autophagy via the inhibition of mTOR and transcriptional up-regulation of LC3 expression [163]. The authors confirmed that the SAHA-mediated induction of autophagy depends on ULK1/2. Recently, the direct acetylation of ULK1 was reported. Lin et al. found that glycogen synthase kinase 3 (GSK3), which is activated by growth factor deprivation and resulting AKT inactivation, phosphorylates and thus activates acyltransferase TIP60 [164]. Activated TIP60 in turn acetylates and stimulates ULK1. ULK1 acetylation presumably occurs at K162 and/or K606, and a non-acetylatable ULK1 mutant failed to rescue autophagy in $U l k 1^{-/-}$MEFs [164]. Next to the direct AKT-mediated ULK1 phosphorylation described above, the GSK3-TIP60-ULK1 axis is another example how AKT-dependent signals are transduced to the ULK1 complex independently of mTOR.

With regard to the downstream signaling machinery, different ULK1 substrates have been reported (Fig. 2), but frequently their exact contribution to the induction of autophagy has still to be examined. Generally, the different ULK1 substrates can be grouped into different categories: (1) components of the ULK1 complex; (2) components of the PtdIns3K complex (see "The PtdIns3K class III complex"); (3) other autophagy-related regulators and proteins, and (4) non-autophagy-related substrates (Table 1; Fig. 2). There likely exist several additional ULK1 substrates which contribute to the regulation of the autophagic flux in a phosphorylation-dependent manner. The identification and characterization of these ULK1 substrates will greatly enhance our understanding of autophagy signaling pathways. Furthermore, it has to be noted that there apparently exist kinase-independent autophagic ULK1 functions, and non-autophagic functions of ULK1 complex components (reviewed in [45]) (Fig. 2). Several observations have recently been reported to underscore the latter aspect: nuclear ULK1 can promote cell death in response to oxidative stress [165], ULK1 can negatively regulate the stimulator of interferon genes (STING) pathway [166], and ULK1 mediates expression of interferon-stimulated genes via the p38alpha MAPK pathway [167]. Finally, also ULK1/2-independent autophagic processes have been reported [84, 122]. The signaling machinery upstream and downstream of the ULK1 complex is summarized in Fig. 2.

\section{The PtdIns3K class III complex}

\section{The yeast PtdIns3K class III complexes}

Next to the ULK1-ATG13-FIP200-ATG101 complex, another multiprotein-complex is important for the formation of autophagosomes. In yeast, the class III phosphatidylinositol 3-kinase (PtdIns3K class III) Vps34 functions in both autophagy and sorting of vacuolar proteins. Two separate Vps34 subcomplexes have been identified to mediate these functions [168]. The autophagyregulating complex I contains Vps34, Vps15, Atg6 (Vps30), and Atg14. In contrast, the sorting of vacuolar proteins is mediated by complex II, which contains Vps38 instead of Atg14 [168]. Accordingly, the unique complexsubunits Atg14 and Vps38 regulate the intracellular localization and the specific functions of these two complexes. Atg14 mediates the localization of complex I to the PAS, whereas Vps38 controls the localization of complex II to endosomes [169, 170]. Recently, Araki et al. reported the identification and characterization of yeast Atg38 [171]. The authors describe that Atg38 physically interacts with Atg14 and Vps34 via its $\mathrm{N}$ terminus. The $\mathrm{C}$ terminus of Atg38 mediates homodimerization, which is indispensable for the integrity of complex I. Accordingly, it appears that the homodimer of Atg38 functions as a linker between the Vps15-Vps34 and Atg14-Atg6 subcomplexes, ultimately facilitating complex I formation [171].

\section{Mammalian PtdIns3K class III complexes}

Similar to the situation in yeast, different PtdIns3K class III complexes could be identified in mammals (reviewed in [172-176]). The mammalian PtdIns3K class III core complex consists of the catalytic subunit VPS34, the adaptor VPS15 (p150), and Beclin 1 (ATG6) [Figs. 1 (panel 2), 3]. Beclin 1 forms the scaffold for the recruitment of additional activators or repressors of the PtdIns $3 \mathrm{~K}$ class III complex. Beclin 1 contains an $\mathrm{N}$-terminal intrinsically disordered region, a BCL2 homology 3 (BH3) domain, a coiled-coil domain, and a $\mathrm{C}$-terminal $\beta$ - $\alpha$ repeated, autophagy-specific (BARA) domain [175]. Additionally, He et al. identified another mammalian ortholog of Beclin 1-termed Beclin 2 - which functions in both autophagy and the degradation of $\mathrm{G}$ protein-coupled receptors [177]. Although we address some of the regulatory signaling pathways targeting and established by Beclin 1, we refer readers to other excellent reviews on this molecule [172-175].

In the recent past, three major subcomplexes have been reported, which contain either ATG14, UV radiation resistance-associated gene protein (UVRAG), or a dimer of UVRAG and RUN domain protein as Beclin 1 interacting and cysteine-rich containing (Rubicon) [Figs. 1 (panel 2), 3].

ATG14 (alternatively called Atg14-like, ATG14L, or Beclin 1-associated autophagy-related key regulator, Barkor) is the putative mammalian homolog of yeast Atg14 and was identified by four different groups [178-181]. Accordingly, the ATG14 containing PtdIns3K class III complex likely represents the functional equivalent to yeast complex I. ATG14 co-localizes with several marker proteins on phagophores, indicating that this complex is 
involved in an early stage of autophagy. Furthermore, ATG14-silencing suppresses autophagosome formation [178-181]. It has additionally been shown that ATG14 increases VPS34 catalytic activity in a Beclin 1-dependent manner [181]. Binding of ATG14 to Beclin 1 is mediated via their respective coiled-coil domains [179-181]. Most interestingly, recently it was shown that ATG14 is not only involved in early steps of autophagosome formation, but also in later steps. Diao et al. reported that ATG14 promotes membrane tethering and fusion of autophagosomes to endolysosomes [182]. This ATG14 function requires ATG14 homo-oligomerization by its cysteine repeats. In contrast, this homo-oligomerization is not required for initial autophagosome formation [182]. Apparently, ATG14 binds to the soluble $N$-ethylmaleimide-sensitive factor attachment protein receptor (SNARE) core domain of syntaxin 17 (STX17) and stabilizes the STX17-SNAP29 binary target-SNARE complex on autophagosomes (Fig. 3) [182]. Previously, Itakura et al. demonstrated that the SNARE protein Stx17 translocates to the outer autophagosomal membrane [183]. Fusion with lysosomes is then mediated by the interaction between autophagosome-resident Stx17, synaptosomal-associated protein 29 (SNAP-29), and the lysosome-resident vesicle-associated membrane protein 8 (VAMP8) [183].

In parallel, all four groups reported that the interactions of ATG14 or UVRAG with the PtdIns3K class III core complex are mutually exclusive, which is probably due to their overlapping binding sites in Beclin 1 [178-181], and accordingly it has been suggested that UVRAG represents the mammalian $\mathrm{Vps} 38$ [178, 184]. Along these lines, UVRAG was shown to primarily associate with Rab9positive late endosomes and partially with Rab5/Rab7positive endocytic compartments, and UVRAG knockdown did not influence autophagic flux and GFP-LC3 dot formation (see "Two ubiquitin-like conjugation systems in autophagy: Atg12/ATG12-Atg5/ATG5 and Atg8/LC3PE") [178]. In contrast, UVRAG has originally been attributed a role in autophagy signaling [185]. Furthermore, Takahashi et al. demonstrated that Bif-1 (also termed endophilin B1) interacts with Beclin 1 through UVRAG, and that loss of Bif-1 suppresses autophagosome formation [186]. In parallel, Liang et al. suggest that UVRAG-mediated activation of the Beclin 1/VPS34 complex suppresses the proliferation and tumorigenicity of human colon cancer cells, and Takahashi et al. observed that Bif-1 knockout enhances spontaneous tumor development [185, 186]. However, the interplay between UVRAG-dependent autophagy and tumor suppression has also been controversially discussed. Knævelsrud et al. demonstrated that UVRAG mutations associated with microsatellite unstable colon cancer do not affect autophagy [187]. Taken together, the role of UVRAG for initial stages of autophagy remains rather elusive. In 2008, Liang et al. reported that UVRAG interacts with the class C Vps complex, which is a key component of the endosomal fusion machinery [188]. This interaction promotes the GTPase activity of Rab7 and autophagosome fusion with late endosomes/lysosomes. The authors also showed that UVRAG enhanced endocytic trafficking, directly supporting the above described UVRAG localization studies. Most interestingly, the effect on autophagosome maturation was independent of Beclin 1 , indicating that UVRAG might play a dual role in autophagy regulation: (1) in combination with Beclin 1 during autophagosome formation and (2) in combination with C Vps/Rab7 during autophagosome maturation [188].

Finally, two of the four groups additionally identified Rubicon as negative regulator of autophagy [179, 181] [Figs. 1 (panel 2), 3]. Rubicon is alternatively called Beclin 1 associated RUN domain-containing protein (Baron) [189]. Rubicon was only found in UVRAG-containing Beclin 1/VPS34-complexes, but not in ATG14-containing ones. Furthermore, Rubicon knockdown also affected rather autophagosome maturation and endocytic trafficking $[179,181]$. However, Zhong et al. observed that Rubicon inhibits VPS34 kinase activity only in the absence of Beclin 1 overexpression, suggesting that the negative regulatory role exerted by Rubicon is Beclin 1-independent [181]. Supporting this notion, it has been speculated that Rubicon interferes with pro-autophagic Rab GTPases via its RUN domain, and that sequestering of Rubicon by Beclin 1 would vice versa promote autophagy [172]. Currently, the dynamics of the above described complexes are intensively being investigated.

Recently, the putative mammalian counterpart of yeast Atg38 has been identified and independently reported by three different groups, which is named nuclear receptor binding factor 2 (NRBF2) [Figs. 1 (panel 2), 3]. Two groups reported that NRBF2 positively regulates autophagy, whereas one group observed autophagy-suppressing effects [190-192]. Accordingly, the autophagy-regulating capability of NRBF2 is not entirely clarified. Of note, NRBF2 was originally identified as interaction partner of nuclear receptors [193, 194]. Similar to its effect on autophagy, both activating and repressing effects of NRBF2 on nuclear receptor signaling have been reported [193, 194].

Baskaran et al. reported the structure of the ATG14containing PtdIns3K complex as determined by single-particle electron microscopy [195]. It appears that the complex is V-shaped, with VPS15 at the base of the V and serving as bridge for VPS34 and the ATG14/Beclin 1 subcomplex.

\section{Beclin 1-interacting proteins}

Next to the stable binding of ATG14, UVRAG and Rubicon to Beclin 1, multiple cellular and viral Beclin 




Fig. 3 Signaling machinery upstream and downstream of the PtdIns3K class III complex. The PtdIns $3 \mathrm{~K}$ class III core complex consists of the catalytic subunit VPS34, the adaptor VPS15 (p150), and Beclin 1 (ATG6). Beclin 1 binds to additional regulatory proteins, including ATG14, NRBF2, UBRAG, Rubicon, AMBRA1, BCL2, and several others (reviewed in [172-175]). Furthermore, there exists considerable crosstalk between the ULK1-complex and the PtdIns3K class III complex (for details see "The PtdIns3K class III complex"). ULK1 phosphorylates Beclin 1, AMBRA1, and VPS34. In turn, AMBRA1

1-interacting proteins have been identified which bind rather transiently or specifically under certain conditions (reviewed in [172-175]) (Fig. 3). In the following, we would like to focus on the association of Beclin 1 with AMBRA1 and viral and cellular BCL2 homologs. However, additional Beclin 1-interacting proteins include EGFR [196], estrogen-receptor [197], FYVE-CENT [198], HMGB1 [199, 200], MyD88/TRIF [201], nPIST [202], PINK1 [203], Rab5 [204], SLAM [205], survivin [206], and VMP1 [207], or the viral proteins HIV NEF [208], HSV-1 ICP34.5 [209], and the influenza virus M2 protein [210].

AMBRA1 is a scaffolding protein with a molecular mass of $\sim 130 \mathrm{kDa}$ [161]. Next to the above described regulation of ULK1, AMBRA1 itself is regulated by ULK1-dependent phosphorylation (see below) (Fig. 3). A recent study by Fimia and colleagues showed that the interaction between AMBRA1 and Cullin E3 ubiquitin ligases regulates the dynamics of autophagic responses [211]. Under fed conditions, Cullin-4 binds to AMBRA1 and reduces its abundance. Under pro-autophagic conditions, ULK1 phosphorylates AMBRA1, leading to its dissociation from Culin-4. Stabilized AMBRA1 in turn can bind to Cullin-5, which leads to the accumulation of the mTOR-inhibitory protein DEPTOR. Under prolonged regulates ULK1 stability and activation. Next to ULK1 itself, several ULK1-regulating kinases-such as mTORC1, AMPK, and AKTalso regulate the PtdIns $3 \mathrm{~K}$ class III complex. The product of the PtdIns3K class III catalytic activity is phosphatidylinositol 3-phosphate (PtdIns3P) (red circles). PtdIns3P then recruits the downstream effectors DFCP1 and proteins of the WIPI-family. For simplicity, the mutually exclusive interactions of ATG14 or UVRAG with Beclin 1 are shown within one complex

autophagic conditions, Cullin-4 reassociates with AMBRA1, leading to its degradation and the termination of the autophagic response [211]. However, AMBRA1 is not only involved in bulk autophagy processes, but also in mitophagy, cell death, cell proliferation, and development (reviewed in [212-214]). Of note, Cianfanelli et al. recently reported that AMBRA1 regulates the dephosphorylation and degradation of the proto-oncogene c-Myc via PP2A [215].

The association between Beclin 1 and viral and cellular BCL2 homologs establishes a direct connection between apoptosis and autophagy signaling pathways [216-224] (Fig. 3). Beclin 1 was originally identified as BCL2-interacting protein by a yeast-two-hybrid screen [219]. The functional relevance of this interaction has been described by Pattingre et al. in 2005 [222]. They showed that BCL2 can inhibit starvation-induced and Beclin 1-dependent autophagy. This has been confirmed for viral BCL2 proteins $[216,218,222,223]$. The BH3 domain of Beclin 1 binds to the hydrophobic BH3-binding cleft of BCL2 [217, 220, 221, 225]. Although the interaction between Beclin 1 and BCL2 inhibits autophagy induction by nutrient deprivation, Beclin 1 does not suppress the anti-apoptotic function of BCL2, as would be expected from "classical" BH3-only proteins [226]. 
The interaction between Beclin 1 and BCL2 is regulated by several stimuli, including competitive binding, self-association, phosphorylation, or ubiquitination [174]. The Beclin 1 BH3 domain might be competitively displaced by other BH3-only proteins or by BH3 mimetics, e.g., ABT737 [220, 225, 227]. Alternatively, membrane-anchored receptors or adaptors, e.g., $\mathrm{IP}_{3} \mathrm{Rs}$ or toll-like receptor-associated Myd88/TRIF, might induce the disruption of the Beclin 1-BCL2 interaction [173]. Finally, it has also been reported that reactive oxygen species promote cytosolic translocation of high mobility group box 1 (HMGB1), where it interacts with Beclin 1 and thus displaces BCL2 [200]. It has also been discussed that Beclin 1-homo-oligomerization might provide a scaffold for further protein-protein interactions and displacement of BCL2 proteins [174]. Additionally, post-translational modifications of both interacting proteins might modulate the Beclin 1-BCL2 interaction. Interestingly, both components serve as phospho-acceptor proteins. Zalckvar et al. reported that the death-associated protein kinase (DAPK) phosphorylates Beclin 1 at T119, which is located within the BH3 domain [228]. In turn, BCL2 might be phosphorylated by the mitogen-activated protein kinases ERK and JNK, respectively. Wei et al. reported that JNK phosphorylates $\mathrm{T} 69$, S70 and S87 within the non-structured loop between BH3 and BH4 of BCL2 [224]. Next to the direct displacement of BCL2 by HMGB1 described above, it has been suggested that HMGB1 promotes the activation of ERK1/2, resulting in the ERK1/2-mediated phosphorylation of BCL2 and its dissociation from Beclin 1 [200]. Interestingly, it has been reported that viral BCL2 proteins inhibit autophagy more effectively than cellular BCL2 proteins. This has been explained by either a stronger affinity of viral BCL2 proteins to Beclin 1 or the fact that viral BCL2 orthologs lack the JNK-dependent phosphorylation sites described above [218, 223, 224, 229]. It appears that the BCL2-dependent blockade of autophagy might be a viral strategy to ensure latency. Finally, it was demonstrated that $\mathrm{K} 117$ within the $\mathrm{BH} 3$ domain of Beclin 1 is a major ubiquitination site [230]. Accordingly, the authors speculate that TRAF6-mediated K63-linked ubiquitination at this site influences the association between Beclin 1 and BCL2.

The interaction between BCL2 and Beclin 1 occurs both at the mitochondrion and at the ER, and both mitochondrion- and ER-targeted BCL2 reduce LC3-II accumulation induced by overexpression of Beclin 1 [231]. However, starvation-induced autophagy is most efficiently inhibited by ER-localized BCL2 [222, 231]. In 2009, Vicencio et al. reported the identification of a trimeric complex consisting of $\mathrm{IP}_{3} \mathrm{Rs}$, Beclin 1 and BCL2 [232]. Apparently $\mathrm{IP}_{3} \mathrm{Rs}$ facilitate the interaction between Beclin 1 and BCL2, thus indirectly impairing autophagy. Upon $\mathrm{IP}_{3} \mathrm{R}$ inhibition, this trimeric complex dissociates and autophagy is induced. The authors further suggest that the $\mathrm{Ca}^{2+}$ channel function of the $\mathrm{IP}_{3} \mathrm{Rs}$ is not contributing to the autophagy-inhibitory effect [232]. However, this has been challenged by other groups [233, 234]. For example, in DT40 cells deficient for all three $\mathrm{IP}_{3} \mathrm{Rs}$, association between Beclin 1 and BCL2 is not affected [235]. Notably, Khan et al. state that the absence of $\mathrm{IP}_{3} \mathrm{Rs}$ in the triple-knockout DT40 cells results in higher levels of basal autophagy, which would confirm the results by Vicenco et al. However, reconstitution with a functionally inactive $\mathrm{D} 2550 \mathrm{~A} \mathrm{IP}_{3} \mathrm{R}$ mutant did not result in a suppression of the autophagic flux, indicating that the $\mathrm{Ca}^{2+}$ channel function of $\mathrm{IP}_{3} \mathrm{Rs}$ is important for the regulation of autophagy [235]. Along these lines, Decuypere et al. suggest that $\mathrm{IP}_{3} \mathrm{R}$-mediated $\mathrm{Ca}^{2+}$ signaling and autophagy induction are indeed two interrelated processes [236]. They showed that $\mathrm{IP}_{3} \mathrm{Rs}$ are sensitized upon starvation, and that this sensitization depends on Beclin 1. In their model, Beclin 1 shuttles from BCL2 to the ligand binding domain of the $\mathrm{IP}_{3} \mathrm{Rs}$ upon starvation, indirectly confirming the importance of ER-localized BCL2 to modulate autophagy (see above). Next to $\mathrm{IP}_{3} \mathrm{Rs}$, another ER-localized transmembrane protein has been implicated in the regulation of the Beclin 1-BCL2 association. Chang et al. reported the identification of the nutrient-deprivation autophagy factor-1 (NAF-1), and its requirement for BCL2 at the ER to functionally antagonize Beclin 1-dependent autophagy [237]. Additionally, NAF-1 also interacts with $\mathrm{IP}_{3} \mathrm{Rs}$. Interaction with $\mathrm{IP}_{3} \mathrm{Rs}$ was also shown for different BCL2 family members (reviewed in [233, 234, 238-240]. Future studies will have to further elucidate the interplay between $\mathrm{IP}_{3} \mathrm{Rs}$, other ER-localized proteins, BCL2 family members, and Beclin 1. However, a central role for the regulation of autophagy has also been attributed to mitochondria-localized BCL2. Strappazzon et al. showed that the positive autophagy regulator AMBRA1 preferentially binds to the mitochondrial pool of BCL2. Upon starvation, AMBRA1 is released and competes with BCL2 for binding to mitochondria- or ER-localized Beclin 1 [241]. Taken together, it appears that BCL2 proteins interfere with Beclin 1 function by at least two different ways, i.e., directly by binding of Beclin 1 or indirectly by binding to the positive regulator AMBRA1 [241, 242].

To date, different models have been brought up to explain the direct BCL2-dependent inhibition of Beclin 1 [243]. Pattingre et al. detected that BCL2 overexpression interferes with the formation of the Beclin 1-VPS34 complex [222]. Furthermore, they confirmed that the functional activity of the PtdIns $3 \mathrm{~K}$ class III complex is reduced. Recently, Wei et al. reported that mitogen-activated protein kinase-activated protein kinase 2 (MAPKAPK2) and MAPKAPK3 positively regulate starvation-induced autophagy by phosphorylating Beclin 1 at 
serine 90 [244]. The authors suggest that BCL2 can block this phosphorylation and thus inhibits autophagy. Noble et al. demonstrated that Beclin 1 forms a dimer in solution, which is bound by BCL2 proteins. UVRAG disrupts this Beclin 1 dimer interface and thus UVRAG-Beclin 1 heterodimers are assembled, which presumably cause the activation of autophagy. In turn, BCL2 proteins reduce the affinity of UVRAG for Beclin 1 and thus stabilize Beclin 1 homodimers [245]. Generally, only ATG14, UVRAG and Rubicon are stably associated with the PtdIns3K class III core complex [172]. Accordingly, the unstable or transient interaction of Beclin 1 with $\mathrm{Bcl}-2$ proteins allows the dynamic regulation of autophagic processes.

\section{Crosstalk between ULK1 and PtdIns3K class III complexes and downstream effectors of PtdIns3P}

It appears that there is a direct crosstalk between the autophagy-initiating ULK1 protein kinase and VPS34/Beclin 1 lipid kinase complexes (Figs. 2, 3, 4). Russell et al. demonstrated that ULK1 directly phosphorylates Beclin 1 at S15 and thereby enhances the activity of the ATG14containing VPS34 complexes (Fig. 3) [246]. This is further supported by the observation that ULK1 also phosphorylates AMBRA1 (Fig. 3) [162]. This phosphorylation triggers the dissociation of AMBRA1 and the associated PtdIns $3 \mathrm{~K}$ class III complex from dynein light chains $1 / 2$. The resulting relocalization of this complex to the ER allows for the nucleation of autophagosomes [162]. Considering the results by Nazio et al. described in "The Atg1/ ULK1 complex", there apparently exists a mutual regulatory circuit involving ULK1 and AMBRA1, i.e., AMBRA1 regulates the stability and kinase activity of ULK1 by controlling its ubiquitination, and in turn ULK1 regulates the association of AMBRA1 with the cytoskeleton via phosphorylation. Recently, Egan et al. reported the direct phosphorylation of VPS34 by ULK1 [124].

There is not only crosstalk between the ULK1 complex and the VPS34/Beclin 1 complex, but these two autophagyinitiating complexes also share common upstream regulators, such as AMPK, mTOR and AKT (Fig. 3). AMPK phosphorylates both Beclin 1 and VPS34, respectively [247]. Apparently, AMPK inhibits the non-autophagy VPS34 complex by phosphorylating T163/S165 in VPS34, but activates the pro-autophagy VPS34 complex by phosphorylating Beclin 1 at S91/S94 [247]. Additionally, mTORC1 inhibits the PtdIns3K activity of the ATG14containing VPS34 complex by phosphorylating ATG14 [248]. Finally, AKT directly phosphorylates Beclin 1 and inhibits autophagy by the formation of a phospho-Beclin 1/14-3-3/vimentin intermediate filament complex [249], and active EGFR binds Beclin 1, leading to its multisite tyrosine phosphorylation [196]. This phosphorylation decreases VPS34 catalytic activity, thereby establishing a direct link between oncogenic receptor tyrosine kinases and the autophagy machinery.

The product of the PtdIns3K class III catalytic activity is phosphatidylinositol 3-phosphate (PtdIns3P). This lipid then recruits further downstream effectors such as DFCP1 (see "Types of autophagy and morphology") and proteins of the Atg18/WIPI-family (see "Atg18/WIPI proteins and Atg2/ATG2") (Fig. 3). This has been confirmed by two studies, showing that knockdown of ATG14 or VPS34 leads to the disappearance of DFCP1- or WIPI1-positive puncta, respectively $[250,251]$. However, it has been observed that autophagy might also be induced independently of VPS34/Beclin 1 [252, 253]. On the one hand this might be explained by alternative cellular sources of PtdIns3P, e.g., through class II PtdIns3Ks [254] or class I PtdIns3Ks in combination with the lipid phosphatases SHIP and INPP4 [255]. On the other hand, Rubinsztein and coworkers recently demonstrated that PtdIns5P can regulate autophagy via PtdIns3P effectors [256].

\section{Atg9/ATG9A}

Atg9 is the only multi-spanning transmembrane protein among the Atgs (reviewed in [257, 258]) (Fig. 1, panel 3). In yeast, it was demonstrated that Atg9 concentrates in clusters that comprised vesicles and tubules, and that these compartments contribute to the de novo formation of the PAS [259]. Yamamoto et al. reported that single-membrane and Golgi-derived Atg9-vesicles with a diameter of 30-60 nm (containing approximately 30 Atg9 molecules) assemble to the PAS upon starvation [260]. These vesicles apparently become part of the phagophore and the outer autophagosomal membrane. Upon autophagosome completion, Atg9 clusters are recycled back to the cytoplasm [260]. It has been shown earlier that Atg9 is recruited to the PAS by Atg17 and that Atg9 cycling depends on Atg1Atg13 and Atg18-Atg2 complexes, respectively [67, 261]. Additionally, several groups identified proteins that are involved in Atg9 trafficking, including Atg11, Atg17, Atg23, Atg27, Trs85, Arp2/3 and actin [262]. Recently, Backues et al. identified a core minimal machinery necessary and sufficient for the trafficking of Atg9 to the PAS, i.e., Atg11, Atg19, Atg23 and Atg27 [262]. Finally, Suzuki et al. recently reported that the Atg13 HORMA domain (described in "The Atg1/ULK1 complex") can interact with Atg9 and thus recruits Atg9 vesicles during autophagosome formation (Fig. 4) [72]. As described above, Atg1-dependent phosphorylation of Atg9 is apparently important for the efficient recruitment of Atg8 and Atg 18 to the site of autophagosome formation (Fig. 4) [68]. However, it has also been noted that the Atg9-positive vesicles described above are unlikely a major supplier of 
lipids for autophagosome biogenesis and thus likely possess an additional important function for autophagosome biogenesis [260].

In 2006, it has been reported that the mammalian Atg9 ortholog ATG9A (also referred to as mAtg9 or Atg9L1) is localized in the trans-Golgi network and in early, late and recycling endosomes [263, 264]. Upon starvation, ATG9A is redistributed to peripheral, endosomal membranes positive for the autophagosomal marker GFP-LC3 (see "Two ubiquitin-like conjugation systems in autophagy: Atg12/ ATG12-Atg5/ATG5 and Atg8/LC3-PE”) [264]. Like in yeast, this redistribution depends on the mammalian $\operatorname{Atg} 1$ homolog ULK1 [264]. An ATG9A compartment in mammals has been proposed which is similar to the one observed in yeast [263]. The authors suggest that ATG9A resides on a distinct tubular-vesicular compartment, and that this "ATG9A reservoir" continuously emanates from vacuolar recycling endosome-like structures by tubulation. They observed that subcellular ATG9A localization is regulated by ULK1 and WIPI2. However, ULK1 and WIPI2 are not required for the recruitment of ATG9A to early DFCP1positive omegasomes [263]. Similar observations were previously made by other groups. For example, it has been demonstrated that ATG9A and ULK1 independently localize to the autophagosome formation site during canonical autophagy and Parkin-mediated mitophagy (see "Two ubiquitin-like conjugation systems in autophagy: Atg12/ ATG12-Atg5/ATG5 and Atg8/LC3-PE”), and that ATG9A and ULK1 are independently recruited to Salmonella-containing vacuoles during xenophagy $[265,266]$. Although ATG9A is essential for the formation of phagophores, it appears that ATG9A only transiently interacts with autophagosomes and does not integrate into the autophagosomal membrane [263]. Recently, Popovic and Dikic reported that TBC1D5 and the AP2 complex are important novel regulators of ATG9A trafficking towards the sites of autophagosome formation [267]. Finally, Puri et al. reported that ATG9A localizes on the plasma membrane in clathrincoated structures and is internalized through early and then recycling endosomes [268]. Notably, the authors describe that ATG16L1 (see "Two ubiquitin-like conjugation systems in autophagy: Atg12/ATG12-Atg5/ATG5 and Atg8/ LC3-PE") is also internalized by clathrin-mediated endocytosis but via different clathrin-coated pits. The ATG9Aand ATG16L1-containing vesicles then "meet" in recycling endosomes in a VAMP3-dependent manner [268].

\section{Atg18/WIPI proteins and Atg2/ATG2}

The Atg 18 proteins constitute the second important family of PtdIns3P effectors (Fig. 1, panel 4). Whereas in yeast three family members have been identified so far, i.e., Atg18, Atg21 and HSV2/Ygr223c, in mammals four Atg18 homologs have been isolated, i.e., WD-repeat protein interacting with phosphoinositides 1-4 (WIPI1-4) [8, 269, 270]. DFCP1 binds to PtdIns3P via its FYVE domain, which was named after the first four proteins shown to contain it, i.e., Fab1, YOTB/ZK632.12, Vac1, and EEA1 [271]. In contrast, the Atg18/WIPI proteins bind to PtdIns$3 \mathrm{P}$ (and PtdIns $(3,5) \mathrm{P}_{2}$ ) via a seven-bladed $\beta$-propeller. Accordingly, the three yeast proteins and the four WIPIs have been called "PROPPINs" [272]. These proteins are WD40-repeat containing proteins and require an FRRGmotif for PtdIns3P-binding [270, 273, 274]. Two groups reported the crystal structure of yeast HSV2/Ygr223c, and these works indicate that there are two phosphoinositide binding sites in PROPPINS [275, 276]. Yeast Atg18 is important for autophagy, whereas Atg21 and HSV2/ Ygr223c are rather involved in the Cvt pathway and in micronucleophagy, respectively [8, 277-279]. In 2010, Nair et al. reported that Atg18 and Atg21 facilitate the recruitment of Atg8-PE to the site of autophagosome formation [280]. During autophagy, Atg18 is in complex with Atg2 [281], and it was demonstrated that autophagosome formation can be achieved in the absence of Atg18 by expressing engineered PAS-targeted Atg2 [282]. In mammals, WIPI1 and WIPI2 share highest homology to Atg18 and have thus been reported to be involved in autophagy [283]. During autophagosome biogenesis, WIPI1/2 colocalize with the Beclin 1/VPS34 complex component ATG14, but not with the second PtdIns3P effector DFCP1 $[8,250]$. It has been suggested that WIPI1/2 localize to the phagophore, whereas DFCP1 localizes to the omegasome [8]. Subsequently, it was demonstrated that WIPI2 positively regulates LC3-lipidation (see "Two ubiquitin-like conjugation systems in autophagy: Atg12/ATG12-Atg5/ ATG5 and Atg8/LC3-PE") and thus obviously contributes to the maturation process of omegasomes to autophagosomes [283]. Recently, Dooley et al. demonstrated that ATG16L1 directly binds WIPI2b (one of five WIPI2 isoforms) (Fig. 4) [284]. They observe that WIPI2b is a PtdIns3P effector upstream of ATG16L1 and is required for LC3 conjugation [284].

Two mammalian Atg2 homologs have been identified, ATG2A and ATG2B, and their simultaneous silencing causes a block in the autophagic flux [285]. Interestingly, ATG2A/B also regulate lipid droplet morphology [285].

\section{Two ubiquitin-like conjugation systems in autophagy: Atg12/ATG12-Atg5/ATG5 and Atg8/ LC3-PE}

\section{Components of the two ubiquitin-like conjugation systems}

Two ubiquitin-like conjugation systems are centrally involved in the expansion of autophagosomes: (1) Atg12/ 
ATG12-Atg5/ATG5 system and (2) Atg8/LC3-phosphatidylethanolamine (PE) system (reviewed in [286]) (Fig. 1, panels 5 and 6). Within these conjugation systems, Atg12 and Atg8 represent the ubiquitin-like proteins, which are conjugated by E1-, E2- and E3-like enzymatic activities to Atg5 and PE, respectively. Within the first system, Atg12 is activated by the E1-like enzyme Atg7. Subsequently Atg12 is transferred to the E2-like Atg10 and irreversibly conjugated to K149 (yeast sequence; corresponds to human K130) of Atg5 [286-289]. The Atg12Atg5 conjugate interacts with Atg16, and this complex forms a homo-oligomer [286, 290, 291]. All yeast Atgs involved in the Atg12-Atg5 conjugation system have mammalian counterparts with identical or similar functions, including an Atg16-like protein (ATG16L1) [286, 292-295]. In yeast, this multimeric complex has a molecular weight of approximately $350 \mathrm{kDa}$, and it has been suggested that the complex consists of an Atg12-Atg5Atg16 tetramer [290]. In mammals, the complex eluted in fractions corresponding to 400 and $800 \mathrm{kDa}$, indicating that it might be composed of four or eight sets of ATG12ATG5-ATG16L1 [292]. However, a crystallographic study combined with analytical ultracentrifugation experiments revealed that yeast Atg16 forms a parallel coiled-coil dimer [296]. The E1-like ATG7, the E2-like ATG3 and the conjugation acceptor ATG5 are essential for autophagy, and neonates of $\operatorname{Atg} 7^{-1-}, \operatorname{Atg} 3^{-1-}$ and $\operatorname{Atg} 5^{-1-}$ mice die at day 1 after birth due to the neonatal starvation period [297299]. Within the second conjugation system, Atg8 is activated by the common E1-like enzyme Atg7 and then transferred to the E2-like Atg3 [286, 300]. However, prior to Atg8 activation by Atg7, the C-terminal R117 has to be removed by the proteolytic activity of Atg4 in order to expose G116 [286, 301]. Interestingly, it has been demonstrated that the Atg12-Atg5 conjugate possesses an E3-like activity for Atg8 conjugation to PE [302, 303]. Although Atg16 is not important for efficient Atg8-PE conjugation in vitro, it is required for Atg8-PE formation in vivo [303]. Atg16 recruits Atg12-Atg5 to the PAS and thus determines the site of Atg8 lipidation [15, 51]. Two structural reports further support this link between the two conjugation systems. First, the crystal structure of Atg12Atg5 indicates that Atg12 serves as binding module for the E2-like Atg3, essentially facilitating the transfer of Atg8 from Atg3 to the PE in the membrane [304]. Second, apparently the Atg12-Atg5 conjugate enhances the E2 activity of Atg3 by rearranging its catalytic site [305].

In the mammalian system, so far nine Atg8 orthologs have been reported. These can be subdivided into two families: (1) the LC3 subfamily consisting of microtubuleassociated proteins 1A/1B light chain 3A (MAP1LC3A or briefly LC3A; two splice variants), LC3B, LC3B2, and LC3C, and (2) the GABARAP/GATE16 subfamily consisting of the $\gamma$-aminobutyric acid receptor-associated protein (GABARAP), GABARAPL1 (also termed ATG8L or GEC1), Golgi-associated ATPase enhancer of $16 \mathrm{kDa}$ (GATE16, also termed GABARAPL2) and GABARAPL3 [306-315]. Additionally, four different mammalian ATG4 isoforms have been identified, i.e., ATG4A-D (also referred to as autophagin-1-4) [316, 317]. LC3B is probably the most extensively studied mammalian ATG8 protein, and it is cleaved C-terminally of G120 within the first 6 min of synthesis [309, 318]. ATG4-mediated cleavage of LC3 generates a cytosolic truncated LC3-I fragment of $18 \mathrm{kDa}$, which lacks the $22 \mathrm{C}$-terminal amino acids of the pro-form [318]. Interestingly, the different ATG4 isoforms possess selective preferences regarding their ATG8 family substrates [309, 319]. Subsequently, LC3-I is converted to the lipidated LC3-II isoform in an E1/E2/E3-cascade similar to the yeast system [295, 309, 320]. Accordingly, the mammalian ATG12-ATG5 conjugate interacts with ATG16L1, which targets the conjugate to the phagophore [292, 321]. There the ATG12-ATG5-ATG16L1 complex exerts its E3-like function and thus determines the site of LC3 lipidation [322]. This has been supported by the observation that forced expression of ATG16L1 at the plasma membrane led to ectopic LC3 lipidation at that site [322]. Similarly to LC3 conversion, the other mammalian ATG8 family members are processed by ATG4 isoforms, form E1- and E2-intermediates with ATG7 and ATG3, and are targeted to the autophagosome [295, 309, 312, 320, 323].

Next to cleavage and lipidation, it has also been reported that LC3 becomes phosphorylated. Jiang et al. observed that T9 and T29 of LC3 can be phosphorylated by PKC [324]. However, mutations of these residues to either alanine or aspartate/glutamate did not affect autophagy. In contrast, Cherra et al. reported the PKA-mediated phosphorylation of LC3 at S12, and this phosphorylation regulates the incorporation of LC3 into the autophagosomal membrane: the pseudophosphorylated S12D mutant showed reduced recruitment to autophagosomes, whereas the nonphosphorylatable S12A mutant exhibited enhanced puncta formation [325]. Of note, Atg8 orthologs of yeast and D. melanogaster lack this PKA site, and it is also absent in the mammalian GABARAP/GATE16 subfamily [325].

\section{Selective autophagy and autophagy receptors/adaptors}

Both conjugates, i.e., ATG12-ATG5 and Atg8/LC3-PE, are targeted to membranes during the autophagic process. Whereas ATG12-ATG5-ATG16L1 is mainly found at the phagophore [292, 321], Atg8/LC3-PE is present on the autophagosomal membrane throughout the whole process of vesicle biogenesis. The exact function of this "decoration" of the autophagosomal membrane is still intensely being investigated. In 2007, Nakatogawa et al. reported that Atg8 
mediates the tethering and hemifusion of liposomes in vitro, and the authors suggested that this function contributes to the expansion of the phagophore in vivo [326]. Additionally, it has been reported that the amount of Atg8 determines the size of autophagosomes [327]. Generally it is tempting to speculate that the different Atg8 family proteins are selectively incorporated into the autophagosomal membrane depending on the autophagic stimulus, the step during the autophagic flux, or the cargo to be degraded. The latter two aspects are supported by two works. The first study proposes that LC3 proteins are rather involved in the elongation of the autophagosomal membrane, whereas GATE-16/ GABARAP proteins function during the later stages of autophagosome maturation [314]. The second work reports that LC3C is required for efficient xenophagic clearance of Salmonella typhimurium [328]. This observation leads over to the best studied function of ATG8 family proteins, i.e., enabling the cell to differentially handle the cargo during selective autophagy. In recent years, a new class of cargorecognition receptors has been identified and characterized, and they have been termed autophagy receptors [329-334]. These autophagy receptors are centrally involved in the recognition of cargo during selective autophagy processes, e.g., mitophagy or xenophagy. In 2005, Bjørkøy et al. discovered that p62 (alternatively called sequestosome 1, SQSTM1) forms protein aggregates which are degraded by autophagy [335]. In turn, inhibition of autophagy resulted in an increase of p62 protein levels. The authors suggested that p62 links polyubiquitinated proteins to the autophagic machinery via LC3. The same group could demonstrate that p62 directly binds to Atg8/LC3 [336]. They found an evolutionarily conserved 22-residue amino acid sequence within p62 which mediates the binding to LC3. This region was dubbed the LC3-interacting region (LIR), LC3 recognition sequence (LRS), or Atg8-family interacting motif (AIM), respectively [336-338]. Johansen et al. compiled a sequence logo from 25 different LIR motifs from 21 different proteins. It appears that LIR motif contains eight amino acids and is $\mathrm{X}_{-3} \mathrm{X}_{-2} \mathrm{X}_{-1} \mathrm{~W}_{0} \mathrm{X}_{1} \mathrm{X}_{2} \mathrm{~L}_{3}$ [330]. In this sequence, $\mathrm{W}$ might be replaced by $\mathrm{F}$ or $\mathrm{Y}$ (aromatic residue), $\mathrm{L}$ by I or $\mathrm{V}$ (large, hydrophobic residue), and acidic amino acids are frequently found in the $\mathrm{X}_{-3} \mathrm{X}_{-2} \mathrm{X}_{-1}$ positions. This suggestion was later confirmed by a compilation of 26 published LIR sequences [339]. Next to the LIR, p62 possess an ubiquitin-associated (UBA) domain and a Phox and Bem1p (PB1) domain, through which p62 can homooligomerize or bind to protein kinases. Accordingly, Johansen et al. proposed three required features of autophagy receptors: (1) existence of a LIR motif, (2) specific recognition of cargo, and (3) ability to polymerize [330]. Interestingly, Itakura et al. demonstrated that the targeting of p62 to the autophagosome formation site depends on the ability to self-associate, but not on LC3 or any other classical ATG [340]. The authors suggest that subsequently p62 oligomers are incorporated into autophagosomes in an LC3-dependent manner. In addition to p62, several additional autophagy receptors have been identified to date, including neighbor of breast cancer 1 (NBR1), optineurin (OPTN), nuclear domain 10 protein 52 (NDP52; alternatively termed $\mathrm{Ca}^{2+}$-binding and coiled-coil domain-containing protein 2, CALCOCO2), Toll interacting protein (TOLLIP), or cellular Casitas B-lineage lymphoma (c-Cbl) [341-345] (reviewed in [329-334, 346]).

Next to autophagy receptors which interact with both ubiquitin and LC3, other proteins have been identified which contribute to selective autophagy processes. These include proteins which interact with ubiquitin (e.g., HDAC6), which bind to LC3 (e.g., NCOA4, BNIP3, Nix, FUNDC1, BCL2L13, or FAM134B), or which indirectly associate with ubiquitinated proteins or LC3 (e.g., Alfy, BAG3, or Tecpr1) (reviewed in $[333,346]$ ). FAM134B is presumably the mammalian ortholog of yeast Atg40 and is involved in ER-phagy [347]. Nuclear receptor coactivator 4 (NCOA4) was shown to mediate the delivery of ferritin to lysosomes [348]. BNIP3, Nix, FUNDC1 and BCL2L13 are mitochondrial proteins and are involved in the removal of mitochondria from maturing reticulocytes, during hypoxiainduced mitophagy, or induce mitochondrial fragmentation and mitophagy. In contrast, mitophagy of damaged mitochondria involves the action of PTEN-induced putative protein kinase 1 (PINK1) and the E3 ubiquitin ligase Parkin (reviewed in [349-351]). It has been suggested that Parkin hyper-ubiquitinates targets in the outer mitochondrial membrane, which are then recognized by autophagy receptors. The Parkin-dependent ubiquitylome in response to mitochondrial depolarization has been reported, and the authors found depolarization-dependent association of Parkin with numerous targets of the mitochondrial outer membrane, autophagy receptors, and the proteasome [352]. Interestingly, the autophagy receptors p62, NDP52, and Tax1BP1 were found to be depolarization-dependently ubiquitinated and associated with Parkin [352]. However, the involvement of p62 in damage-induced mitophagy is controversially discussed (reviewed in [349-351]). It appears that p62 is recruited to ubiquitinated cargo at damaged mitochondria and contributes to mitochondrial clustering, but its exact contribution to the mitophagic process itself awaits further clarification. Next to p62, it has been reported that optineurin is an autophagy receptor for damaged mitochondria in parkin-mediated mitophagy [353]. During the last 2 years additional mechanistic details have been deciphered with regard to PINK1/Parkindependent mitophagy. Activated PINK1 phosphorylates both Parkin and ubiquitin at S65, and these phosphorylations relieve the autoinhibition of Parkin, leading to an active phospho-ubiquitin-dependent E3 ligase and a 
Fig. 4 The ATG "spiderweb". This scheme depicts the crosstalk between the six ATG signaling modules described in this review. The adjacent positioning of proteins within the single modules does not necessarily reflect direct interactions of the components. Lines can indicate both interaction and/or phosphorylation (by ULK1). Crosstalks identified for yeast orthologs are indicated by red lines

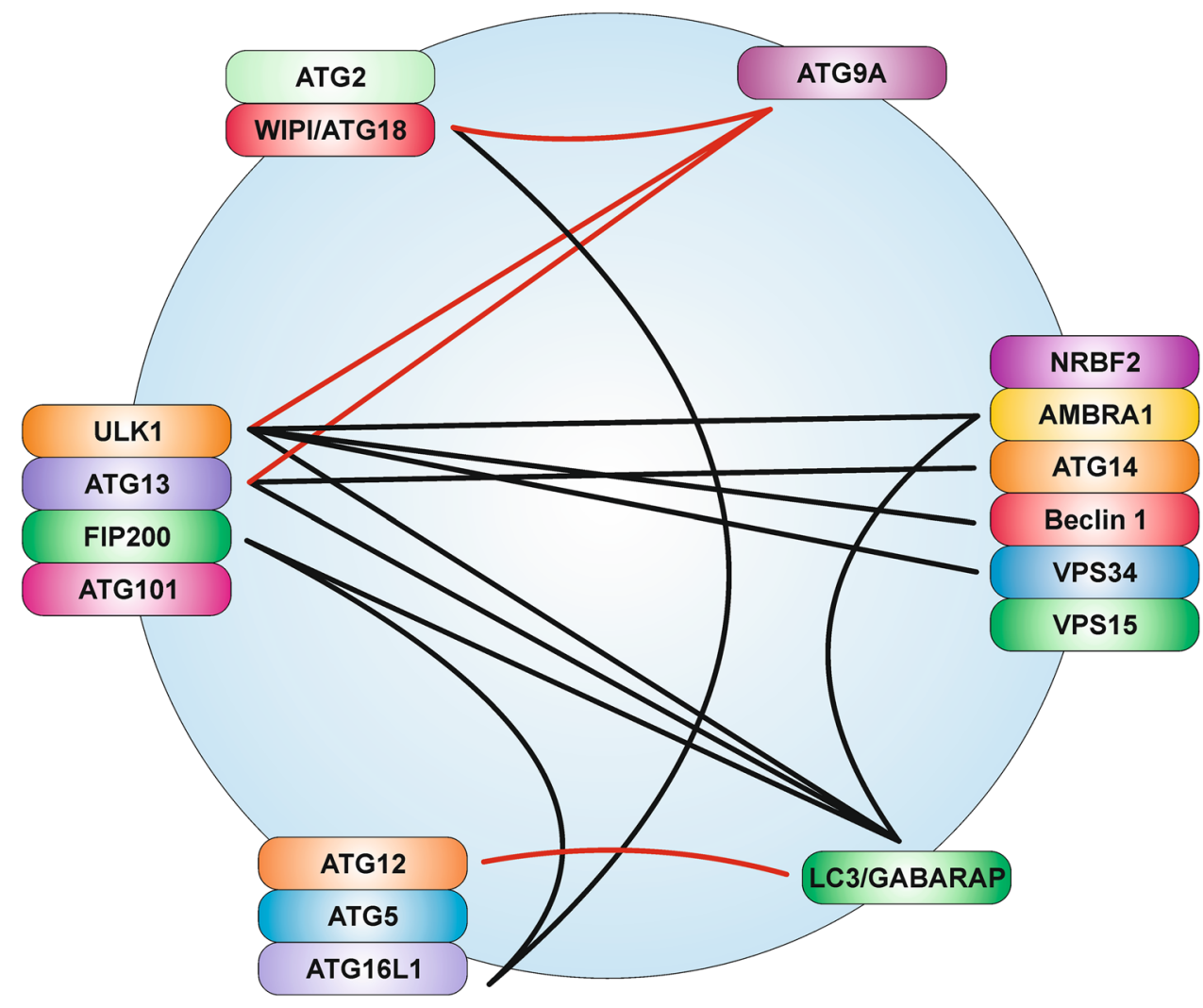

feedforward signaling amplification loop [354-356]. Recently, Lazarou et al. suggested that NDP52 and optineurin are directly recruited to damaged mitochondria by PINK1-generated phospho-ubiquitin and thus support both Parkin-dependent and -independent mitophagy [357]. Generally, the interplay between these different routes of mitophagy (i.e., BNIP3/NIX/FUNDC1/BCL2L13 and PINK1/Parkin) is not entirely clarified. Furthermore, there likely exist additional pathways like the cardiolipin-mediated removal of injured mitochondria in neurons or the recently reported AMBRA1-dependent mitophagy, which can be both Parkin-dependent and -independent but requires LC3-binding (Fig. 4) [358, 359]. So far, the complementarity or even redundancy of the different mitophagy mechanisms remains elusive.

Future studies will have to delineate how ubiquitin signals regulate the selection of autophagy cargo. It is likely that additional autophagy receptors will be identified in the future, and next to "classical" autophagy receptors other forms of receptors will emerge. For example, cargo recognition by Tecpr1 is ubiquitin-independent. Instead, Tecpr1 binds to ATG5 and WIPI2 [139, 360]. Additionally, post-translational modifications such as phosphorylation might influence the function of autophagy receptors and presumably the cargo selection process, as shown for p62 and optineurin [345, 361, 362]. Finally, recently it has been demonstrated that N-terminal arginylation of the ER chaperone $\mathrm{BiP}$ is induced by cytosolic misfolded proteins [363]. Furthermore, cytosolic arginylated $\mathrm{BiP}$ binds to both the misfolded proteins and the $\mathrm{ZZ}$ domain of p62, leading to p62 aggregation, increased p62-binding to LC3, and targeting to autophagosomes [363]. Next to autophagy receptors, the term autophagy adaptor has been established [346]. Autophagy adaptors are ATG8 family-binding proteins which serve as anchors for the autophagy signaling machinery in order to facilitate autophagosome initiation, elongation, transport and fusion to lysosomes [346]. Accordingly, autophagy adaptors include components of the ULK1-complex (see below) and the Beclin 1/VPS34complex, proteins of the ubiquitin-like ATG5/ATG12 and Atg8/LC3 conjugation systems, and proteins of the autophagosome-lysosome fusion machinery [346]. Recently, Wollert and colleagues described that Atg8-PE directly recruits Atg12-Atg5 conjugates through a noncanonical AIM in Atg12 (Fig. 4) [364]. Then Atg16 initiates a membrane scaffold by crosslinking Atg8-PE/ Atg12-Atg5 complexes into a 2D meshwork [364]. The authors postulate that cargo receptors compete with Atg12-Atg5 for Atg8-PE binding, thus explaining why 
Atg8-PE can function both as a membrane scaffold and as cargo receptor [364].

Apparently there is also crosstalk between the ULK1 complex and components of the ubiquitin-like conjugation systems (Figs. 2, 4). Three articles focusing on the interaction between Atg1/ULK1 and Atg8 family proteins have been published in the recent past. Notably, the association of ULK1 with Gate 16 and GABARAP was already described in the year 2000 by Okazaki et al., and they mapped the interaction sites to ULK1 amino acids 287-416 [365]. In the first of the three mentioned publications, Kraft et al. showed that Atg8 binds to a LIR within Atg1 [57]. They suggest that Atg8 targets Atg1 to autophagosomes where it might contribute to autophagosome maturation and/or their fusion to lysosomes. Additionally, the Atg8-Atg1 interaction targets the Atg1 complex for vacuolar degradation. The authors also demonstrated that mammalian ULK1 harbors a LIR and that ULK1 interacts with GABARAP, Gate16 and LC3B, thus directly confirming the results previously obtained by Okazaki et al. Similar to their observations in yeast, ULK1 was LIR-dependently targeted to autophagosomes [57]. In the second manuscript, Nakatogawa et al. independently confirmed the association between yeast Atg8 and Atg1 [366]. Mutation of the Atg8 family interacting motif (AIM) of Atg1 abolishes Atg1 transport to and degradation in vacuoles. Interestingly, AIM mutation caused a significant defect in autophagy, but did not affect PAS organization or the initiation of phagophore formation [366]. This result suggests that there are indeed two functions of Atg1/ULK1: (1) initiation of phagophore formation and (2) autophagosome expansion/maturation and/or fusion to vacuoles/lysosomes. Finally, the ULK1 LIR domain (D ${ }^{356}$ FVMV) was also described by Alemu et al. [339]. Notably, they additionally found LIR sequences within ATG13 (D ${ }^{443}$ FVMI) and FIP200 (D ${ }^{701}$ FETI). Apparently, all three components of the ULK1 complex have preferences towards the GABARAPsubfamily of mammalian ATG8 proteins. As described above, the GATE-16/GABARAP family was reported to play a role in later stages of autophagy, indirectly suggesting that the ULK1 complex components have a function at a later stage, too. Alemu et al. verified that the LIR motif in ULK1 is required for the association of ULK1 with phagophores and/ or autophagosomes. However, in contrast to the two reports by Kraft et al. and Nakatogawa et al., they state that ULK1 is mainly degraded by the proteasome with only marginal contribution from autophagy, which is in accordance to observations made by Joo et al. [123]. Another level of crosstalk between the ULK1 kinase complex and the ubiquitin-like conjugation systems was deciphered recently by three works. Gammoh et al. and Nishimura et al. reported that FIP200 can directly interact with ATG16L1 [94, 103]. Gammoh et al. mapped the binding site within ATG16L1 to amino acids 229-242 and named this region FIP200-binding domain (FBD). Importantly, deletion of the FBD does neither abolish ATG16L1-binding to ATG5 nor selfdimerization. Expression of the FBD-deleted ATG16L1 in the ATG16L1-negative background could not fully reconstitute autophagy induced by amino acid starvation or the mTOR inhibitor Torin1 [94]. Similar results were reported by Nishimura et al. [103]. They showed that the FIP200ATG16L1 interaction is independent of ATG14 or PtdIns3P, and that the interaction is important for ATG16L1 targeting to the phagophore. The authors narrowed down the interaction domain to two regions of ATG16L1, i.e., amino acids 230-250 (roughly overlapping with the FBD reported by Gammoh et al.) and 288-300. They additionally suggest that the ATG12-ATG5-ATG16L1 complex and the ULK1ATG13-FIP200-ATG101 complex form one large unit in the cytoplasm, which then targets the phagophore. Accordingly, the authors describe their observation that ULK1 and ATG5 are recruited to the same compartment with similar kinetics (see "Molecular hierarchy of Atg/ATG proteins"). Most surprisingly, they observed a blockade of the autophagic flux when they express an ATG16L1 $\Delta(230-300)$

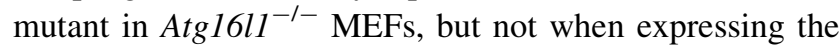
ATG16L1 (1-230) version, which also lacks the FIP200interacting domain. They proposed a model involving a selfinhibitory role for the C-terminal WD-repeat domain of ATG16L1. If this domain is deleted, the N-terminal half of ATG16L1 uncoordinatedly targets membranes, including the autophagosome formation site [103]. Finally, Lim et al. recently reported that ULK1 phosphorylates S405 and S409 within the ubiquitin-association (UBA) domain of p62 [361]. The S409 phosphorylation increases the binding affinity of p62 to ubiquitin. Collectively, the observations described above support a role of the ULK1 complex not only for autophagy initiation, but also for later steps of the autophagic cascade.

\section{ATG8 proteins and monitoring autophagy}

The detection of PE-conjugated GFP-LC3 at the autophagosomal double-membrane by confocal laser scanning microscopy is an established method for the analysis of autophagic processes [367]. This method has even been optimized by using the tandem fluorescence mRFP-EGFP-LC3 fusion protein [368]. Upon fusion of mature autophagosomes with lysosomes, the resulting low $\mathrm{pH}$ quenches the GFP fluorescence and accordingly autolysosomes can be detected as RFP-only structures [368]. By this means, the autophagic flux can be monitored. An improved tandem fluorescence-tagged mTagRFPmWasabi-LC3 has been described by Zhou et al. [369]. Alternatively, the conjugation of LC3 to PE can also be detected by immunoblot analysis, since the lipidated LC3-II exhibits a slightly increased mobility in SDS-PAGE 
compared to the unlipidated LC3-I. In contrast to the Atg12/ATG12-Atg5/ATG5 conjugate, Atg8/LC3 proteins can be deconjugated from PE by the activity of Atg4/ATG4 isoforms [301]. It appears that this deconjugation is important to maintain an appropriate supply of Atg8/LC3 at early stages of autophagy, and to facilitate the maturation into fusion-capable autophagosomes at later stages [370]. Although the lipidation of LC3 is the basis for several standard detection methods of autophagy, several caveats have to be considered. Apparently, LC3 lipidation can occur in an autophagy-independent manner (reviewed in [371]). LC3-II can be detected in cells in which certain ATGs are deleted, e.g., in Fip200 ${ }^{-1-}$ MEFs [82], BecnI ${ }^{-/-}$ ES cells [134], $B E C N 1^{-1-}$ DT40 (own unpublished observation), Ulk1 ${ }^{-l-}$ MEFs [83, 110], Ulk1/2 ${ }^{-1-}$ MEFs $[84,372]$, or in cells in which certain ATGs are severely reduced by RNAi, e.g., Beclin 1 [134, 373], ATG13 [107, 109, 110], ULK2 [110], ATG14 [178], or VPS34 [178]. A similar observation was made for the yeast system. Atg8PE was detected in yeast strains deficient for Atg1, Atg2, Atg6, Atg9, Atg13, Atg14, Atg16, or Atg17, and slightly also in strains deficient for Atg5 or Atg12 [15]. These observations indicate that LC3 is lipidated under conditions in which the autophagic flux is inhibited. Vice versa, a recent report by Szalai et al. suggests that autophagy of cytoplasmic bulk cargo does not require LC3 [374].

Finally, in 2007 Sanjuan et al. described that particles that engage TLRs on macrophages while they are phagocytosed trigger LC3 recruitment to the phagosome [375]. This processed was termed LC3-associated phagocytosis (LAP). LAP requires ATG5 and ATG7 and is preceded by Beclin 1 recruitment and PtdIns3K kinase activity [375]. Importantly, LC3 recruitment to the phagosomes was not associated with observable double-membrane structures. Next to TLR ligand-coated particles, LAP was observed upon phagocytosis of beads with LPS, killed yeast, or E. coli bacteria [375]. This indicates that autophagy proteins contribute to the elimination of pathogens not only through canonical autophagy/xenophagy, but also through LAP. Finally, a similar decoration of single membrane structures with LC3 was also described for phagosomes containing apoptotic cells, macropinosomes, and entotic vacuoles [376, 377] (reviewed in [378]).

\section{Molecular hierarchy of Atg/ATG proteins}

\section{Genetic hierarchy of Atg/ATG proteins}

The functional units established by the Atg/ATG proteins are recruited to the PAS or the phagophore in a defined order, and historically the analysis of the hierarchical appearance of Atgs/ATGs has been subject of several investigations. In 2007, Suzuki et al. reported the hierarchy of Atg proteins in PAS organization of yeast $[8,51]$. Apparently, Atg17 functions as scaffold for the recruitment of the other Atgs to the PAS. Atg1-Atg13, Atg9 and the PtdIns3K complex I act in initial stages, whereas Atg18-Atg2, Atg16-Atg5-Atg12 and Atg8-PE units are recruited to the PAS subsequently. In 2013, Suzuki et al. fine-mapped the localization of Atgs during autophagosome formation in yeast [379]. The authors defined specific localization sites: (1) the vacuole-isolation membrane contact site (VICS), (2) the isolation membrane (IM), and (3) the edge of the IM close to the ER (IM edge). They showed that Atg13, Atg17 and the yeast PtdIns3K complex I localize to the VICS, whereas Atg1, Atg8 and the Atg16-Atg5-Atg12 complex label the VICS and the IM. Finally, Atg2-Atg18 and Atg9 localized at the IM edge [379].

Itakura et al. performed a hierarchical analysis of mammalian ATGs [250]. Upon starvation, ULK1, ATG14, WIPI1, LC3 and ATG16L1 are recruited to the identical compartment, whereas DFCP1 localizes adjacently to these ATGs. Apparently, the ULK1 complex is the most upstream unit, and this unit is required for the recruitment of the ATG14-containing PtdIns3K class III complex. Puncta formation of DFCP1 and WIPI1 requires the presence of FIP200 and ATG14. Finally, LC3 and the ATG16L1-ATG5-ATG12 complex are the most downstream units [250]. Later it could be shown that ATG9A and FIP200 independently localize to the autophagosome formation site, but that both are necessary for the recruitment of the downstream factors ATG14 and WIPI1 [265].

Notably, the ATG recruitment hierarchy appears to depend on the autophagic stimulus. For example, ULK1 and ATG9A localize independently to the autophagosome formation site during starvation-induced autophagy, mitophagy, and Salmonella xenophagy [265, 266]. In contrast, LC3 recruitment depends on FIP200 and PtdIns3K class III complex during starvation-induced autophagy, whereas LC3 recruitment to CCCP-depolarized mitochondria or Salmonella-containing vacuoles (SCVs) is independent of FIP200 or ATG9A, respectively [265, 266]. These data indicate that there exist differences between canonical autophagy and selective autophagy processes such as mitophagy or xenophagy. With regard to Salmonella xenophagy, Noda et al. proposed a "Three-axis model" for ATG recruitment [380]. In this model, ULK1 and ATG9A are recruited independently to SCVs. Within the third axis, LC3 is recruited to SCVs by the ATG16L1 complex, but this recruitment does not depend on the other factors. The authors propose that the SCVs might represent an alternative membrane target for ATG16L1 recruitment, which is not present during starvation-induced autophagy [380]. 


\section{Temporal hierarchy of Atg/ATG proteins}

The above described analyses of the genetic hierarchy of Atg/ATG proteins revealed the functional interdependence among the single components. However, this does not necessarily correspond to the temporal recruitment of Atg/ ATG proteins to the autophagosome formation site. The temporal aspect of ATG recruitment-i.e., the timing of accumulation peaks among mammalian ATG proteinswas addressed by Koyama-Honda et al. [381]. This study indicates that ULK1 and ATG5 complexes were synchronously recruited, although they are differently positioned in the genetic hierarchy. This might be explained by the above-mentioned interaction between FIP200 and ATG16L1. Furthermore, this observation led the authors to reassess the dependency of ULK1/ATG5 recruitment on PtdIns3K activity. It appears that both ULK1 and ATG5 can be stabilized by PtdIns3P at early stages, and that the ULK1 complex but not the ATG5 complex can become partially PtdIns3P-independent at later stages of autophagy [381]. Finally, the authors observe that the different ATGs are recruited to pre-existing vacuole membrane protein 1 (VMP1)-positive structures of the ER, although it has previously been suggested that VMP1 functions at a later step of autophagy $[250,381]$.

\section{Network of Atg/ATG proteins}

In recent years, it became more and more evident that the genetic interdependence of different ATGs combined with the differential association and dissociation of ATGs from the phagophore/autophagosomal membrane allow for the plasticity of an ATG-dependent autophagic response. Accordingly, the molecular regulation of autophagy rather resembles a "spiderweb-like" network than a one-way signaling cascade (see Fig. 4). Along these lines, different "signaling and scaffolding platforms", which orchestrate the interplay between Atg/ATGs and non-Atg/ATGs during autophagy, have been proposed. For example, the exocyst complex has been implicated as protein scaffold for the autophagy machinery. The exocyst is a hetero-octameric complex involved in post-Golgi trafficking and vesicle tethering to the plasma membrane [382]. Bodemann et al. discovered that two exocyst subcomplexes containing either Sec5 or Exo84 regulate starvation-induced autophagy [383]. In this model, the Sec5 exocyst subcomplex exhibits a perinuclear localization and harbors the ULK1 kinase and PtdIns3K class III complexes. However, this subcomplex is autophagy-inactive. Along these lines, mTORC1 associated with the Sec5-subcomplex. Upon nutrient-deprivation, the Ras-like small GTPase RalB is activated, interacts with the exocyst, and promotes the replacement of Sec5 by Exo84. The Exo84-subcomplex is autophagy-active, and serves as platform for catalytically active ULK1 and Beclin 1/VPS34 complexes. Furthermore, the autophagy-active Exo84-subcomplex is localized to cytosolic puncta, presumably representing sites of autophagosome formation $[382,383]$. Whereas the exocyst represents a signaling platform during non-selective starvation-induced autophagy, there likely exist corresponding platforms during selective autophagy processes. Of note, Deretic and colleagues recently described two alternative platforms which are connected to xenophagic processes. They found that tripartite motif protein family (TRIM) members regulate selective autophagy in multiple ways $[384,385]$. On the one hand, several TRIM family members can act as platforms to assemble ULK1- and VPS34/ Beclin 1-complexes ("TRIMosomes"). On the other hand, TRIMs can also function as autophagy receptors which directly bind their cargo, as exemplified by TRIM5 [384, 385]. TRIM5 recognizes and targets HIV-1 for autophagic destruction by directly binding both the viral capsid and ATG8 family proteins [384]. By this means, TRIM5 combines scaffolding and receptor properties [384, 385]. Similarly, Deretic and colleagues reported that immunityrelated GTPase family M protein (IRGM) - which is a risk factor in Crohn's disease-can assemble the core autophagy machinery and link it to innate immunity receptors, collectively promoting antimicrobial autophagy [386]. In the future, additional scaffolding platforms are likely to be identified.

\section{Conclusion}

Over the past 20 years, the signal transduction of autophagy has become a central research field in cell biology. The molecular understanding of this process has been initiated by the identification of Atg/ATG proteins, and at present the network character of this signaling machinery and the identification of scaffolding/signaling platforms are shifting into focus. Furthermore, the importance of selective vs non-selective bulk degradation of cytoplasmic cargo is more and more appreciated. Generally, autophagic responses are constituted by two different branches. The short-term regulation mainly relies on protein-protein interactions and post-translational modifications such as phosphorylation, ubiquitination, or acetylation. In contrast, the long-term regulation of autophagy depends on transcriptional alterations [387], and the crosstalk between these two regulatory systems represents another important field of research.

Autophagy and its dysregulation have been implicated in different human diseases or processes, such as cancer, neurodegeneration, microbial infections, or aging. It is 
entirely conceivable that the modulation of autophagic signaling pathways represents a therapeutic target for several of these (patho-)physiological settings. The detailed understanding of the autophagy signaling machinery and its crosstalk is of central importance for the design of targeted therapies. One important example is tumorigenesis. In recent years, the ambivalent role of autophagy for cancer development has been characterized. On the one hand, it was demonstrated that various ATGs suppress tumor growth and that accordingly different autophagy-compromised mice are tumor-prone, e.g., Becn1 ${ }^{+/-}$mice [388]. In addition to its tumor suppressing effects, it has been postulated that autophagy might function as an alternative cell death mechanism. Collectively, these data form the basis for various preclinical studies supporting autophagy induction for cancer treatment [389]. On the other hand, autophagy functions as a cyto-protective mechanism, and thus contributes to the survival of cancer cells under nutrient-deprived conditions frequently found in tumors or metastasizing cancer cells [390]. Additionally, it could be shown that these cyto-protective effects support the resistance of cancer cells to metabolic or genotoxic stress induced by hormonal deprivation, chemotherapy or radiation [6, 389]. Furthermore, some cancer types have been shown to be "autophagy addicted", and they depend on autophagy even in the absence of external stresses (e.g., RAS-driven cancers) [391]. Accordingly, the disruption of autophagic signaling pathways has also evolved as a therapeutic strategy and is applied in many preclinical studies and ongoing clinical trials [389]. In summary, it has been proposed that the pro- and anti-tumorigenic potential of autophagy is tumor stage-dependent [392]. Taking this into consideration, therapies based on autophagy induction might be beneficial for the prevention of tumorigenesis or tumor progression, whereas treatments employing the inhibition of autophagy likely support tumor regression or enable the overcoming of therapy resistance [6].

So far, the availability of autophagy-inhibiting compounds used in preclinical studies or even clinical trials is very limited. Currently, all clinical trials pursuing the inhibition of autophagy make use of the antimalarial lysosomotropic drugs chloroquine or hydroxychloroquine, which inhibit the fusion of autophagosomes with lysosomes [389]. However, several non-autophagic effects of these compounds have been reported [389]. With regard to preclinical studies, additional autophagy-inhibitory regimens have been tested, including bafilomycin $\mathrm{A}_{1}$, ammonium chloride, 3-methyladenine, or siRNA against several essential ATGs [389, 391]. However, these compounds are not specific or cannot be employed for clinical trials. Recently, three different VPS34-selective inhibitors have been reported, i.e., VPS34-IN1, SAR405, and PIK-III [255, 393, 394]. For SAR405, the authors reported a synergistic antiproliferative activity in renal tumor cell lines in combination with the mTOR inhibitor everolimus [394]. With regard to the ULK1 complex, the structure of the ULK1 kinase domain in complex with multiple inhibitors has been reported [118]. Furthermore, recently the first ULK1/2 inhibitors have been reported and characterized, i.e., MRT67307/MRT68921 and SBI-0206965 [124, 395]. Similar to the results obtained with the VPS34-inhibitor SAR405, the ULK1-inhibitor SBI-0206965 synergizes with mTOR inhibition to induce cell death in A549 non-small cell lung cancer cells [124]. Generally, it has become evident that MTOR inhibitors and other anticancer drugs induce cytoprotective autophagy, ultimately leading to a compromised efficacy of these compounds. Therefore, combinatorial therapies employing these agents and parallel ULK1 and/or VPS34 inhibition represents a promising anticancer strategy. Collectively, the development of targeted therapies-based on the molecular understanding of the autophagy signaling machinery-will be a central task for the coming years.

Acknowledgments We would like to apologize to all our colleagues whose important work could not be properly reviewed here because of space limitations. Like all reviews, it is necessarily incomplete. Parts of this review have been taken from the habilitation thesis written by B.S. Related research by our group is/was supported by grants from the Deutsche Forschungsgemeinschaft (STO 864/3-1 and STO 864/4-1 to B.S.), the Research Committee of the Medical Faculty of the Heinrich-Heine-University Düsseldorf 58/2013 (to B.S.), and the Düsseldorf School of Oncology (to S.W. and B.S.; funded by the Comprehensive Cancer Center Düsseldorf/Deutsche Krebshilfe and the Medical Faculty of the Heinrich-Heine-University Düsseldorf).

\section{Compliance with ethical standards}

Conflict of interest The authors declare that they have no conflict of interest.

Open Access This article is distributed under the terms of the Creative Commons Attribution 4.0 International License (http:// creativecommons.org/licenses/by/4.0/), which permits unrestricted use, distribution, and reproduction in any medium, provided you give appropriate credit to the original author(s) and the source, provide a link to the Creative Commons license, and indicate if changes were made.

\section{References}

1. Ashford TP, Porter KR (1962) Cytoplasmic components in hepatic cell lysosomes. J Cell Biol 12:198-202

2. Novikoff AB, Essner E (1962) Cytolysomes and mitochondrial degeneration. J Cell Biol 15:140-146

3. Klionsky DJ (2008) Autophagy revisited: a conversation with Christian de Duve. Autophagy 4(6):740-743

4. Choi AM, Ryter SW, Levine B (2013) Autophagy in human health and disease. N Engl J Med 368(7):651-662

5. Levine B, Kroemer G (2008) Autophagy in the pathogenesis of disease. Cell 132(1):27-42 
6. Mizushima N, Levine B, Cuervo AM, Klionsky DJ (2008) Autophagy fights disease through cellular self-digestion. Nature 451(7182):1069-1075

7. Ravikumar B, Sarkar S, Davies JE, Futter M, Garcia-Arencibia M, Green-Thompson ZW, Jimenez-Sanchez M, Korolchuk VI, Lichtenberg M, Luo S, Massey DC, Menzies FM, Moreau K, Narayanan U, Renna M, Siddiqi FH, Underwood BR, Winslow AR, Rubinsztein DC (2010) Regulation of mammalian autophagy in physiology and pathophysiology. Physiol Rev 90(4):1383-1435

8. Mizushima N, Yoshimori T, Ohsumi Y (2011) The role of Atg proteins in autophagosome formation. Annu Rev Cell Dev Biol 27:107-132

9. Klionsky DJ (2007) Autophagy: from phenomenology to molecular understanding in less than a decade. Nat Rev Mol Cell Biol 8(11):931-937

10. Mizushima N (2007) Autophagy: process and function. Genes Dev 21(22):2861-2873

11. Al Rawi S, Louvet-Vallee S, Djeddi A, Sachse M, Culetto E, Hajjar C, Boyd L, Legouis R, Galy V (2012) Allophagy: a macroautophagic process degrading spermatozoid-inherited organelles. Autophagy 8(3):421-423

12. Klionsky DJ, Cuervo AM, Dunn WA Jr, Levine B, van der Klei I, Seglen PO (2007) How shall I eat thee? Autophagy 3(5):413-416

13. Reggiori F, Komatsu M, Finley K, Simonsen A (2012) Selective types of autophagy. Int J Cell Biol 2012:156272

14. Sato M, Sato K (2012) Maternal inheritance of mitochondrial DNA: degradation of paternal mitochondria by allogeneic organelle autophagy, allophagy. Autophagy 8(3):424-425

15. Suzuki K, Kirisako T, Kamada Y, Mizushima N, Noda T, Ohsumi Y (2001) The pre-autophagosomal structure organized by concerted functions of APG genes is essential for autophagosome formation. EMBO J 20(21):5971-5981

16. Axe EL, Walker SA, Manifava M, Chandra P, Roderick HL, Habermann A, Griffiths G, Ktistakis NT (2008) Autophagosome formation from membrane compartments enriched in phosphatidylinositol 3-phosphate and dynamically connected to the endoplasmic reticulum. J Cell Biol 182(4):685-701

17. Hayashi-Nishino M, Fujita N, Noda T, Yamaguchi A, Yoshimori T, Yamamoto A (2009) A subdomain of the endoplasmic reticulum forms a cradle for autophagosome formation. Nat Cell Biol 11(12):1433-1437

18. Yla-Anttila P, Vihinen H, Jokitalo E, Eskelinen EL (2009) 3D tomography reveals connections between the phagophore and endoplasmic reticulum. Autophagy 5(8):1180-1185

19. Longatti A, Tooze SA (2012) Recycling endosomes contribute to autophagosome formation. Autophagy 8(11):1682-1683

20. Tooze SA, Yoshimori T (2010) The origin of the autophagosomal membrane. Nat Cell Biol 12(9):831-835

21. Hailey DW, Rambold AS, Satpute-Krishnan P, Mitra K, Sougrat R, Kim PK, Lippincott-Schwartz J (2010) Mitochondria supply membranes for autophagosome biogenesis during starvation. Cell 141(4):656-667

22. Hamasaki M, Furuta N, Matsuda A, Nezu A, Yamamoto A, Fujita N, Oomori H, Noda T, Haraguchi T, Hiraoka Y, Amano A, Yoshimori T (2013) Autophagosomes form at ER-mitochondria contact sites. Nature 495(7441):389-393

23. Ge L, Melville D, Zhang M, Schekman R (2013) The ER-Golgi intermediate compartment is a key membrane source for the LC3 lipidation step of autophagosome biogenesis. Elife 2:e00947

24. Graef M, Friedman JR, Graham C, Babu M, Nunnari J (2013) ER exit sites are physical and functional core autophagosome biogenesis components. Mol Biol Cell 24(18):2918-2931
25. Tan D, Cai Y, Wang J, Zhang J, Menon S, Chou HT, FerroNovick S, Reinisch KM, Walz T (2013) The EM structure of the TRAPPIII complex leads to the identification of a requirement for COPII vesicles on the macroautophagy pathway. Proc Natl Acad Sci USA 110(48):19432-19437

26. Biazik J, Yla-Anttila P, Vihinen H, Jokitalo E, Eskelinen EL (2015) Ultrastructural relationship of the phagophore with surrounding organelles. Autophagy 11:439-451

27. Yang Z, Klionsky DJ (2010) Eaten alive: a history of macroautophagy. Nat Cell Biol 12 (9):814-822

28. Tsukada M, Ohsumi Y (1993) Isolation and characterization of autophagy-defective mutants of Saccharomyces cerevisiae. FEBS Lett 333(1-2):169-174

29. Harding TM, Morano KA, Scott SV, Klionsky DJ (1995) Isolation and characterization of yeast mutants in the cytoplasm to vacuole protein targeting pathway. J Cell Biol 131(3):591-602

30. Klionsky DJ, Cregg JM, Dunn WA Jr, Emr SD, Sakai Y, Sandoval IV, Sibirny A, Subramani S, Thumm M, Veenhuis M, Ohsumi Y (2003) A unified nomenclature for yeast autophagyrelated genes. Dev Cell 5(4):539-545

31. Mukaiyama H, Oku M, Baba M, Samizo T, Hammond AT, Glick BS, Kato N, Sakai Y (2002) Paz2 and 13 other PAZ gene products regulate vacuolar engulfment of peroxisomes during micropexophagy. Genes Cells 7(1):75-90

32. Sakai Y, Koller A, Rangell LK, Keller GA, Subramani S (1998) Peroxisome degradation by microautophagy in Pichia pastoris: identification of specific steps and morphological intermediates. J Cell Biol 141(3):625-636

33. Thumm M, Egner R, Koch B, Schlumpberger M, Straub M, Veenhuis M, Wolf DH (1994) Isolation of autophagocytosis mutants of Saccharomyces cerevisiae. FEBS Lett 349(2):275-280

34. Titorenko VI, Keizer I, Harder W, Veenhuis M (1995) Isolation and characterization of mutants impaired in the selective degradation of peroxisomes in the yeast Hansenula polymorpha. J Bacteriol 177(2):357-363

35. Yuan W, Tuttle DL, Shi YJ, Ralph GS, Dunn WA Jr (1997) Glucose-induced microautophagy in Pichia pastoris requires the alpha-subunit of phosphofructokinase. J Cell Sci 110(Pt 16): 1935-1945

36. Mochida K, Oikawa Y, Kimura Y, Kirisako H, Hirano H, Ohsumi Y, Nakatogawa H (2015) Receptor-mediated selective autophagy degrades the endoplasmic reticulum and the nucleus. Nature 522(7556):359-362

37. Hosokawa N, Sasaki T, Iemura S, Natsume $T$, Hara $T$, Mizushima N (2009) Atg101, a novel mammalian autophagy protein interacting with Atg13. Autophagy 5(7):973-979

38. Mercer CA, Kaliappan A, Dennis PB (2009) A novel, human Atg13 binding protein, Atg101, interacts with ULK1 and is essential for macroautophagy. Autophagy 5(5):649-662

39. Subramani S, Malhotra V (2013) Non-autophagic roles of autophagy-related proteins. EMBO Rep 14(2):143-151

40. Matsuura A, Tsukada M, Wada Y, Ohsumi Y (1997) Apg1p, a novel protein kinase required for the autophagic process in Saccharomyces cerevisiae. Gene 192(2):245-250

41. Funakoshi T, Matsuura A, Noda T, Ohsumi Y (1997) Analyses of APG13 gene involved in autophagy in yeast, Saccharomyces cerevisiae. Gene 192(2):207-213

42. Alers S, Löffler AS, Wesselborg S, Stork B (2012) Role of AMPK-mTOR-Ulk1/2 in the regulation of autophagy: cross talk, shortcuts, and feedbacks. Mol Cell Biol 32(1):2-11

43. Alers S, Löffler AS, Wesselborg S, Stork B (2012) The incredible ULKs. Cell Commun Signal 10(1):7

44. Mizushima N (2010) The role of the Atg1/ULK1 complex in autophagy regulation. Curr Opin Cell Biol 22(2):132-139 
45. Wong PM, Puente C, Ganley IG, Jiang X (2013) The ULK1 complex: sensing nutrient signals for autophagy activation. Autophagy 9(2):124-137

46. Kabeya Y, Kawamata T, Suzuki K, Ohsumi Y (2007) Cis1/ Atg31 is required for autophagosome formation in Saccharomyces cerevisiae. Biochem Biophys Res Commun 356(2):405-410

47. Kamada Y, Funakoshi T, Shintani T, Nagano K, Ohsumi M, Ohsumi Y (2000) Tor-mediated induction of autophagy via an Apg1 protein kinase complex. J Cell Biol 150(6):1507-1513

48. Kawamata T, Kamada Y, Suzuki K, Kuboshima N, Akimatsu H, Ota S, Ohsumi M, Ohsumi Y (2005) Characterization of a novel autophagy-specific gene, ATG29. Biochem Biophys Res Commun 338(4):1884-1889

49. Kabeya Y, Noda NN, Fujioka Y, Suzuki K, Inagaki F, Ohsumi Y (2009) Characterization of the Atg17-Atg29-Atg31 complex specifically required for starvation-induced autophagy in Saccharomyces cerevisiae. Biochem Biophys Res Commun 389(4):612-615

50. Kawamata T, Kamada Y, Kabeya Y, Sekito T, Ohsumi Y (2008) Organization of the pre-autophagosomal structure responsible for autophagosome formation. Mol Biol Cell 19(5):2039-2050

51. Suzuki K, Kubota Y, Sekito T, Ohsumi Y (2007) Hierarchy of Atg proteins in pre-autophagosomal structure organization. Genes Cells 12(2):209-218

52. Cheong H, Yorimitsu T, Reggiori F, Legakis JE, Wang CW, Klionsky DJ (2005) Atg17 regulates the magnitude of the autophagic response. Mol Biol Cell 16(7):3438-3453

53. Kabeya Y, Kamada Y, Baba M, Takikawa H, Sasaki M, Ohsumi $\mathrm{Y}$ (2005) Atg17 functions in cooperation with Atg1 and Atg13 in yeast autophagy. Mol Biol Cell 16(5):2544-2553

54. Cheong H, Nair U, Geng J, Klionsky DJ (2008) The Atg1 kinase complex is involved in the regulation of protein recruitment to initiate sequestering vesicle formation for nonspecific autophagy in Saccharomyces cerevisiae. Mol Biol Cell 19(2):668-681

55. Noda T, Ohsumi Y (1998) Tor, a phosphatidylinositol kinase homologue, controls autophagy in yeast. J Biol Chem 273(7):3963-3966

56. Kamada Y, Yoshino K, Kondo C, Kawamata T, Oshiro N, Yonezawa K, Ohsumi Y (2010) Tor directly controls the Atg1 kinase complex to regulate autophagy. Mol Cell Biol 30(4):1049-1058

57. Kraft C, Kijanska M, Kalie E, Siergiejuk E, Lee SS, Semplicio G, Stoffel I, Brezovich A, Verma M, Hansmann I, Ammerer G, Hofmann K, Tooze S, Peter M (2012) Binding of the Atg1/ ULK1 kinase to the ubiquitin-like protein Atg8 regulates autophagy. EMBO J 31(18):3691-3703

58. Kijanska M, Dohnal I, Reiter W, Kaspar S, Stoffel I, Ammerer G, Kraft C, Peter M (2010) Activation of Atg1 kinase in autophagy by regulated phosphorylation. Autophagy 6(8): 1168-1178

59. Yeh YY, Wrasman K, Herman PK (2010) Autophosphorylation within the Atg1 activation loop is required for both kinase activity and the induction of autophagy in Saccharomyces cerevisiae. Genetics 185(3):871-882

60. Budovskaya YV, Stephan JS, Deminoff SJ, Herman PK (2005) An evolutionary proteomics approach identifies substrates of the cAMP-dependent protein kinase. Proc Natl Acad Sci USA 102(39):13933-13938

61. Stephan JS, Yeh YY, Ramachandran V, Deminoff SJ, Herman PK (2009) The Tor and PKA signaling pathways independently target the Atg1/Atg13 protein kinase complex to control autophagy. Proc Natl Acad Sci USA 106(40):17049-17054

62. Umekawa M, Klionsky DJ (2012) The Ksp1 kinase regulates autophagy via the target of rapamycin complex 1 (TORC1) pathway. J Biol Chem 287:16300-16310
63. Wang Z, Wilson WA, Fujino MA, Roach PJ (2001) Antagonistic controls of autophagy and glycogen accumulation by Snflp, the yeast homolog of AMP-activated protein kinase, and the cyclindependent kinase Pho85p. Mol Cell Biol 21(17):5742-5752

64. Yorimitsu T, Zaman S, Broach JR, Klionsky DJ (2007) Protein kinase A and Sch9 cooperatively regulate induction of autophagy in Saccharomyces cerevisiae. Mol Biol Cell 18(10):4180-4189

65. Yorimitsu T, He C, Wang K, Klionsky DJ (2009) Tap42-associated protein phosphatase type $2 \mathrm{~A}$ negatively regulates induction of autophagy. Autophagy 5(5):616-624

66. Ptacek J, Devgan G, Michaud G, Zhu H, Zhu X, Fasolo J, Guo H, Jona G, Breitkreutz A, Sopko R, McCartney RR, Schmidt MC, Rachidi N, Lee SJ, Mah AS, Meng L, Stark MJ, Stern DF, De Virgilio C, Tyers M, Andrews B, Gerstein M, Schweitzer B, Predki PF, Snyder M (2005) Global analysis of protein phosphorylation in yeast. Nature 438(7068):679-684

67. Reggiori F, Tucker KA, Stromhaug PE, Klionsky DJ (2004) The Atg1-Atg13 complex regulates Atg9 and Atg23 retrieval transport from the pre-autophagosomal structure. Dev Cell 6(1):79-90

68. Papinski D, Schuschnig M, Reiter W, Wilhelm L, Barnes CA, Maiolica A, Hansmann I, Pfaffenwimmer T, Kijanska M, Stoffel I, Lee SS, Brezovich A, Lou JH, Turk BE, Aebersold R, Ammerer G, Peter M, Kraft C (2014) Early steps in autophagy depend on direct phosphorylation of Atg9 by the Atg1 kinase. Mol Cell 53(3):471-483

69. Ragusa MJ, Stanley RE, Hurley JH (2012) Architecture of the Atg17 complex as a scaffold for autophagosome biogenesis. Cell 151(7):1501-1512

70. Chew LH, Setiaputra D, Klionsky DJ, Yip CK (2013) Structural characterization of the Saccharomyces cerevisiae autophagy regulatory complex Atg17-Atg31-Atg29. Autophagy 9(10):1467-1474

71. Jao CC, Ragusa MJ, Stanley RE, Hurley JH (2013) A HORMA domain in Atg13 mediates PI 3-kinase recruitment in autophagy. Proc Natl Acad Sci USA 110(14):5486-5491

72. Suzuki SW, Yamamoto H, Oikawa Y, Kondo-Kakuta C, Kimura Y, Hirano H, Ohsumi Y (2015) Atg13 HORMA domain recruits Atg9 vesicles during autophagosome formation. Proc Natl Acad Sci USA 112(11):3350-3355

73. Fujioka Y, Suzuki SW, Yamamoto H, Kondo-Kakuta C, Kimura Y, Hirano H, Akada R, Inagaki F, Ohsumi Y, Noda NN (2014) Structural basis of starvation-induced assembly of the autophagy initiation complex. Nat Struct Mol Biol 21(6):513-521

74. Stjepanovic G, Davies CW, Stanley RE, Ragusa MJ, Kim do J, Hurley JH (2014) Assembly and dynamics of the autophagyinitiating Atg1 complex. Proc Natl Acad Sci USA 111(35):12793-12798

75. Kofinger J, Ragusa MJ, Lee IH, Hummer G, Hurley JH (2015) Solution structure of the Atg1 complex: implications for the architecture of the phagophore assembly site. Structure 23:809-818

76. Noda NN, Fujioka Y (2015) Atg1 family kinases in autophagy initiation. Cell Mol Life Sci 72(16):3083-3096

77. Chan EY, Tooze SA (2009) Evolution of Atg1 function and regulation. Autophagy 5(6):758-765

78. Yan J, Kuroyanagi H, Kuroiwa A, Matsuda Y, Tokumitsu H, Tomoda T, Shirasawa T, Muramatsu M (1998) Identification of mouse ULK1, a novel protein kinase structurally related to $C$. elegans UNC-51. Biochem Biophys Res Commun 246(1):222-227

79. Kuroyanagi H, Yan J, Seki N, Yamanouchi Y, Suzuki Y, Takano T, Muramatsu M, Shirasawa T (1998) Human ULK1, a novel serine/threonine kinase related to UNC-51 kinase of 
Caenorhabditis elegans: cDNA cloning, expression, and chromosomal assignment. Genomics 51(1):76-85

80. Yan J, Kuroyanagi H, Tomemori T, Okazaki N, Asato K, Matsuda Y, Suzuki Y, Ohshima Y, Mitani S, Masuho Y, Shirasawa T, Muramatsu M (1999) Mouse ULK2, a novel member of the UNC-51-like protein kinases: unique features of functional domains. Oncogene 18(43):5850-5859

81. Chan EY, Kir S, Tooze SA (2007) siRNA screening of the kinome identifies ULK1 as a multidomain modulator of autophagy. J Biol Chem 282(35):25464-25474

82. Hara T, Takamura A, Kishi C, Iemura S, Natsume T, Guan JL, Mizushima N (2008) FIP200, a ULK-interacting protein, is required for autophagosome formation in mammalian cells. J Cell Biol 181(3):497-510

83. Kundu M, Lindsten T, Yang CY, Wu J, Zhao F, Zhang J, Selak MA, Ney PA, Thompson CB (2008) Ulk1 plays a critical role in the autophagic clearance of mitochondria and ribosomes during reticulocyte maturation. Blood 112(4):1493-1502

84. Cheong H, Lindsten T, Wu J, Lu C, Thompson CB (2011) Ammonia-induced autophagy is independent of ULK1/ULK2 kinases. Proc Natl Acad Sci USA 108(27):11121-11126

85. Young AR, Narita M, Ferreira M, Kirschner K, Sadaie M, Darot JF, Tavare S, Arakawa S, Shimizu S, Watt FM (2009) Autophagy mediates the mitotic senescence transition. Genes Dev 23(7):798-803

86. Meijer WH, van der Klei IJ, Veenhuis M, Kiel JA (2007) ATG genes involved in non-selective autophagy are conserved from yeast to man, but the selective Cvt and pexophagy pathways also require organism-specific genes. Autophagy 3(2):106-116

87. Abbi S, Ueda H, Zheng C, Cooper LA, Zhao J, Christopher R, Guan JL (2002) Regulation of focal adhesion kinase by a novel protein inhibitor FIP200. Mol Biol Cell 13(9):3178-3191

88. Ueda H, Abbi S, Zheng C, Guan JL (2000) Suppression of Pyk2 kinase and cellular activities by FIP200. J Cell Biol 149(2):423-430

89. Chano T, Ikegawa S, Kontani K, Okabe H, Baldini N, Saeki Y (2002) Identification of RB1CC1, a novel human gene that can induce RB1 in various human cells. Oncogene 21(8):1295-1298

90. Gan B, Guan JL (2008) FIP200, a key signaling node to coordinately regulate various cellular processes. Cell Signal 20(5):787-794

91. Chano T, Ikebuchi K, Ochi Y, Tameno H, Tomita Y, Jin Y, Inaji $\mathrm{H}$, Ishitobi M, Teramoto K, Nishimura I, Minami K, Inoue H, Isono T, Saitoh M, Shimada T, Hisa Y, Okabe H (2010) RB1CC1 activates RB1 pathway and inhibits proliferation and cologenic survival in human cancer. PLoS ONE 5(6):e11404

92. Chano T, Saji M, Inoue H, Minami K, Kobayashi T, Hino O, Okabe H (2006) Neuromuscular abundance of RB1CC1 contributes to the non-proliferating enlarged cell phenotype through both RB1 maintenance and TSC1 degradation. Int J Mol Med 18(3):425-432

93. Choi JD, Ryu M, Ae Park M, Jeong G, Lee JS (2013) FIP200 inhibits beta-catenin-mediated transcription by promoting APCindependent beta-catenin ubiquitination. Oncogene 32(19):2421-2432

94. Gammoh N, Florey O, Overholtzer M, Jiang X (2013) Interaction between FIP200 and ATG16L1 distinguishes ULK1 complex-dependent and -independent autophagy. Nat Struct Mol Biol 20(2):144-149

95. Gan B, Melkoumian ZK, Wu X, Guan KL, Guan JL (2005) Identification of FIP200 interaction with the TSC1-TSC2 complex and its role in regulation of cell size control. J Cell Biol 170(3):379-389

96. Gan B, Peng X, Nagy T, Alcaraz A, Gu H, Guan JL (2006) Role of FIP200 in cardiac and liver development and its regulation of
TNFalpha and TSC-mTOR signaling pathways. J Cell Biol 175(1):121-133

97. Kobayashi S, Yoneda-Kato N, Itahara N, Yoshida A, Kato JY (2013) The COP1 E3-ligase interacts with FIP200, a key regulator of mammalian autophagy. BMC Biochem 14:1

98. Koinuma D, Shinozaki M, Nagano Y, Ikushima H, Horiguchi K, Goto K, Chano T, Saitoh M, Imamura T, Miyazono K, Miyazawa K (2011) RB1CC1 protein positively regulates transforming growth factor-beta signaling through the modulation of Arkadia E3 ubiquitin ligase activity. J Biol Chem 286(37):32502-32512

99. Maucuer A, Camonis JH, Sobel A (1995) Stathmin interaction with a putative kinase and coiled-coil-forming protein domains. Proc Natl Acad Sci USA 92(8):3100-3104

100. Meiselbach H, Sticht H, Enz R (2006) Structural analysis of the protein phosphatase 1 docking motif: molecular description of binding specificities identifies interacting proteins. Chem Biol 13(1):49-59

101. Melkoumian ZK, Peng X, Gan B, Wu X, Guan JL (2005) Mechanism of cell cycle regulation by FIP200 in human breast cancer cells. Cancer Res 65(15):6676-6684

102. Morselli E, Shen S, Ruckenstuhl C, Bauer MA, Marino G, Galluzzi L, Criollo A, Michaud M, Maiuri MC, Chano T, Madeo F, Kroemer G (2011) p53 inhibits autophagy by interacting with the human ortholog of yeast Atg17, RB1CC1/FIP200. Cell Cycle 10(16):2763-2769

103. Nishimura T, Kaizuka T, Cadwell K, Sahani MH, Saitoh T, Akira S, Virgin HW, Mizushima N (2013) FIP200 regulates targeting of Atg16L1 to the isolation membrane. EMBO Rep 14(3):284-291

104. Ochi $\mathrm{Y}$, Chano $\mathrm{T}$, Ikebuchi $\mathrm{K}$, Inoue $\mathrm{H}$, Isono $\mathrm{T}$, Arai $\mathrm{A}$, Tameno H, Shimada T, Hisa Y, Okabe H (2011) RB1CC1 activates the p16 promoter through the interaction with hSNF5. Oncol Rep 26(4):805-812

105. Pfeuffer T, Goebel W, Laubinger J, Bachmann M, Kuhn M (2000) LaXp180, a mammalian ActA-binding protein, identified with the yeast two-hybrid system, co-localizes with intracellular Listeria monocytogenes. Cell Microbiol 2(2):101-114

106. Hara T, Mizushima N (2009) Role of ULK-FIP200 complex in mammalian autophagy: FIP200, a counterpart of yeast Atg17? Autophagy 5(1):85-87

107. Chan EY, Longatti A, McKnight NC, Tooze SA (2009) Kinaseinactivated ULK proteins inhibit autophagy via their conserved C-terminal domains using an Atg13-independent mechanism. Mol Cell Biol 29(1):157-171

108. Ganley IG, du Lam H, Wang J, Ding X, Chen S, Jiang X (2009) ULK1.ATG13.FIP200 complex mediates mTOR signaling and is essential for autophagy. J Biol Chem 284(18):12297-12305

109. Hosokawa N, Hara T, Kaizuka T, Kishi C, Takamura A, Miura Y, Iemura S, Natsume T, Takehana K, Yamada N, Guan JL, Oshiro N, Mizushima N (2009) Nutrient-dependent mTORC1 association with the ULK1-Atg13-FIP200 complex required for autophagy. Mol Biol Cell 20(7):1981-1991

110. Jung CH, Jun CB, Ro SH, Kim YM, Otto NM, Cao J, Kundu M, Kim DH (2009) ULK-Atg13-FIP200 complexes mediate mTOR signaling to the autophagy machinery. Mol Biol Cell 20(7):1992-2003

111. Hieke N, Löffler AS, Kaizuka T, Berleth N, Böhler P, Driessen S, Stuhldreier F, Friesen O, Assani K, Schmitz K, Peter C, Diedrich B, Dengjel J, Holland P, Simonsen A, Wesselborg S, Mizushima N, Stork B (2015) Expression of a ULK1/2 bindingdeficient ATG13 variant can partially restore autophagic activity in ATG13-deficient cells. Autophagy 11(9):1471-1483

112. Lee JW, Park S, Takahashi Y, Wang HG (2010) The association of AMPK with ULK1 regulates autophagy. PLoS ONE 5(11):e15394 
113. Martin-Castellanos C, Blanco M, Rozalen AE, Perez-Hidalgo L, Garcia AI, Conde F, Mata J, Ellermeier C, Davis L, San-Segundo P, Smith GR, Moreno S (2005) A large-scale screen in $S$. pombe identifies seven novel genes required for critical meiotic events. Curr Biol 15(22):2056-2062

114. Sun LL, Li M, Suo F, Liu XM, Shen EZ, Yang B, Dong MQ, He WZ, Du LL (2013) Global analysis of fission yeast mating genes reveals new autophagy factors. PLoS Genet 9(8):e1003715

115. Suzuki H, Kaizuka T, Mizushima N, Noda NN (2015) Structure of the Atg101-Atg13 complex reveals essential roles of Atg101 in autophagy initiation. Nat Struct Mol Biol 22(7):572-580

116. Steffan JS (2010) Does Huntingtin play a role in selective macroautophagy? Cell Cycle 9(17):3401-3413

117. Michel M, Schwarten M, Decker C, Nagel-Steger L, Willbold $\mathrm{D}$, Weiergraber $\mathrm{OH}$ (2015) The mammalian autophagy initiator complex contains two HORMA domain proteins. Autophagy

118. Lazarus MB, Novotny CJ, Shokat KM (2015) Structure of the human autophagy initiating kinase ULK1 in complex with potent inhibitors. ACS Chem Biol 10(1):257-261

119. Dorsey FC, Rose KL, Coenen S, Prater SM, Cavett V, Cleveland JL, Caldwell-Busby J (2009) Mapping the phosphorylation sites of Ulk1. J Proteome Res 8(11):5253-5263

120. Mack HI, Zheng B, Asara JM, Thomas SM (2012) AMPKdependent phosphorylation of ULK1 regulates ATG9 localization. Autophagy 8(8):1197-1214

121. Shang L, Chen S, Du F, Li S, Zhao L, Wang X (2011) Nutrient starvation elicits an acute autophagic response mediated by Ulk1 dephosphorylation and its subsequent dissociation from AMPK. Proc Natl Acad Sci USA 108(12):4788-4793

122. Alers S, Löffler AS, Paasch F, Dieterle AM, Keppeler H, Lauber K, Campbell DG, Fehrenbacher B, Schaller M, Wesselborg S, Stork B (2011) Atg13 and FIP200 act independently of Ulk1 and Ulk2 in autophagy induction. Autophagy 7(12):1423-1433

123. Joo JH, Dorsey FC, Joshi A, Hennessy-Walters KM, Rose KL, McCastlain K, Zhang J, Iyengar R, Jung CH, Suen DF, Steeves MA, Yang CY, Prater SM, Kim DH, Thompson CB, Youle RJ, Ney PA, Cleveland JL, Kundu M (2011) Hsp90-Cdc37 chaperone complex regulates Ulk1- and Atg13-mediated mitophagy. Mol Cell 43(4):572-585

124. Egan DF, Chun MG, Vamos M, Zou H, Rong J, Miller CJ, Lou HJ, Raveendra-Panickar D, Yang CC, Sheffler DJ, Teriete P, Asara JM, Turk BE, Cosford ND, Shaw RJ (2015) Small molecule inhibition of the autophagy kinase ULK1 and identification of ULK1 substrates. Mol Cell 59(2):285-297

125. Jewell JL, Russell RC, Guan KL (2013) Amino acid signalling upstream of mTOR. Nat Rev Mol Cell Biol 14(3):133-139

126. Laplante M, Sabatini DM (2012) mTOR signaling in growth control and disease. Cell 149(2):274-293

127. Zoncu R, Efeyan A, Sabatini DM (2011) mTOR: from growth signal integration to cancer, diabetes and ageing. Nat Rev Mol Cell Biol 12(1):21-35

128. Bach M, Larance M, James DE, Ramm G (2011) The serine/ threonine kinase ULK1 is a target of multiple phosphorylation events. Biochem J 440(2):283-291

129. Hardie DG (2011) AMP-activated protein kinase: an energy sensor that regulates all aspects of cell function. Genes Dev 25(18):1895-1908

130. Hardie DG, Ross FA, Hawley SA (2012) AMPK: a nutrient and energy sensor that maintains energy homeostasis. Nat Rev Mol Cell Biol 13(4):251-262

131. Hardie DG, Ross FA, Hawley SA (2012) AMP-activated protein kinase: a target for drugs both ancient and modern. Chem Biol 19(10):1222-1236

132. Samari HR, Seglen PO (1998) Inhibition of hepatocytic autophagy by adenosine, aminoimidazole-4-carboxamide riboside, and N6-mercaptopurine riboside. Evidence for involvement of amp-activated protein kinase. J Biol Chem 273(37):23758-23763

133. Liang J, Shao SH, Xu ZX, Hennessy B, Ding Z, Larrea M, Kondo S, Dumont DJ, Gutterman JU, Walker CL, Slingerland JM, Mills GB (2007) The energy sensing LKB1-AMPK pathway regulates $\mathrm{p} 27$ (kip1) phosphorylation mediating the decision to enter autophagy or apoptosis. Nat Cell Biol 9(2):218-224

134. Matsui Y, Takagi H, Qu X, Abdellatif M, Sakoda H, Asano T, Levine B, Sadoshima J (2007) Distinct roles of autophagy in the heart during ischemia and reperfusion: roles of AMP-activated protein kinase and Beclin 1 in mediating autophagy. Circ Res 100(6):914-922

135. Meley D, Bauvy C, Houben-Weerts JH, Dubbelhuis PF, Helmond MT, Codogno P, Meijer AJ (2006) AMP-activated protein kinase and the regulation of autophagic proteolysis. J Biol Chem 281(46):34870-34879

136. Viana R, Aguado C, Esteban I, Moreno D, Viollet B, Knecht E, Sanz P (2008) Role of AMP-activated protein kinase in autophagy and proteasome function. Biochem Biophys Res Commun 369(3):964-968

137. Gwinn DM, Shackelford DB, Egan DF, Mihaylova MM, Mery A, Vasquez DS, Turk BE, Shaw RJ (2008) AMPK phosphorylation of raptor mediates a metabolic checkpoint. Mol Cell 30(2):214-226

138. Inoki K, Zhu T, Guan KL (2003) TSC2 mediates cellular energy response to control cell growth and survival. Cell 115(5):577-590

139. Behrends C, Sowa ME, Gygi SP, Harper JW (2010) Network organization of the human autophagy system. Nature 466(7302):68-76

140. Egan DF, Shackelford DB, Mihaylova MM, Gelino S, Kohnz RA, Mair W, Vasquez DS, Joshi A, Gwinn DM, Taylor R, Asara JM, Fitzpatrick J, Dillin A, Viollet B, Kundu M, Hansen M, Shaw RJ (2011) Phosphorylation of ULK1 (hATG1) by AMPactivated protein kinase connects energy sensing to mitophagy. Science 331(6016):456-461

141. Kim J, Kundu M, Viollet B, Guan KL (2011) AMPK and mTOR regulate autophagy through direct phosphorylation of Ulk1. Nat Cell Biol 13(2):132-141

142. Sanchez AM, Csibi A, Raibon A, Cornille K, Gay S, Bernardi H, Candau R (2012) AMPK promotes skeletal muscle autophagy through activation of forkhead FoxO3a and interaction with Ulk1. J Cell Biochem 113(2):695-710

143. Löffler AS, Alers S, Dieterle AM, Keppeler H, Franz-Wachtel M, Kundu M, Campbell DG, Wesselborg S, Alessi DR, Stork B (2011) Ulk1-mediated phosphorylation of AMPK constitutes a negative regulatory feedback loop. Autophagy 7(7):696-706

144. Chang YY, Neufeld TP (2009) An Atg1/Atg13 complex with multiple roles in TOR-mediated autophagy regulation. Mol Biol Cell 20(7):2004-2014

145. Ogura K, Okada T, Mitani S, Gengyo-Ando K, Baillie DL, Kohara Y, Goshima Y (2010) Protein phosphatase 2A cooperates with the autophagy-related kinase UNC-51 to regulate axon guidance in Caenorhabditis elegans. Development 137(10): 1657-1667

146. Banreti A, Lukacsovich T, Csikos G, Erdelyi M, Sass M (2012) PP2A regulates autophagy in two alternative ways in Drosophila. Autophagy 8(4):623-636

147. Blankson H, Holen I, Seglen PO (1995) Disruption of the cytokeratin cytoskeleton and inhibition of hepatocytic autophagy by okadaic acid. Exp Cell Res 218(2):522-530

148. Magnaudeix A, Wilson CM, Page G, Bauvy C, Codogno P, Leveque P, Labrousse F, Corre-Delage M, Yardin C, Terro F (2013) PP2A blockade inhibits autophagy and causes intraneuronal accumulation of ubiquitinated proteins. Neurobiol Aging 34(3):770-790 
149. Samari HR, Moller MT, Holden L, Asmyhr T, Seglen PO (2005) Stimulation of hepatocytic AMP-activated protein kinase by okadaic acid and other autophagy-suppressive toxins. Biochem J 386(Pt 2):237-244

150. Yin X, Zhang N, Di W (2013) Regulation of LC3-dependent protective autophagy in ovarian cancer cells by protein phosphatase 2A. Int J Gynecol Cancer 23(4):630-641

151. Lee SB, Kim S, Lee J, Park J, Lee G, Kim Y, Kim JM, Chung J (2007) ATG1, an autophagy regulator, inhibits cell growth by negatively regulating S6 kinase. EMBO Rep 8(4):360-365

152. Scott RC, Juhasz G, Neufeld TP (2007) Direct induction of autophagy by Atg1 inhibits cell growth and induces apoptotic cell death. Curr Biol 17(1):1-11

153. Dunlop EA, Hunt DK, Acosta-Jaquez HA, Fingar DC, Tee AR (2011) ULK1 inhibits mTORC1 signaling, promotes multisite Raptor phosphorylation and hinders substrate binding. Autophagy 7(7):737-747

154. Jung CH, Seo M, Otto NM, Kim DH (2011) ULK1 inhibits the kinase activity of mTORC1 and cell proliferation. Autophagy 7(10):1212-1221

155. Korolchuk VI, Menzies FM, Rubinsztein DC (2010) Mechanisms of cross-talk between the ubiquitin-proteasome and autophagy-lysosome systems. FEBS Lett 584(7):1393-1398

156. Driessen S, Berleth N, Friesen O, Löffler AS, Böhler P, Hieke N, Stuhldreier F, Peter C, Schink KO, Schultz SW, Stenmark H, Holland P, Simonsen A, Wesselborg S, Stork B (2015) Deubiquitinase inhibition by WP1130 leads to ULK1 aggregation and blockade of autophagy. Autophagy 11(9):1458-1470

157. Zhou X, Babu JR, da Silva S, Shu Q, Graef IA, Oliver T, Tomoda T, Tani T, Wooten MW, Wang F (2007) Unc-51-like kinase 1/2-mediated endocytic processes regulate filopodia extension and branching of sensory axons. Proc Natl Acad Sci USA 104(14):5842-5847

158. Jiao H, Su GQ, Dong W, Zhang L, Xie W, Yao LM, Chen P, Wang ZX, Liou YC, You H (2015) Chaperone-like protein p32 regulates ULK1 stability and autophagy. Cell Death Differ

159. Li J, Qi W, Chen G, Feng D, Liu J, Ma B, Zhou C, Mu C, Zhang W, Chen Q, Zhu Y (2015) Mitochondrial outer-membrane E3 ligase MUL1 ubiquitinates ULK1 and regulates selenite-induced mitophagy. Autophagy 11(8):1216-1229

160. Nazio F, Strappazzon F, Antonioli M, Bielli P, Cianfanelli V, Bordi M, Gretzmeier C, Dengjel J, Piacentini M, Fimia GM, Cecconi F (2013) mTOR inhibits autophagy by controlling ULK1 ubiquitylation, self-association and function through AMBRA1 and TRAF6. Nat Cell Biol 15(4):406-416

161. Fimia GM, Stoykova A, Romagnoli A, Giunta L, Di Bartolomeo S, Nardacci R, Corazzari M, Fuoco C, Ucar A, Schwartz P, Gruss P, Piacentini M, Chowdhury K, Cecconi F (2007) Ambra1 regulates autophagy and development of the nervous system. Nature 447(7148):1121-1125

162. Di Bartolomeo S, Corazzari M, Nazio F, Oliverio S, Lisi G, Antonioli M, Pagliarini V, Matteoni S, Fuoco C, Giunta L, D'Amelio M, Nardacci R, Romagnoli A, Piacentini M, Cecconi F, Fimia GM (2010) The dynamic interaction of AMBRA1 with the dynein motor complex regulates mammalian autophagy. J Cell Biol 191(1):155-168

163. Gammoh N, Lam D, Puente C, Ganley I, Marks PA, Jiang X (2012) Role of autophagy in histone deacetylase inhibitor-induced apoptotic and nonapoptotic cell death. Proc Natl Acad Sci USA 109(17):6561-6565

164. Lin SY, Li TY, Liu Q, Zhang C, Li X, Chen Y, Zhang SM, Lian G, Ruan K, Wang Z, Zhang CS, Chien KY, Wu J, Li Q, Han J, Lin SC (2012) GSK3-TIP60-ULK1 signaling pathway links growth factor deprivation to autophagy. Science 336(6080):477-481
165. Joshi A, Iyengar R, Joo JH, Li-Harms XJ, Wright C, Marino R, Winborn BJ, Phillips A, Temirov J, Sciarretta S, Kriwacki R, Peng J, Shelat A, Kundu M (2015) Nuclear ULK1 promotes cell death in response to oxidative stress through PARP1. Cell Death Differ

166. Konno H, Konno K, Barber GN (2013) Cyclic dinucleotides trigger ULK1 (ATG1) phosphorylation of STING to prevent sustained innate immune signaling. Cell 155(3):688-698

167. Saleiro D, Mehrotra S, Kroczynska B, Beauchamp EM, Lisowski P, Majchrzak-Kita B, Bhagat TD, Stein BL, McMahon B, Altman JK, Kosciuczuk EM, Baker DP, Jie C, Jafari N, Thompson CB, Levine RL, Fish EN, Verma AK, Platanias LC (2015) Central role of ULK1 in type I interferon signaling. Cell Rep 11(4):605-617

168. Kihara A, Noda T, Ishihara N, Ohsumi Y (2001) Two distinct Vps34 phosphatidylinositol 3-kinase complexes function in autophagy and carboxypeptidase Y sorting in Saccharomyces cerevisiae. J Cell Biol 152(3):519-530

169. Obara K, Ohsumi Y (2011) PtdIns 3-kinase orchestrates autophagosome formation in yeast. J Lipids 2011:498768

170. Obara K, Sekito T, Ohsumi Y (2006) Assortment of phosphatidylinositol 3-kinase complexes-Atg14p directs association of complex I to the pre-autophagosomal structure in Saccharomyces cerevisiae. Mol Biol Cell 17(4):1527-1539

171. Araki Y, Ku WC, Akioka M, May AI, Hayashi Y, Arisaka F, Ishihama Y, Ohsumi Y (2013) Atg38 is required for autophagyspecific phosphatidylinositol 3-kinase complex integrity. J Cell Biol 203(2):299-313

172. Funderburk SF, Wang QJ, Yue Z (2010) The Beclin 1-VPS34 complex - at the crossroads of autophagy and beyond. Trends Cell Biol 20(6):355-362

173. He C, Levine B (2010) The Beclin 1 interactome. Curr Opin Cell Biol 22(2):140-149

174. Kang R, Zeh HJ, Lotze MT, Tang D (2011) The Beclin 1 network regulates autophagy and apoptosis. Cell Death Differ 18(4):571-580

175. Levine B, Liu R, Dong X, Zhong Q (2015) Beclin orthologs: integrative hubs of cell signaling, membrane trafficking, and physiology. Trends Cell Biol 25:533-544

176. Matsunaga K, Noda T, Yoshimori T (2009) Binding rubicon to cross the rubicon. Autophagy 5(6):876-877

177. He C, Wei Y, Sun K, Li B, Dong X, Zou Z, Liu Y, Kinch LN, Khan S, Sinha S, Xavier RJ, Grishin NV, Xiao G, Eskelinen EL, Scherer PE, Whistler JL, Levine B (2013) Beclin 2 functions in autophagy, degradation of $\mathrm{G}$ protein-coupled receptors, and metabolism. Cell 154(5):1085-1099

178. Itakura E, Kishi C, Inoue K, Mizushima N (2008) Beclin 1 forms two distinct phosphatidylinositol 3-kinase complexes with mammalian Atg14 and UVRAG. Mol Biol Cell 19(12):5360-5372

179. Matsunaga K, Saitoh T, Tabata K, Omori H, Satoh T, Kurotori N, Maejima I, Shirahama-Noda K, Ichimura T, Isobe T, Akira S, Noda T, Yoshimori T (2009) Two Beclin 1-binding proteins, Atg14L and Rubicon, reciprocally regulate autophagy at different stages. Nat Cell Biol 11(4):385-396

180. Sun Q, Fan W, Chen K, Ding X, Chen S, Zhong Q (2008) Identification of Barkor as a mammalian autophagy-specific factor for Beclin 1 and class III phosphatidylinositol 3-kinase. Proc Natl Acad Sci USA 105(49):19211-19216

181. Zhong Y, Wang QJ, Li X, Yan Y, Backer JM, Chait BT, Heintz N, Yue Z (2009) Distinct regulation of autophagic activity by Atg14L and Rubicon associated with Beclin 1-phosphatidylinositol-3-kinase complex. Nat Cell Biol 11(4):468-476

182. Diao J, Liu R, Rong Y, Zhao M, Zhang J, Lai Y, Zhou Q, Wilz LM, Li J, Vivona S, Pfuetzner RA, Brunger AT, Zhong Q 
(2015) ATG14 promotes membrane tethering and fusion of autophagosomes to endolysosomes. Nature 520:563-566

183. Itakura E, Kishi-Itakura C, Mizushima N (2012) The hairpintype tail-anchored SNARE syntaxin 17 targets to autophagosomes for fusion with endosomes/lysosomes. Cell 151(6):1256-1269

184. Itakura E, Mizushima N (2009) Atg14 and UVRAG: mutually exclusive subunits of mammalian Beclin 1-PI3K complexes. Autophagy 5(4):534-536

185. Liang C, Feng P, Ku B, Dotan I, Canaani D, Oh BH, Jung JU (2006) Autophagic and tumour suppressor activity of a novel Beclin1-binding protein UVRAG. Nat Cell Biol 8(7):688-699

186. Takahashi Y, Coppola D, Matsushita N, Cualing HD, Sun M, Sato Y, Liang C, Jung JU, Cheng JQ, Mule JJ, Pledger WJ, Wang HG (2007) Bif-1 interacts with Beclin 1 through UVRAG and regulates autophagy and tumorigenesis. Nat Cell Biol 9(10):1142-1151

187. Knaevelsrud H, Ahlquist T, Merok MA, Nesbakken A, Stenmark H, Lothe RA, Simonsen A (2010) UVRAG mutations associated with microsatellite unstable colon cancer do not affect autophagy. Autophagy 6(7):863-870

188. Liang C, Lee JS, Inn KS, Gack MU, Li Q, Roberts EA, Vergne I, Deretic V, Feng P, Akazawa C, Jung JU (2008) Beclin1-binding UVRAG targets the class $\mathrm{C}$ Vps complex to coordinate autophagosome maturation and endocytic trafficking. Nat Cell Biol 10(7):776-787

189. Sun Q, Fan W, Zhong Q (2009) Regulation of Beclin 1 in autophagy. Autophagy 5(5):713-716

190. Cao Y, Wang Y, Abi Saab WF, Yang F, Pessin JE, Backer JM (2014) NRBF2 regulates macroautophagy as a component of Vps34 Complex I. Biochem J 461(2):315-322

191. Lu J, He L, Behrends C, Araki M, Araki K, Jun Wang Q, Catanzaro JM, Friedman SL, Zong WX, Fiel MI, Li M, Yue Z (2014) NRBF2 regulates autophagy and prevents liver injury by modulating Atg14L-linked phosphatidylinositol-3 kinase III activity. Nat Commun 5:3920

192. Zhong Y, Morris DH, Jin L, Patel MS, Karunakaran SK, Fu YJ, Matuszak EA, Weiss HL, Chait BT, Wang QJ (2014) Nrbf2 protein suppresses autophagy by modulating Atg14L proteincontaining Beclin 1-Vps34 complex architecture and reducing intracellular phosphatidylinositol-3 phosphate levels. J Biol Chem 289(38):26021-26037

193. Flores AM, Li L, Aneskievich BJ (2004) Isolation and functional analysis of a keratinocyte-derived, ligand-regulated nuclear receptor comodulator. J Invest Dermatol 123(6):1092-1101

194. Yasumo H, Masuda N, Furusawa T, Tsukamoto T, Sadano H, Osumi T (2000) Nuclear receptor binding factor-2 (NRBF-2), a possible gene activator protein interacting with nuclear hormone receptors. Biochim Biophys Acta 1490(1-2):189-197

195. Baskaran S, Carlson LA, Stjepanovic G, Young LN, Kim do J, Grob P, Stanley RE, Nogales E, Hurley JH (2014) Architecture and dynamics of the autophagic phosphatidylinositol 3-kinase complex. Elife 3:e05115

196. Wei Y, Zou Z, Becker N, Anderson M, Sumpter R, Xiao G, Kinch L, Koduru P, Christudass CS, Veltri RW, Grishin NV, Peyton M, Minna J, Bhagat G, Levine B (2013) EGFR-mediated Beclin 1 phosphorylation in autophagy suppression, tumor progression, and tumor chemoresistance. Cell 154(6):1269-1284

197. John S, Nayvelt I, Hsu HC, Yang P, Liu W, Das GM, Thomas T, Thomas TJ (2008) Regulation of estrogenic effects by beclin 1 in breast cancer cells. Cancer Res 68(19):7855-7863

198. Sagona AP, Nezis IP, Bache KG, Haglund K, Bakken AC, Skotheim RI, Stenmark H (2011) A tumor-associated mutation of FYVE-CENT prevents its interaction with Beclin 1 and interferes with cytokinesis. PLoS ONE 6(3):e17086
199. Kang R, Livesey KM, Zeh HJ, Loze MT, Tang D (2010) HMGB1: a novel Beclin 1-binding protein active in autophagy. Autophagy 6(8):1209-1211

200. Tang D, Kang R, Livesey KM, Cheh CW, Farkas A, Loughran P, Hoppe G, Bianchi ME, Tracey KJ, Zeh HJ 3rd, Lotze MT (2010) Endogenous HMGB1 regulates autophagy. J Cell Biol 190(5):881-892

201. Shi CS, Kehrl JH (2008) MyD88 and Trif target Beclin 1 to trigger autophagy in macrophages. J Biol Chem 283(48):33175-33182

202. Yue Z, Horton A, Bravin M, DeJager PL, Selimi F, Heintz N (2002) A novel protein complex linking the delta 2 glutamate receptor and autophagy: implications for neurodegeneration in lurcher mice. Neuron 35(5):921-933

203. Michiorri S, Gelmetti V, Giarda E, Lombardi F, Romano F, Marongiu R, Nerini-Molteni S, Sale P, Vago R, Arena G, Torosantucci L, Cassina L, Russo MA, Dallapiccola B, Valente EM, Casari G (2010) The Parkinson-associated protein PINK1 interacts with Beclin1 and promotes autophagy. Cell Death Differ 17(6):962-974

204. Ravikumar B, Imarisio S, Sarkar S, O'Kane CJ, Rubinsztein DC (2008) Rab5 modulates aggregation and toxicity of mutant huntingtin through macroautophagy in cell and fly models of Huntington disease. J Cell Sci 121(Pt 10):1649-1660

205. Berger SB, Romero X, Ma C, Wang G, Faubion WA, Liao G, Compeer E, Keszei M, Rameh L, Wang N, Boes M, Regueiro JR, Reinecker HC, Terhorst C (2010) SLAM is a microbial sensor that regulates bacterial phagosome functions in macrophages. Nat Immunol 11(10):920-927

206. Niu TK, Cheng Y, Ren X, Yang JM (2010) Interaction of Beclin 1 with survivin regulates sensitivity of human glioma cells to TRAIL-induced apoptosis. FEBS Lett 584(16):3519-3524

207. Ropolo A, Grasso D, Pardo R, Sacchetti ML, Archange C, Lo Re A, Seux M, Nowak J, Gonzalez CD, Iovanna JL, Vaccaro MI (2007) The pancreatitis-induced vacuole membrane protein 1 triggers autophagy in mammalian cells. J Biol Chem 282(51):37124-37133

208. Kyei GB, Dinkins C, Davis AS, Roberts E, Singh SB, Dong C, Wu L, Kominami E, Ueno T, Yamamoto A, Federico M, Panganiban A, Vergne I, Deretic V (2009) Autophagy pathway intersects with HIV-1 biosynthesis and regulates viral yields in macrophages. J Cell Biol 186(2):255-268

209. Orvedahl A, Alexander D, Talloczy Z, Sun Q, Wei Y, Zhang W, Burns D, Leib DA, Levine B (2007) HSV-1 ICP34.5 confers neurovirulence by targeting the Beclin 1 autophagy protein. Cell Host Microbe 1(1):23-35

210. Gannage M, Dormann D, Albrecht R, Dengjel J, Torossi T, Ramer PC, Lee M, Strowig T, Arrey F, Conenello G, Pypaert M, Andersen J, Garcia-Sastre A, Munz C (2009) Matrix protein 2 of influenza A virus blocks autophagosome fusion with lysosomes. Cell Host Microbe 6(4):367-380

211. Antonioli M, Albiero F, Nazio F, Vescovo T, Perdomo AB, Corazzari M, Marsella C, Piselli P, Gretzmeier C, Dengjel J, Cecconi F, Piacentini M, Fimia GM (2014) AMBRA1 interplay with cullin E3 ubiquitin ligases regulates autophagy dynamics. Dev Cell 31(6):734-746

212. Cianfanelli V, Cecconi F (2015) AMBRA1: when autophagy meets cell proliferation. Autophagy 11(9):1705-1707

213. Cianfanelli V, De Zio D, Di Bartolomeo S, Nazio F, Strappazzon F, Cecconi F (2015) Ambral at a glance. J Cell Sci 128(11):2003-2008

214. Fimia GM, Corazzari M, Antonioli M, Piacentini M (2013) Ambral at the crossroad between autophagy and cell death. Oncogene 32(28):3311-3318

215. Cianfanelli V, Fuoco C, Lorente M, Salazar M, Quondamatteo F, Gherardini PF, De Zio D, Nazio F, Antonioli M, D'Orazio M, 
Skobo T, Bordi M, Rohde M, Dalla Valle L, Helmer-Citterich M, Gretzmeier C, Dengjel J, Fimia GM, Piacentini M, Di Bartolomeo S, Velasco G, Cecconi F (2015) AMBRA1 links autophagy to cell proliferation and tumorigenesis by promoting c-Myc dephosphorylation and degradation. Nat Cell Biol 17(1):20-30

216. E X, Hwang S, Oh S, Lee JS, Jeong JH, Gwack Y, Kowalik TF, Sun R, Jung JU, Liang C (2009) Viral Bcl-2-mediated evasion of autophagy aids chronic infection of gammaherpesvirus 68. PLoS Pathog 5(10):e1000609

217. Feng W, Huang S, Wu H, Zhang M (2007) Molecular basis of Bcl-xL's target recognition versatility revealed by the structure of Bcl-xL in complex with the BH3 domain of Beclin-1. J Mol Biol 372(1):223-235

218. Ku B, Woo JS, Liang C, Lee KH, Hong HS, E X, Kim KS, Jung JU, Oh BH (2008) Structural and biochemical bases for the inhibition of autophagy and apoptosis by viral BCL-2 of murine gamma-herpesvirus 68. PLoS Pathog 4(2):e25

219. Liang XH, Kleeman LK, Jiang HH, Gordon G, Goldman JE, Berry G, Herman B, Levine B (1998) Protection against fatal Sindbis virus encephalitis by beclin, a novel Bcl-2-interacting protein. J Virol 72(11):8586-8596

220. Maiuri MC, Le Toumelin G, Criollo A, Rain JC, Gautier F, Juin P, Tasdemir E, Pierron G, Troulinaki K, Tavernarakis N, Hickman JA, Geneste O, Kroemer G (2007) Functional and physical interaction between $\mathrm{Bcl}-\mathrm{X}(\mathrm{L})$ and a $\mathrm{BH} 3$-like domain in Beclin-1. EMBO J 26(10):2527-2539

221. Oberstein A, Jeffrey PD, Shi Y (2007) Crystal structure of the Bcl-XL-Beclin 1 peptide complex: Beclin 1 is a novel BH3-only protein. J Biol Chem 282(17):13123-13132

222. Pattingre S, Tassa A, Qu X, Garuti R, Liang XH, Mizushima N, Packer M, Schneider MD, Levine B (2005) Bcl-2 antiapoptotic proteins inhibit Beclin 1-dependent autophagy. Cell 122(6):927-939

223. Sinha S, Colbert CL, Becker N, Wei Y, Levine B (2008) Molecular basis of the regulation of Beclin 1-dependent autophagy by the gamma-herpesvirus $68 \mathrm{Bcl}-2$ homolog M11. Autophagy 4(8):989-997

224. Wei Y, Pattingre S, Sinha S, Bassik M, Levine B (2008) JNK1mediated phosphorylation of Bcl-2 regulates starvation-induced autophagy. Mol Cell 30(6):678-688

225. Erlich S, Mizrachy L, Segev O, Lindenboim L, Zmira O, AdiHarel S, Hirsch JA, Stein R, Pinkas-Kramarski R (2007) Differential interactions between Beclin 1 and Bcl-2 family members. Autophagy 3(6):561-568

226. Ciechomska IA, Goemans GC, Skepper JN, Tolkovsky AM (2009) Bcl-2 complexed with Beclin-1 maintains full antiapoptotic function. Oncogene 28(21):2128-2141

227. Maiuri MC, Criollo A, Tasdemir E, Vicencio JM, Tajeddine N, Hickman JA, Geneste O, Kroemer G (2007) BH3-only proteins and $\mathrm{BH} 3$ mimetics induce autophagy by competitively disrupting the interaction between Beclin 1 and $\mathrm{Bcl}-2 / \mathrm{Bcl}-\mathrm{X}(\mathrm{L})$. Autophagy 3(4):374-376

228. Zalckvar E, Berissi H, Mizrachy L, Idelchuk Y, Koren I, Eisenstein M, Sabanay H, Pinkas-Kramarski R, Kimchi A (2009) DAP-kinase-mediated phosphorylation on the BH3 domain of beclin 1 promotes dissociation of beclin 1 from BclXL and induction of autophagy. EMBO Rep 10(3):285-292

229. Liang C, E X, Jung JU (2008) Downregulation of autophagy by herpesvirus Bcl-2 homologs. Autophagy 4(3):268-272

230. Shi CS, Kehrl JH (2010) TRAF6 and A20 regulate lysine 63-linked ubiquitination of Beclin-1 to control TLR4-induced autophagy. Sci Signal 3(123):ra42

231. Ciechomska IA, Goemans CG, Tolkovsky AM (2009) Why doesn't Beclin 1, a BH3-only protein, suppress the anti-apoptotic function of Bcl-2? Autophagy 5(6):880-881
232. Vicencio JM, Ortiz C, Criollo A, Jones AW, Kepp O, Galluzzi L, Joza N, Vitale I, Morselli E, Tailler M, Castedo M, Maiuri MC, Molgo J, Szabadkai G, Lavandero S, Kroemer G (2009) The inositol 1,4,5-trisphosphate receptor regulates autophagy through its interaction with Beclin 1. Cell Death Differ 16(7):1006-1017

233. Cardenas C, Foskett JK (2012) Mitochondrial $\mathrm{Ca}(2+)$ signals in autophagy. Cell Calcium 52(1):44-51

234. Decuypere JP, Bultynck G, Parys JB (2011) A dual role for $\mathrm{Ca}(2+)$ in autophagy regulation. Cell Calcium 50(3):242-250

235. Khan MT, Joseph SK (2010) Role of inositol trisphosphate receptors in autophagy in DT40 cells. J Biol Chem 285(22):16912-16920

236. Decuypere JP, Welkenhuyzen K, Luyten T, Ponsaerts R, Dewaele M, Molgo J, Agostinis P, Missiaen L, De Smedt H, Parys JB, Bultynck G (2011) Ins(1,4,5)P3 receptor-mediated $\mathrm{Ca}^{2+}$ signaling and autophagy induction are interrelated. Autophagy 7(12):1472-1489

237. Chang NC, Nguyen M, Germain M, Shore GC (2010) Antagonism of Beclin 1-dependent autophagy by BCL-2 at the endoplasmic reticulum requires NAF-1. EMBO J 29(3):606-618

238. Decuypere JP, Monaco G, Bultynck G, Missiaen L, De Smedt H (1813) Parys JB (2011) The IP(3) receptor-mitochondria connection in apoptosis and autophagy. Biochim Biophys Acta 5:1003-1013

239. Giorgi C, Baldassari F, Bononi A, Bonora M, De Marchi E, Marchi S, Missiroli S, Patergnani S, Rimessi A, Suski JM, Wieckowski MR, Pinton P (2012) Mitochondrial $\mathrm{Ca}(2+)$ and apoptosis. Cell Calcium 52(1):36-43

240. Monaco G, Vervliet T, Akl H, Bultynck G (2013) The selective BH4-domain biology of Bcl-2-family members: IP3Rs and beyond. Cell Mol Life Sci 70(7):1171-1183

241. Strappazzon F, Vietri-Rudan M, Campello S, Nazio F, Florenzano F, Fimia GM, Piacentini M, Levine B, Cecconi F (2011) Mitochondrial BCL-2 inhibits AMBRA1-induced autophagy. EMBO J 30(7):1195-1208

242. Tooze SA, Codogno $P$ (2011) Compartmentalized regulation of autophagy regulators: fine-tuning AMBRA1 by Bcl-2. EMBO J 30(7):1185-1186

243. Zhou F, Yang Y, Xing D (2011) Bcl-2 and Bcl-xL play important roles in the crosstalk between autophagy and apoptosis. FEBS J 278(3):403-413

244. Wei Y, An Z, Zou Z, Sumpter R, Su M, Zang X, Sinha S, Gaestel M, Levine B (2015) The stress-responsive kinases MAPKAPK2/MAPKAPK3 activate starvation-induced autophagy through Beclin 1 phosphorylation. Elife 4:e05289

245. Noble CG, Dong JM, Manser E, Song H (2008) Bcl-xL and UVRAG cause a monomer-dimer switch in Beclin1. J Biol Chem 283(38):26274-26282

246. Russell RC, Tian Y, Yuan H, Park HW, Chang YY, Kim J, Kim H, Neufeld TP, Dillin A, Guan KL (2013) ULK1 induces autophagy by phosphorylating Beclin-1 and activating VPS34 lipid kinase. Nat Cell Biol 15(7):741-750

247. Kim J, Kim YC, Fang C, Russell RC, Kim JH, Fan W, Liu R, Zhong Q, Guan KL (2013) Differential regulation of distinct Vps34 complexes by AMPK in nutrient stress and autophagy. Cell 152(1-2):290-303

248. Yuan HX, Russell RC, Guan KL (2013) Regulation of PIK3C3/ VPS34 complexes by MTOR in nutrient stress-induced autophagy. Autophagy 9(12):1983-1995

249. Wang RC, Wei Y, An Z, Zou Z, Xiao G, Bhagat G, White M, Reichelt J, Levine B (2012) Akt-mediated regulation of autophagy and tumorigenesis through Beclin 1 phosphorylation. Science 338(6109):956-959

250. Itakura E, Mizushima N (2010) Characterization of autophagosome formation site by a hierarchical analysis of mammalian Atg proteins. Autophagy 6(6):764-776 
251. Matsunaga K, Morita E, Saitoh T, Akira S, Ktistakis NT, Izumi T, Noda T, Yoshimori T (2010) Autophagy requires endoplasmic reticulum targeting of the PI3-kinase complex via Atg14L. J Cell Biol 190(4):511-521

252. Codogno P, Mehrpour M, Proikas-Cezanne T (2012) Canonical and non-canonical autophagy: variations on a common theme of self-eating? Nat Rev Mol Cell Biol 13(1):7-12

253. Scarlatti F, Maffei R, Beau I, Codogno P, Ghidoni R (2008) Role of non-canonical Beclin 1-independent autophagy in cell death induced by resveratrol in human breast cancer cells. Cell Death Differ 15(8):1318-1329

254. Devereaux K, Dall'Armi C, Alcazar-Roman A, Ogasawara Y, Zhou X, Wang F, Yamamoto A, De Camilli P, Di Paolo G (2013) Regulation of mammalian autophagy by class II and III PI 3-kinases through PI3P synthesis. PLoS ONE 8(10):e76405

255. Bago R, Malik N, Munson MJ, Prescott AR, Davies P, Sommer E, Shpiro N, Ward R, Cross D, Ganley IG, Alessi DR (2014) Characterization of VPS34-IN1, a selective inhibitor of Vps34, reveals that the phosphatidylinositol 3-phosphate-binding SGK3 protein kinase is a downstream target of class III phosphoinositide 3-kinase. Biochem J 463(3):413-427

256. Vicinanza M, Korolchuk VI, Ashkenazi A, Puri C, Menzies FM, Clarke JH, Rubinsztein DC (2015) PI(5)P regulates autophagosome biogenesis. Mol Cell 57(2):219-234

257. Tooze SA (2010) The role of membrane proteins in mammalian autophagy. Semin Cell Dev Biol 21(7):677-682

258. Webber JL, Tooze SA (2010) New insights into the function of Atg9. FEBS Lett 584(7):1319-1326

259. Mari M, Griffith J, Rieter E, Krishnappa L, Klionsky DJ, Reggiori F (2010) An Atg9-containing compartment that functions in the early steps of autophagosome biogenesis. J Cell Biol 190(6):1005-1022

260. Yamamoto H, Kakuta S, Watanabe TM, Kitamura A, Sekito T, Kondo-Kakuta C, Ichikawa R, Kinjo M, Ohsumi Y (2012) Atg9 vesicles are an important membrane source during early steps of autophagosome formation. J Cell Biol 198(2):219-233

261. Sekito T, Kawamata T, Ichikawa R, Suzuki K, Ohsumi Y (2009) Atg17 recruits Atg9 to organize the pre-autophagosomal structure. Genes Cells 14(5):525-538

262. Backues SK, Orban DP, Bernard A, Singh K, Cao Y, Klionsky DJ (2015) Atg23 and Atg27 act at the early stages of Atg9 trafficking in S. cerevisiae. Traffic 16(2):172-190

263. Orsi A, Razi M, Dooley HC, Robinson D, Weston AE, Collinson LM, Tooze SA (2012) Dynamic and transient interactions of Atg9 with autophagosomes, but not membrane integration, are required for autophagy. Mol Biol Cell 23(10):1860-1873

264. Young AR, Chan EY, Hu XW, Kochl R, Crawshaw SG, High S, Hailey DW, Lippincott-Schwartz J, Tooze SA (2006) Starvation and ULK1-dependent cycling of mammalian Atg9 between the TGN and endosomes. J Cell Sci 119(Pt 18):3888-3900

265. Itakura E, Kishi-Itakura C, Koyama-Honda I, Mizushima N (2012) Structures containing Atg9A and the ULK1 complex independently target depolarized mitochondria at initial stages of Parkin-mediated mitophagy. J Cell Sci 125(Pt 6):1488-1499

266. Kageyama S, Omori H, Saitoh T, Sone T, Guan JL, Akira S, Imamoto F, Noda T, Yoshimori T (2011) The LC3 recruitment mechanism is separate from Atg9L1-dependent membrane formation in the autophagic response against Salmonella. Mol Biol Cell 22(13):2290-2300

267. Popovic D, Dikic I (2014) TBC1D5 and the AP2 complex regulate ATG9 trafficking and initiation of autophagy. EMBO Rep 15(4):392-401

268. Puri C, Renna M, Bento CF, Moreau K, Rubinsztein DC (2013) Diverse autophagosome membrane sources coalesce in recycling endosomes. Cell 154(6):1285-1299
269. Proikas-Cezanne T, Waddell S, Gaugel A, Frickey T, Lupas A, Nordheim A (2004) WIPI-1alpha (WIPI49), a member of the novel 7-bladed WIPI protein family, is aberrantly expressed in human cancer and is linked to starvation-induced autophagy. Oncogene 23(58):9314-9325

270. Stromhaug PE, Reggiori F, Guan J, Wang CW, Klionsky DJ (2004) Atg21 is a phosphoinositide binding protein required for efficient lipidation and localization of Atg8 during uptake of aminopeptidase I by selective autophagy. Mol Biol Cell 15(8):3553-3566

271. Stenmark H, Aasland R, Toh BH, D'Arrigo A (1996) Endosomal localization of the autoantigen EEA1 is mediated by a zincbinding FYVE finger. J Biol Chem 271(39):24048-24054

272. Michell RH, Heath VL, Lemmon MA, Dove SK (2006) Phosphatidylinositol 3,5-bisphosphate: metabolism and cellular functions. Trends Biochem Sci 31(1):52-63

273. Dove SK, Piper RC, McEwen RK, Yu JW, King MC, Hughes DC, Thuring J, Holmes AB, Cooke FT, Michell RH, Parker PJ, Lemmon MA (2004) Svplp defines a family of phosphatidylinositol 3,5-bisphosphate effectors. EMBO J 23(9):1922-1933

274. Jeffries TR, Dove SK, Michell RH, Parker PJ (2004) PtdInsspecific MPR pathway association of a novel WD40 repeat protein, WIPI49. Mol Biol Cell 15(6):2652-2663

275. Baskaran S, Ragusa MJ, Boura E, Hurley JH (2012) Two-site recognition of phosphatidylinositol 3-phosphate by PROPPINs in autophagy. Mol Cell 47(3):339-348

276. Krick R, Busse RA, Scacioc A, Stephan M, Janshoff A, Thumm M, Kuhnel K (2012) Structural and functional characterization of the two phosphoinositide binding sites of PROPPINs, a betapropeller protein family. Proc Natl Acad Sci USA 109(30):E2042-E2049

277. Barth H, Meiling-Wesse K, Epple UD, Thumm M (2001) Autophagy and the cytoplasm to vacuole targeting pathway both require Aut10p. FEBS Lett 508(1):23-28

278. Barth H, Meiling-Wesse K, Epple UD, Thumm M (2002) Mailp is essential for maturation of proaminopeptidase I but not for autophagy. FEBS Lett 512(1-3):173-179

279. Krick R, Henke S, Tolstrup J, Thumm M (2008) Dissecting the localization and function of Atg18, Atg21 and Ygr223c. Autophagy 4(7):896-910

280. Nair U, Cao Y, Xie Z, Klionsky DJ (2010) Roles of the lipidbinding motifs of Atg18 and Atg21 in the cytoplasm to vacuole targeting pathway and autophagy. J Biol Chem 285(15):11476-11488

281. Obara K, Sekito T, Niimi K, Ohsumi Y (2008) The Atg18-Atg2 complex is recruited to autophagic membranes via phosphatidylinositol 3-phosphate and exerts an essential function. J Biol Chem 283(35):23972-23980

282. Kobayashi T, Suzuki K, Ohsumi Y (2012) Autophagosome formation can be achieved in the absence of Atg18 by expressing engineered PAS-targeted Atg2. FEBS Lett 586(16):2473-2478

283. Polson HE, de Lartigue J, Rigden DJ, Reedijk M, Urbe S, Clague MJ, Tooze SA (2010) Mammalian Atg18 (WIPI2) localizes to omegasome-anchored phagophores and positively regulates LC3 lipidation. Autophagy 6(4):506-522

284. Dooley HC, Razi M, Polson HE, Girardin SE, Wilson MI, Tooze SA (2014) WIPI2 links LC3 conjugation with PI3P, autophagosome formation, and pathogen clearance by recruiting Atg12-5-16L1. Mol Cell 55(2):238-252

285. Velikkakath AK, Nishimura T, Oita E, Ishihara N, Mizushima N (2012) Mammalian Atg2 proteins are essential for autophagosome formation and important for regulation of size and distribution of lipid droplets. Mol Biol Cell 23(5):896-909

286. Geng J, Klionsky DJ (2008) The Atg8 and Atg12 ubiquitin-like conjugation systems in macroautophagy. 'Protein modifications: 
beyond the usual suspects' review series. EMBO Rep 9(9):859-864

287. Mizushima N, Noda T, Yoshimori T, Tanaka Y, Ishii T, George MD, Klionsky DJ, Ohsumi M, Ohsumi Y (1998) A protein conjugation system essential for autophagy. Nature 395(6700):395-398

288. Shintani T, Mizushima N, Ogawa Y, Matsuura A, Noda T, Ohsumi Y (1999) Apg10p, a novel protein-conjugating enzyme essential for autophagy in yeast. EMBO J 18(19):5234-5241

289. Tanida I, Mizushima N, Kiyooka M, Ohsumi M, Ueno T, Ohsumi Y, Kominami E (1999) Apg7p/Cvt2p: a novel proteinactivating enzyme essential for autophagy. Mol Biol Cell 10(5):1367-1379

290. Kuma A, Mizushima N, Ishihara N, Ohsumi Y (2002) Formation of the approximately 350-kDa Apg12-Apg5.Apg16 multimeric complex, mediated by Apg 16 oligomerization, is essential for autophagy in yeast. J Biol Chem 277(21):18619-18625

291. Mizushima N, Noda T, Ohsumi Y (1999) Apg16p is required for the function of the Apg12p-Apg5p conjugate in the yeast autophagy pathway. EMBO J 18(14):3888-3896

292. Mizushima N, Kuma A, Kobayashi Y, Yamamoto A, Matsubae M, Takao T, Natsume T, Ohsumi Y, Yoshimori T (2003) Mouse Apg16L, a novel WD-repeat protein, targets to the autophagic isolation membrane with the Apg12-Apg5 conjugate. J Cell Sci 116(Pt 9):1679-1688

293. Mizushima N, Sugita H, Yoshimori T, Ohsumi Y (1998) A new protein conjugation system in human. The counterpart of the yeast Apg12p conjugation system essential for autophagy. J Biol Chem 273(51):33889-33892

294. Mizushima N, Yoshimori T, Ohsumi Y (2002) Mouse Apg10 as an Apg12-conjugating enzyme: analysis by the conjugationmediated yeast two-hybrid method. FEBS Lett 532(3):450-454

295. Tanida I, Tanida-Miyake E, Ueno T, Kominami E (2001) The human homolog of Saccharomyces cerevisiae Apg7p is a Protein-activating enzyme for multiple substrates including human Apg12p, GATE-16, GABARAP, and MAP-LC3. J Biol Chem 276(3):1701-1706

296. Fujioka Y, Noda NN, Nakatogawa H, Ohsumi Y, Inagaki $F$ (2010) Dimeric coiled-coil structure of Saccharomyces cerevisiae Atg16 and its functional significance in autophagy. J Biol Chem 285(2):1508-1515

297. Komatsu M, Waguri S, Ueno T, Iwata J, Murata S, Tanida I, Ezaki J, Mizushima N, Ohsumi Y, Uchiyama Y, Kominami E, Tanaka K, Chiba T (2005) Impairment of starvation-induced and constitutive autophagy in Atg7-deficient mice. J Cell Biol 169(3):425-434

298. Kuma A, Hatano M, Matsui M, Yamamoto A, Nakaya H, Yoshimori T, Ohsumi Y, Tokuhisa T, Mizushima N (2004) The role of autophagy during the early neonatal starvation period. Nature 432(7020):1032-1036

299. Sou YS, Waguri S, Iwata J, Ueno T, Fujimura T, Hara T, Sawada N, Yamada A, Mizushima N, Uchiyama Y, Kominami E, Tanaka K, Komatsu M (2008) The Atg8 conjugation system is indispensable for proper development of autophagic isolation membranes in mice. Mol Biol Cell 19(11):4762-4775

300. Ichimura Y, Kirisako T, Takao T, Satomi Y, Shimonishi Y, Ishihara N, Mizushima N, Tanida I, Kominami E, Ohsumi M, Noda T, Ohsumi Y (2000) A ubiquitin-like system mediates protein lipidation. Nature 408(6811):488-492

301. Kirisako T, Ichimura Y, Okada H, Kabeya Y, Mizushima N, Yoshimori T, Ohsumi M, Takao T, Noda T, Ohsumi Y (2000) The reversible modification regulates the membrane-binding state of Apg8/Aut7 essential for autophagy and the cytoplasm to vacuole targeting pathway. J Cell Biol 151(2):263-276

302. Fujioka Y, Noda NN, Fujii K, Yoshimoto K, Ohsumi Y, Inagaki F (2008) In vitro reconstitution of plant Atg8 and Atg12 conjugation systems essential for autophagy. J Biol Chem 283(4):1921-1928

303. Hanada T, Noda NN, Satomi Y, Ichimura Y, Fujioka Y, Takao T, Inagaki F, Ohsumi Y (2007) The Atg12-Atg5 conjugate has a novel E3-like activity for protein lipidation in autophagy. J Biol Chem 282(52):37298-37302

304. Noda NN, Fujioka Y, Hanada T, Ohsumi Y, Inagaki F (2013) Structure of the Atg12-Atg5 conjugate reveals a platform for stimulating Atg8-PE conjugation. EMBO Rep 14(2):206-211

305. Sakoh-Nakatogawa M, Matoba K, Asai E, Kirisako H, Ishii J, Noda NN, Inagaki F, Nakatogawa H, Ohsumi Y (2013) Atg12Atg5 conjugate enhances E2 activity of Atg3 by rearranging its catalytic site. Nat Struct Mol Biol 20(4):433-439

306. Bai H, Inoue J, Kawano T, Inazawa J (2012) A transcriptional variant of the LC3A gene is involved in autophagy and frequently inactivated in human cancers. Oncogene 31(40):4397-4408

307. He H, Dang Y, Dai F, Guo Z, Wu J, She X, Pei Y, Chen Y, Ling W, Wu C, Zhao S, Liu JO, Yu L (2003) Post-translational modifications of three members of the human MAP1LC3 family and detection of a novel type of modification for MAP1LC3B. J Biol Chem 278(31):29278-29287

308. Hemelaar J, Lelyveld VS, Kessler BM, Ploegh HL (2003) A single protease, Apg4B, is specific for the autophagy-related ubiquitin-like proteins GATE-16, MAP1-LC3, GABARAP, and Apg8L. J Biol Chem 278(51):51841-51850

309. Kabeya Y, Mizushima N, Yamamoto A, Oshitani-Okamoto S, Ohsumi Y, Yoshimori T (2004) LC3, GABARAP and GATE16 localize to autophagosomal membrane depending on form-II formation. J Cell Sci 117(Pt 13):2805-2812

310. Paz Y, Elazar Z, Fass D (2000) Structure of GATE-16, membrane transport modulator and mammalian ortholog of autophagocytosis factor Aut7p. J Biol Chem 275(33):25445-25450

311. Shpilka T, Weidberg H, Pietrokovski S, Elazar Z (2011) Atg8: an autophagy-related ubiquitin-like protein family. Genome Biol 12(7):226

312. Tanida I, Komatsu M, Ueno T, Kominami E (2003) GATE-16 and GABARAP are authentic modifiers mediated by Apg7 and Apg3. Biochem Biophys Res Commun 300(3):637-644

313. Tanida I, Sou YS, Minematsu-Ikeguchi N, Ueno T, Kominami E (2006) Atg8L/Apg8L is the fourth mammalian modifier of mammalian Atg8 conjugation mediated by human Atg4B, Atg7 and Atg3. FEBS J 273(11):2553-2562

314. Weidberg H, Shvets E, Shpilka T, Shimron F, Shinder V, Elazar Z (2010) LC3 and GATE-16/GABARAP subfamilies are both essential yet act differently in autophagosome biogenesis. EMBO J 29(11):1792-1802

315. Xin Y, Yu L, Chen Z, Zheng L, Fu Q, Jiang J, Zhang P, Gong R, Zhao S (2001) Cloning, expression patterns, and chromosome localization of three human and two mouse homologues of GABA(A) receptor-associated protein. Genomics 74(3):408-413

316. Marino G, Uria JA, Puente XS, Quesada V, Bordallo J, LopezOtin C (2003) Human autophagins, a family of cysteine proteinases potentially implicated in cell degradation by autophagy. J Biol Chem 278(6):3671-3678

317. Scherz-Shouval R, Sagiv Y, Shorer H, Elazar Z (2003) The $\mathrm{COOH}$ terminus of GATE-16, an intra-Golgi transport modulator, is cleaved by the human cysteine protease $\mathrm{HsApg} 4 \mathrm{~A}$. J Biol Chem 278(16):14053-14058

318. Kabeya Y, Mizushima N, Ueno T, Yamamoto A, Kirisako T, Noda T, Kominami E, Ohsumi Y, Yoshimori T (2000) LC3, a mammalian homologue of yeast Apg8p, is localized in autophagosome membranes after processing. EMBO $\mathrm{J}$ 19(21):5720-5728 
319. Li M, Hou Y, Wang J, Chen X, Shao ZM, Yin XM (2011) Kinetics comparisons of mammalian Atg4 homologues indicate selective preferences toward diverse Atg8 substrates. J Biol Chem 286(9):7327-7338

320. Tanida I, Tanida-Miyake E, Komatsu M, Ueno T, Kominami E (2002) Human Apg3p/Aut1p homologue is an authentic E2 enzyme for multiple substrates, GATE-16, GABARAP, and MAP-LC3, and facilitates the conjugation of hApg12p to hApg5p. J Biol Chem 277(16):13739-13744

321. Mizushima N, Yamamoto A, Hatano M, Kobayashi Y, Kabeya Y, Suzuki K, Tokuhisa T, Ohsumi Y, Yoshimori T (2001) Dissection of autophagosome formation using Apg5-deficient mouse embryonic stem cells. J Cell Biol 152(4):657-668

322. Fujita N, Itoh T, Omori H, Fukuda M, Noda T, Yoshimori T (2008) The Atg16L complex specifies the site of LC3 lipidation for membrane biogenesis in autophagy. Mol Biol Cell 19(5):2092-2100

323. Tanida I, Sou YS, Ezaki J, Minematsu-Ikeguchi N, Ueno T, Kominami E (2004) HsAtg4B/HsApg4B/autophagin-1 cleaves the carboxyl termini of three human Atg8 homologues and delipidates microtubule-associated protein light chain 3- and GABAA receptor-associated protein-phospholipid conjugates. J Biol Chem 279(35):36268-36276

324. Jiang H, Cheng D, Liu W, Peng J, Feng J (2010) Protein kinase C inhibits autophagy and phosphorylates LC3. Biochem Biophys Res Commun 395(4):471-476

325. Cherra SJ 3rd, Kulich SM, Uechi G, Balasubramani M, Mountzouris J, Day BW, Chu CT (2010) Regulation of the autophagy protein LC3 by phosphorylation. J Cell Biol 190(4):533-539

326. Nakatogawa H, Ichimura Y, Ohsumi Y (2007) Atg8, a ubiquitinlike protein required for autophagosome formation, mediates membrane tethering and hemifusion. Cell 130(1):165-178

327. Xie Z, Nair U, Klionsky DJ (2008) Atg8 controls phagophore expansion during autophagosome formation. Mol Biol Cell 19(8):3290-3298

328. von Muhlinen N, Akutsu M, Ravenhill BJ, Foeglein A, Bloor S, Rutherford TJ, Freund SM, Komander D, Randow F (2012) LC3C, bound selectively by a noncanonical LIR motif in NDP52, is required for antibacterial autophagy. Mol Cell 48(3):329-342

329. Dikic I, Johansen T, Kirkin V (2010) Selective autophagy in cancer development and therapy. Cancer Res 70(9):3431-3434

330. Johansen T, Lamark T (2011) Selective autophagy mediated by autophagic adapter proteins. Autophagy 7(3):279-296

331. Kirkin V, McEwan DG, Novak I, Dikic I (2009) A role for ubiquitin in selective autophagy. Mol Cell 34(3):259-269

332. Kraft C, Peter M, Hofmann K (2010) Selective autophagy: ubiquitin-mediated recognition and beyond. Nat Cell Biol 12(9):836-841

333. Shaid S, Brandts CH, Serve H, Dikic I (2013) Ubiquitination and selective autophagy. Cell Death Differ 20(1):21-30

334. Sumpter R Jr, Levine B (2010) Autophagy and innate immunity: triggering, targeting and tuning. Semin Cell Dev Biol 21(7):699-711

335. Bjorkoy G, Lamark T, Brech A, Outzen H, Perander M, Overvatn A, Stenmark H, Johansen T (2005) p62/SQSTM1 forms protein aggregates degraded by autophagy and has a protective effect on huntingtin-induced cell death. J Cell Biol 171(4):603-614

336. Pankiv S, Clausen TH, Lamark T, Brech A, Bruun JA, Outzen H, Overvatn A, Bjorkoy G, Johansen T (2007) p62/SQSTM1 binds directly to $\operatorname{Atg} 8 / \mathrm{LC} 3$ to facilitate degradation of ubiquitinated protein aggregates by autophagy. J Biol Chem 282(33):24131-24145

337. Ichimura Y, Kumanomidou T, Sou YS, Mizushima T, Ezaki J, Ueno T, Kominami E, Yamane T, Tanaka K, Komatsu M (2008)
Structural basis for sorting mechanism of p62 in selective autophagy. J Biol Chem 283(33):22847-22857

338. Noda NN, Ohsumi Y, Inagaki F (2010) Atg8-family interacting motif crucial for selective autophagy. FEBS Lett 584(7):1379-1385

339. Alemu EA, Lamark T, Torgersen KM, Birgisdottir AB, Larsen KB, Jain A, Olsvik H, Overvatn A, Kirkin V, Johansen T (2012) ATG8 family proteins act as scaffolds for assembly of the ULK complex: sequence requirements for LC3-interacting region (LIR) motifs. J Biol Chem 287(47):39275-39290

340. Itakura E, Mizushima N (2011) p62 Targeting to the autophagosome formation site requires self-oligomerization but not LC3 binding. J Cell Biol 192(1):17-27

341. Kirkin V, Lamark T, Sou YS, Bjorkoy G, Nunn JL, Bruun JA, Shvets E, McEwan DG, Clausen TH, Wild P, Bilusic I, Theurillat JP, Overvatn A, Ishii T, Elazar Z, Komatsu M, Dikic I, Johansen T (2009) A role for NBR1 in autophagosomal degradation of ubiquitinated substrates. Mol Cell 33(4):505-516

342. Lu K, Psakhye I, Jentsch S (2014) Autophagic clearance of polyQ proteins mediated by ubiquitin-Atg8 adaptors of the conserved CUET protein family. Cell 158(3):549-563

343. Sandilands E, Serrels B, McEwan DG, Morton JP, Macagno JP, McLeod K, Stevens C, Brunton VG, Langdon WY, Vidal M, Sansom OJ, Dikic I, Wilkinson S, Frame MC (2012) Autophagic targeting of Src promotes cancer cell survival following reduced FAK signalling. Nat Cell Biol 14(1):51-60

344. Thurston TL, Ryzhakov G, Bloor S, von Muhlinen N, Randow F (2009) The TBK1 adaptor and autophagy receptor NDP52 restricts the proliferation of ubiquitin-coated bacteria. Nat Immunol 10(11):1215-1221

345. Wild P, Farhan H, McEwan DG, Wagner S, Rogov VV, Brady NR, Richter B, Korac J, Waidmann O, Choudhary C, Dotsch V, Bumann D, Dikic I (2011) Phosphorylation of the autophagy receptor optineurin restricts Salmonella growth. Science 333(6039):228-233

346. Stolz A, Ernst A, Dikic I (2014) Cargo recognition and trafficking in selective autophagy. Nat Cell Biol 16(6):495-501

347. Khaminets A, Heinrich T, Mari M, Grumati P, Huebner AK, Akutsu M, Liebmann L, Stolz A, Nietzsche S, Koch N, Mauthe M, Katona I, Qualmann B, Weis J, Reggiori F, Kurth I, Hubner CA, Dikic I (2015) Regulation of endoplasmic reticulum turnover by selective autophagy. Nature 522(7556):354-358

348. Mancias JD, Wang X, Gygi SP, Harper JW, Kimmelman AC (2014) Quantitative proteomics identifies NCOA4 as the cargo receptor mediating ferritinophagy. Nature 509(7498):105-109

349. Ashrafi G, Schwarz TL (2013) The pathways of mitophagy for quality control and clearance of mitochondria. Cell Death Differ 20(1):31-42

350. Novak I (2012) Mitophagy: a complex mechanism of mitochondrial removal. Antioxid Redox Signal 17(5):794-802

351. Youle RJ, Narendra DP (2011) Mechanisms of mitophagy. Nat Rev Mol Cell Biol 12(1):9-14

352. Sarraf SA, Raman M, Guarani-Pereira V, Sowa ME, Huttlin EL, Gygi SP, Harper JW (2013) Landscape of the PARKIN-dependent ubiquitylome in response to mitochondrial depolarization. Nature 496(7445):372-376

353. Wong YC, Holzbaur EL (2014) Optineurin is an autophagy receptor for damaged mitochondria in parkin-mediated mitophagy that is disrupted by an ALS-linked mutation. Proc Natl Acad Sci USA 111(42):E4439-E4448

354. Kane LA, Lazarou M, Fogel AI, Li Y, Yamano K, Sarraf SA, Banerjee S, Youle RJ (2014) PINK1 phosphorylates ubiquitin to activate Parkin E3 ubiquitin ligase activity. J Cell Biol 205(2):143-153

355. Kazlauskaite A, Kondapalli C, Gourlay R, Campbell DG, Ritorto MS, Hofmann K, Alessi DR, Knebel A, Trost M, Muqit 
MM (2014) Parkin is activated by PINK1-dependent phosphorylation of ubiquitin at Ser65. Biochem J 460(1):127-139

356. Koyano F, Okatsu K, Kosako H, Tamura Y, Go E, Kimura M, Kimura Y, Tsuchiya H, Yoshihara H, Hirokawa T, Endo T, Fon EA, Trempe JF, Saeki Y, Tanaka K, Matsuda N (2014) Ubiquitin is phosphorylated by PINK1 to activate parkin. Nature 510(7503):162-166

357. Lazarou M, Sliter DA, Kane LA, Sarraf SA, Wang C, Burman JL, Sideris DP, Fogel AI, Youle RJ (2015) The ubiquitin kinase PINK1 recruits autophagy receptors to induce mitophagy. Nature 524:309-314

358. Chu CT, Bayir H, Kagan VE (2014) LC3 binds externalized cardiolipin on injured mitochondria to signal mitophagy in neurons: implications for Parkinson disease. Autophagy 10(2):376-378

359. Strappazzon F, Nazio F, Corrado M, Cianfanelli V, Romagnoli A, Fimia GM, Campello S, Nardacci R, Piacentini M, Campanella M, Cecconi F (2015) AMBRA1 is able to induce mitophagy via LC3 binding, regardless of PARKIN and p62/ SQSTM1. Cell Death Differ 22(3):419-432

360. Ogawa M, Yoshikawa Y, Kobayashi T, Mimuro H, Fukumatsu M, Kiga K, Piao Z, Ashida H, Yoshida M, Kakuta S, Koyama T, Goto Y, Nagatake T, Nagai S, Kiyono H, Kawalec M, Reichhart JM, Sasakawa C (2011) A Tecpr1-dependent selective autophagy pathway targets bacterial pathogens. Cell Host Microbe 9(5):376-389

361. Lim J, Lachenmayer ML, Wu S, Liu W, Kundu M, Wang R, Komatsu M, Oh YJ, Zhao Y, Yue Z (2015) Proteotoxic stress induces phosphorylation of p62/SQSTM1 by ULK1 to regulate selective autophagic clearance of protein aggregates. PLoS Genet 11(2):e1004987

362. Matsumoto G, Wada K, Okuno M, Kurosawa M, Nukina N (2011) Serine 403 phosphorylation of p62/SQSTM1 regulates selective autophagic clearance of ubiquitinated proteins. Mol Cell 44(2):279-289

363. Cha-Molstad H, Sung KS, Hwang J, Kim KA, Yu JE, Yoo YD, Jang JM, Han DH, Molstad M, Kim JG, Lee YJ, Zakrzewska A, Kim SH, Kim ST, Kim SY, Lee HG, Soung NK, Ahn JS, Ciechanover A, Kim BY, Kwon YT (2015) Amino-terminal arginylation targets endoplasmic reticulum chaperone $\mathrm{BiP}$ for autophagy through p62 binding. Nat Cell Biol 17(7):917-929

364. Kaufmann A, Beier V, Franquelim HG, Wollert T (2014) Molecular mechanism of autophagic membrane-scaffold assembly and disassembly. Cell 156(3):469-481

365. Okazaki N, Yan J, Yuasa S, Ueno T, Kominami E, Masuho Y, Koga H, Muramatsu M (2000) Interaction of the Unc-51-like kinase and microtubule-associated protein light chain 3 related proteins in the brain: possible role of vesicular transport in axonal elongation. Brain Res Mol Brain Res 85(1-2):1-12

366. Nakatogawa H, Ohbayashi S, Sakoh-Nakatogawa M, Kakuta S, Suzuki SW, Kirisako H, Kondo-Kakuta C, Noda NN, Yamamoto H, Ohsumi Y (2012) The autophagy-related protein kinase Atg1 interacts with the ubiquitin-like protein Atg8 via the Atg8 family interacting motif to facilitate autophagosome formation. J Biol Chem 287(34):28503-28507

367. Klionsky DJ, Abdalla FC, Abeliovich H, Abraham RT, Acevedo-Arozena A, Adeli K, Agholme L, Agnello M, Agostinis P, Aguirre-Ghiso JA, Ahn HJ, Ait-Mohamed O, Ait-Si-Ali S, Akematsu T, Akira S, Al-Younes HM, Al-Zeer MA, Albert ML, Albin RL, Alegre-Abarrategui J, Aleo MF, Alirezaei M, Almasan A, Almonte-Becerril M, Amano A et al (2012) Guidelines for the use and interpretation of assays for monitoring autophagy. Autophagy 8(4):445-544

368. Kimura S, Noda T, Yoshimori T (2007) Dissection of the autophagosome maturation process by a novel reporter protein, tandem fluorescent-tagged LC3. Autophagy 3(5):452-460
369. Zhou C, Zhong W, Zhou J, Sheng F, Fang Z, Wei Y, Chen Y, Deng X, Xia B, Lin J (2012) Monitoring autophagic flux by an improved tandem fluorescent-tagged LC3 (mTagRFP-mWasabiLC3) reveals that high-dose rapamycin impairs autophagic flux in cancer cells. Autophagy 8(8):1215-1226

370. Yu ZQ, Ni T, Hong B, Wang HY, Jiang FJ, Zou S, Chen Y, Zheng XL, Klionsky DJ, Liang Y, Xie Z (2012) Dual roles of Atg8-PE deconjugation by Atg4 in autophagy. Autophagy 8(6):883-892

371. Mizushima N, Yoshimori T, Levine B (2010) Methods in mammalian autophagy research. Cell 140(3):313-326

372. McAlpine F, Williamson LE, Tooze SA, Chan EY (2013) Regulation of nutrient-sensitive autophagy by uncoordinated 51-like kinases 1 and 2. Autophagy 9(3):361-373

373. Zeng X, Overmeyer JH, Maltese WA (2006) Functional specificity of the mammalian Beclin-Vps34 PI 3-kinase complex in macroautophagy versus endocytosis and lysosomal enzyme trafficking. J Cell Sci 119(Pt 2):259-270

374. Szalai P, Hagen LK, Saetre F, Luhr M, Sponheim M, Overbye A, Mills IG, Seglen PO, Engedal N (2015) Autophagic bulk sequestration of cytosolic cargo is independent of LC3, but requires GABARAPs. Exp Cell Res 333(1):21-38

375. Sanjuan MA, Dillon CP, Tait SW, Moshiach S, Dorsey F, Connell S, Komatsu M, Tanaka K, Cleveland JL, Withoff S, Green DR (2007) Toll-like receptor signalling in macrophages links the autophagy pathway to phagocytosis. Nature 450(7173):1253-1257

376. Florey O, Kim SE, Sandoval CP, Haynes CM, Overholtzer M (2011) Autophagy machinery mediates macroendocytic processing and entotic cell death by targeting single membranes. Nat Cell Biol 13(11):1335-1343

377. Martinez J, Almendinger J, Oberst A, Ness R, Dillon CP, Fitzgerald P, Hengartner MO, Green DR (2011) Microtubuleassociated protein 1 light chain 3 alpha (LC3)-associated phagocytosis is required for the efficient clearance of dead cells. Proc Natl Acad Sci USA 108(42):17396-17401

378. Florey O, Overholtzer M (2012) Autophagy proteins in macroendocytic engulfment. Trends Cell Biol 22(7):374-380

379. Suzuki K, Akioka M, Kondo-Kakuta C, Yamamoto H, Ohsumi Y (2013) Fine mapping of autophagy-related proteins during autophagosome formation in Saccharomyces cerevisiae. J Cell Sci 126:2534-2544

380. Noda T, Kageyama S, Fujita N, Yoshimori T (2012) Three-axis model for Atg recruitment in autophagy against Salmonella. Int J Cell Biol 2012:389562

381. Koyama-Honda I, Itakura E, Fujiwara TK, Mizushima N (2013) Temporal analysis of recruitment of mammalian ATG proteins to the autophagosome formation site. Autophagy 9(10):1491-1499

382. Farre JC, Subramani S (2011) Rallying the exocyst as an autophagy scaffold. Cell 144(2):172-174

383. Bodemann BO, Orvedahl A, Cheng T, Ram RR, Ou YH, Formstecher E, Maiti M, Hazelett CC, Wauson EM, Balakireva M, Camonis JH, Yeaman C, Levine B, White MA (2011) RalB and the exocyst mediate the cellular starvation response by direct activation of autophagosome assembly. Cell 144(2):253-267

384. Mandell MA, Jain A, Arko-Mensah J, Chauhan S, Kimura T, Dinkins C, Silvestri G, Munch J, Kirchhoff F, Simonsen A, Wei Y, Levine B, Johansen T, Deretic V (2014) TRIM proteins regulate autophagy and can target autophagic substrates by direct recognition. Dev Cell 30(4):394-409

385. Mandell MA, Kimura T, Jain A, Johansen T, Deretic V (2014) TRIM proteins regulate autophagy: TRIM5 is a selective autophagy receptor mediating HIV-1 restriction. Autophagy 10(12):2387-2388 
386. Chauhan S, Mandell MA, Deretic V (2015) IRGM governs the core autophagy machinery to conduct antimicrobial defense. Mol Cell 58(3):507-521

387. Settembre C, Ballabio A (2014) Cell metabolism: autophagy transcribed. Nature 516(7529):40-41

388. Long JS, Ryan KM (2012) New frontiers in promoting tumour cell death: targeting apoptosis, necroptosis and autophagy. Oncogene 31:5045-5060

389. Chen N, Karantza V (2011) Autophagy as a therapeutic target in cancer. Cancer Biol Ther 11(2):157-168

390. Brech A, Ahlquist T, Lothe RA, Stenmark H (2009) Autophagy in tumour suppression and promotion. Mol Oncol 3(4):366-375

391. Thorburn A, Thamm DH, Gustafson DL (2014) Autophagy and cancer therapy. Mol Pharmacol 85(6):830-838

392. Rosenfeldt MT, Ryan KM (2009) The role of autophagy in tumour development and cancer therapy. Expert Rev Mol Med 11:e36

393. Dowdle WE, Nyfeler B, Nagel J, Elling RA, Liu S, Triantafellow E, Menon S, Wang Z, Honda A, Pardee G, Cantwell J, Luu C, Cornella-Taracido I, Harrington E, Fekkes P, Lei H, Fang Q, Digan ME, Burdick D, Powers AF, Helliwell SB, D'Aquin S, Bastien J, Wang H, Wiederschain D et al (2014) Selective VPS34 inhibitor blocks autophagy and uncovers a role for NCOA4 in ferritin degradation and iron homeostasis in vivo. Nat Cell Biol 16(11):1069-1079

394. Ronan B, Flamand O, Vescovi L, Dureuil C, Durand L, Fassy F, Bachelot MF, Lamberton A, Mathieu M, Bertrand T, Marquette JP, El-Ahmad Y, Filoche-Romme B, Schio L, Garcia-Echeverria C, Goulaouic H, Pasquier B (2014) A highly potent and selective Vps34 inhibitor alters vesicle trafficking and autophagy. Nat Chem Biol 10(12):1013-1019

395. Petherick KJ, Conway OJ, Mpamhanga C, Osborne SA, Kamal A, Saxty B, Ganley IG (2015) Pharmacological inhibition of ULK1 kinase blocks mammalian target of rapamycin (mTOR)dependent autophagy. J Biol Chem 290(18):11376-11383

396. Hara K, Maruki Y, Long X, Yoshino K, Oshiro N, Hidayat S, Tokunaga C, Avruch J, Yonezawa K (2002) Raptor, a binding partner of target of rapamycin (TOR), mediates TOR action. Cell 110(2):177-189

397. Kim DH, Sarbassov DD, Ali SM, King JE, Latek RR, Erdjument-Bromage H, Tempst P, Sabatini DM (2002) mTOR interacts with raptor to form a nutrient-sensitive complex that signals to the cell growth machinery. Cell 110(2):163-175

398. Sarbassov DD, Ali SM, Kim DH, Guertin DA, Latek RR, Erdjument-Bromage H, Tempst P, Sabatini DM (2004) Rictor, a novel binding partner of mTOR, defines a rapamycin-insensitive and raptor-independent pathway that regulates the cytoskeleton. Curr Biol 14(14):1296-1302
399. Sancak Y, Bar-Peled L, Zoncu R, Markhard AL, Nada S, Sabatini DM (2010) Ragulator-Rag complex targets mTORC1 to the lysosomal surface and is necessary for its activation by amino acids. Cell 141(2):290-303

400. Inoki K, Li Y, Zhu T, Wu J, Guan KL (2002) TSC2 is phosphorylated and inhibited by Akt and suppresses mTOR signalling. Nat Cell Biol 4(9):648-657

401. Manning BD, Tee AR, Logsdon MN, Blenis J, Cantley LC (2002) Identification of the tuberous sclerosis complex-2 tumor suppressor gene product tuberin as a target of the phosphoinositide 3-kinase/akt pathway. Mol Cell 10(1):151-162

402. Potter CJ, Pedraza LG, Xu T (2002) Akt regulates growth by directly phosphorylating Tsc2. Nat Cell Biol 4(9):658-665

403. Sancak Y, Thoreen CC, Peterson TR, Lindquist RA, Kang SA, Spooner E, Carr SA, Sabatini DM (2007) PRAS40 is an insulinregulated inhibitor of the mTORC1 protein kinase. Mol Cell 25(6):903-915

404. Thedieck K, Polak P, Kim ML, Molle KD, Cohen A, Jeno P, Arrieumerlou C, Hall MN (2007) PRAS40 and PRR5-like protein are new mTOR interactors that regulate apoptosis. PLoS ONE 2(11):e1217

405. Vander Haar E, Lee SI, Bandhakavi S, Griffin TJ, Kim DH (2007) Insulin signalling to mTOR mediated by the Akt/PKB substrate PRAS40. Nat Cell Biol 9(3):316-323

406. Corradetti MN, Inoki K, Bardeesy N, DePinho RA, Guan KL (2004) Regulation of the TSC pathway by LKB1: evidence of a molecular link between tuberous sclerosis complex and PeutzJeghers syndrome. Genes Dev 18(13):1533-1538

407. Inoki K, Ouyang H, Zhu T, Lindvall C, Wang Y, Zhang X, Yang Q, Bennett C, Harada Y, Stankunas K, Wang CY, He X, MacDougald OA, You M, Williams BO, Guan KL (2006) TSC2 integrates Wnt and energy signals via a coordinated phosphorylation by AMPK and GSK3 to regulate cell growth. Cell 126(5):955-968

408. Tang HW, Wang YB, Wang SL, Wu MH, Lin SY, Chen GC (2011) Atg1-mediated myosin II activation regulates autophagosome formation during starvation-induced autophagy. EMBO J 30(4):636-651

409. Wu W, Tian W, Hu Z, Chen G, Huang L, Li W, Zhang X, Xue P, Zhou C, Liu L, Zhu Y, Li L, Zhang L, Sui S, Zhao B, Feng D (2014) ULK1 translocates to mitochondria and phosphorylates FUNDC1 to regulate mitophagy. EMBO Rep 15(5):566-575

410. Rajesh S, Bago R, Odintsova E, Muratov G, Baldwin G, Sridhar P, Overduin M, Berditchevski F (2011) Binding to syntenin-1 protein defines a new mode of ubiquitin-based interactions regulated by phosphorylation. $\mathrm{J}$ Biol Chem 286(45):39606-39614 